\title{
Constitutional Regulation for Establishing the Federal Supreme Court in Iraq and its Relation to the Rights of the Regions
}

\author{
Abdulmalik Younis Mohammed ${ }^{1}$ \& Soran Ali Hasan ${ }^{2}$
}

Received: Feb24, 2018 Reviewed: Mar29, 2018Accepted: Apr10, 2018

Abstract

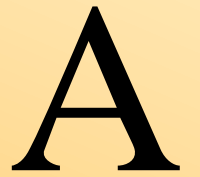

fteradopting of the federalism and voluntary union for a new Iraqi state in the Constitutional Regulation of 2004, and their emphasizing in the Executed Constitution of 2005, there was a radical change in the whole governmental institutions including the judicial system especially in recognition of bilateral of the judiciary structure system in both federal and regional level and establishing of the Federal Supreme Court (which represents the highest judicial foundation on the level of federal judicial in terms of the status, legal force of its decimations, its relation with the constitutional subjects and the disputes betweenthe federal entities and institutions).Passing this Court through three various constitutional and legislative stages, and waiting to receive another new legislative regulation, despite the extent of participation of the regions in matters related to the establishment, structure and exercising of the court's competences, caused to several issues concerning with the previous matters, which led to instability and lack of legal regulation stipulated in the Executed Iraqi Constitution 2005 to determine the number of members, way of recruitment and the proceedings of the Court. This research paper depends on analytical approach to interpret the constitutional and legal rules and judgments related to the ways of establishment, structure of and participation of the regions in the Court and stating the issues connected to such ways.

Keywords:Federal Supreme Court, Jurisdiction of the Federal court, Establishing of the Federal Supreme Court, Rights of Regions

\section{Recommended citation:}

Mohammed,Y. A. \&Hasan,S. A. (2018). Constitutional Regulation for establishing the Federal Supreme Court in Iraq and its relation to the rights of the regions. International Journal of Kurdish Studies 4 (2), 454-477. doi: 10.21600/ ijoks.454468

\footnotetext{
${ }^{1}$ Professor Dr., Department of Law, College of Law and Political Since, Salahaddin University, KRG,Iraq, Email: cra.erbil@yahoo.com

${ }^{2}$ Assistant Lecturer. Department of Law, Faculty of Law and International Relations, Soran University, KRG, Iraq.

PhD. Student. Department of Law, College of Law and Political Since, Salahaddin University, KRG, Iraq. Email: soran.hassan@soran.edu.iq
} 


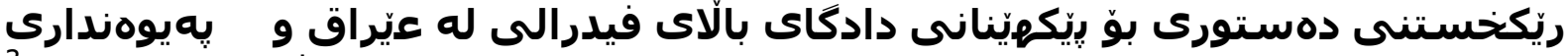 به مافى هa برئمهكان \\ تويّزينهوهيهكى شـيكارييه}

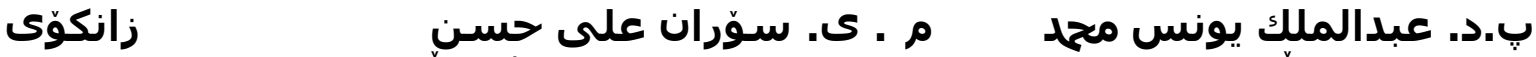

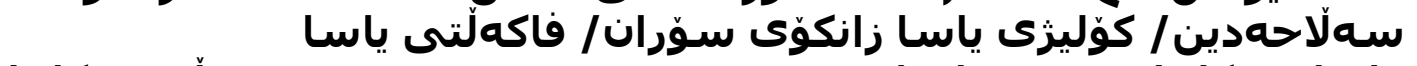 و به يوهندييه زيّودهولّهتييهكان/ بوشى ياسا}

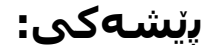

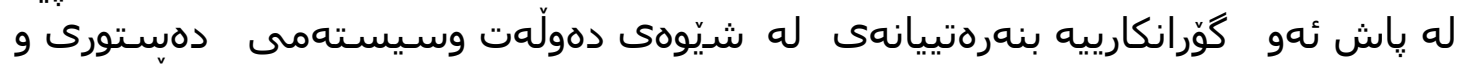

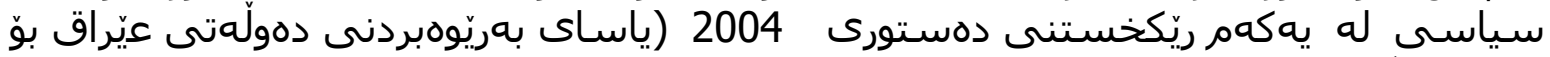

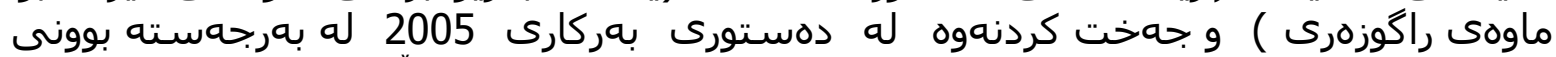

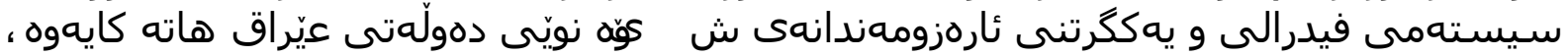

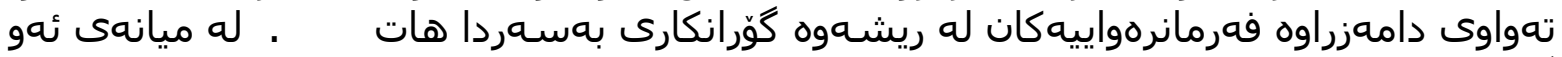

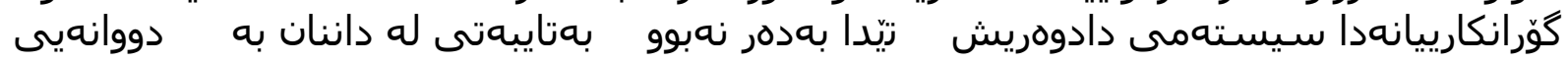
فيدرالى، بهتايبهتيِيِكِيْينانى

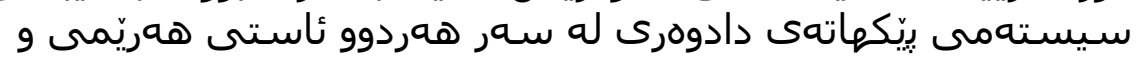

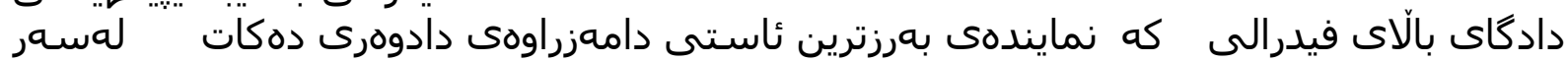

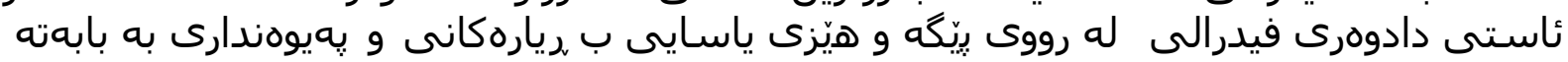

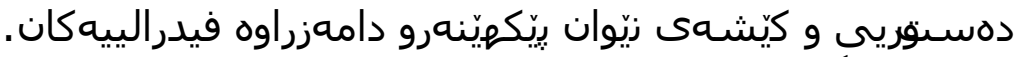

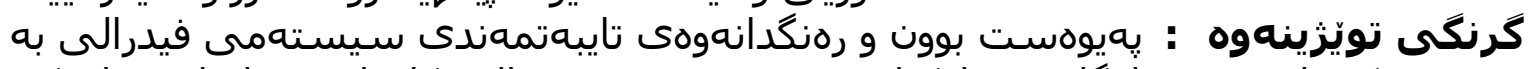

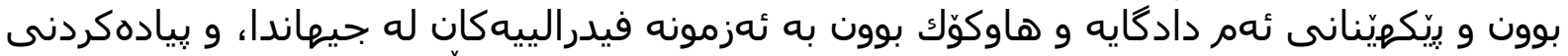

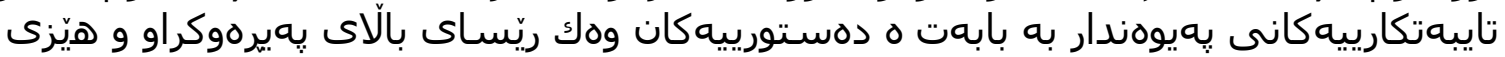

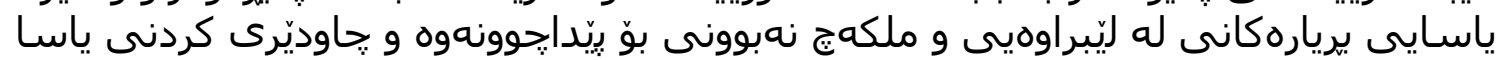

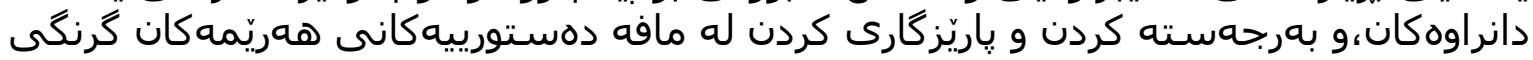

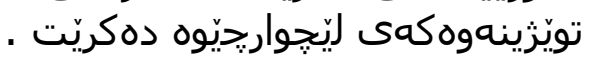

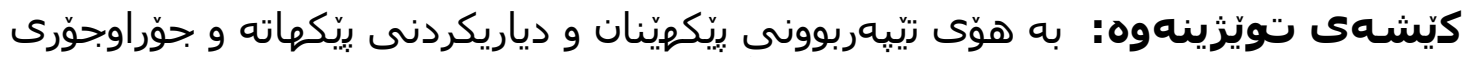

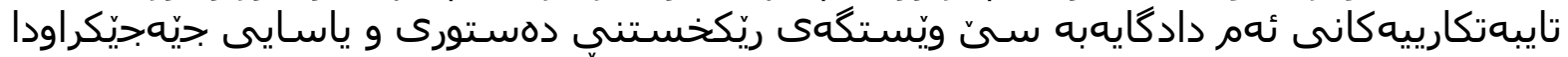

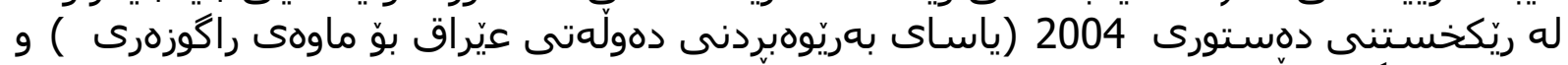

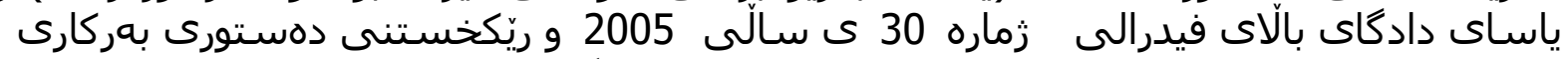

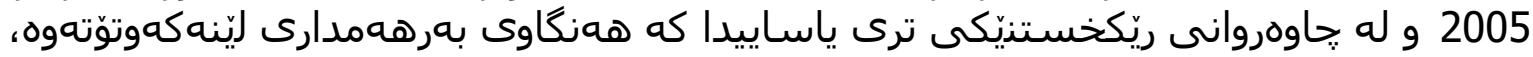

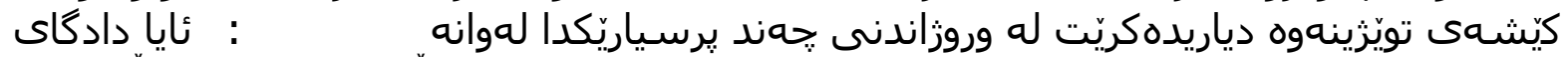

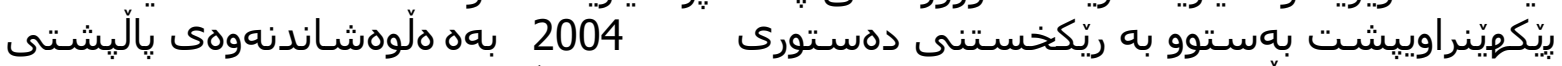

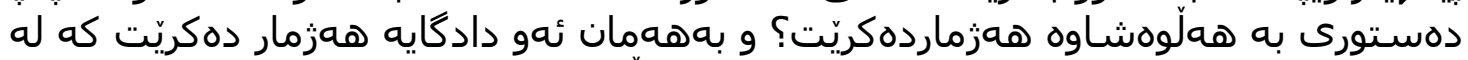

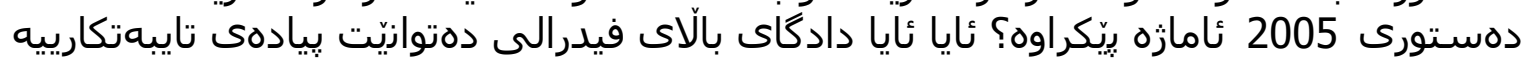

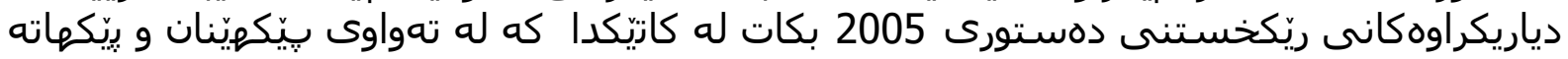

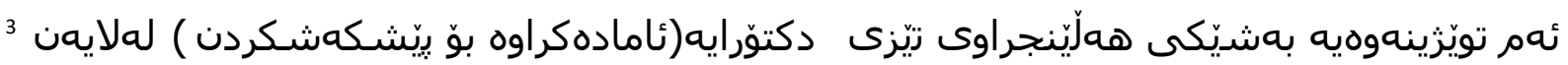

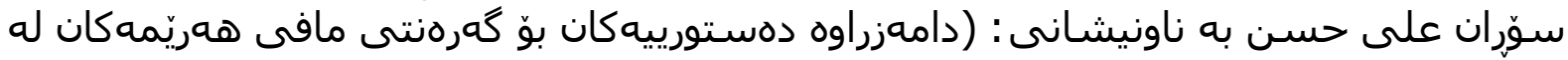

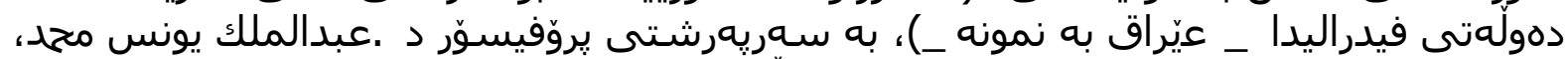

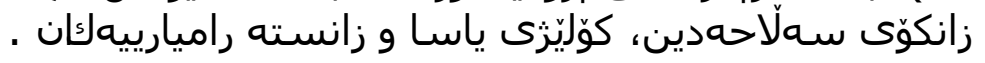


و تايبهتكارييه كانيدا جياوازن؟ ئايا ههريّمهكانمافى بهشداربوونيان له بِينكيِينان و بِينكهاتهى

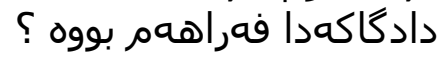

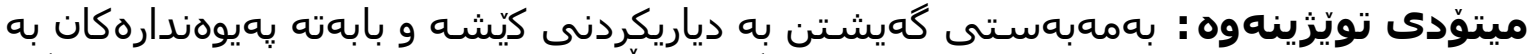

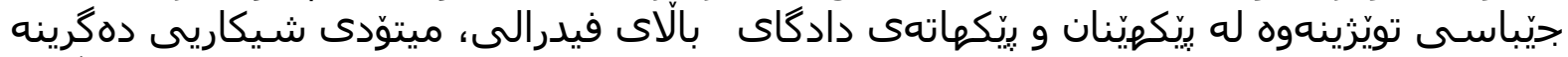

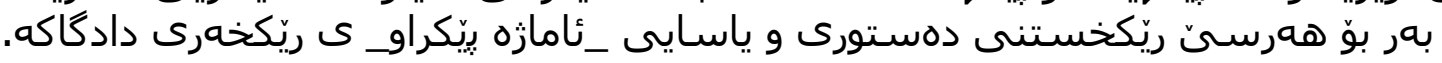

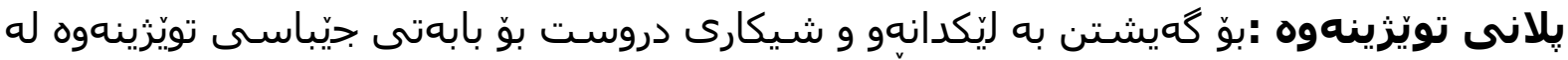

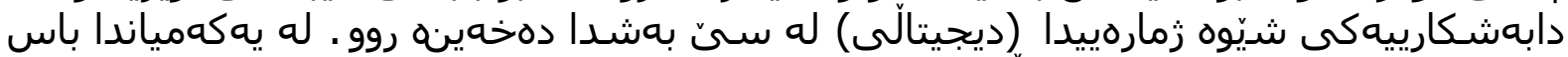

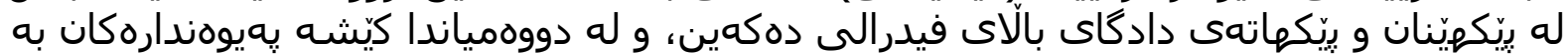

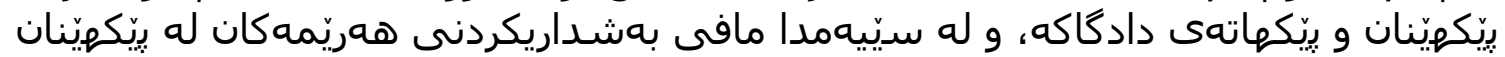

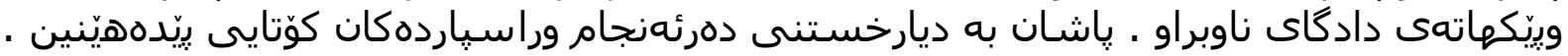

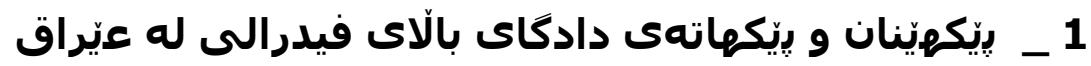

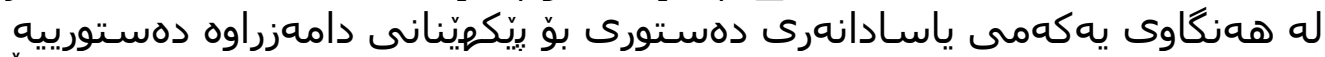

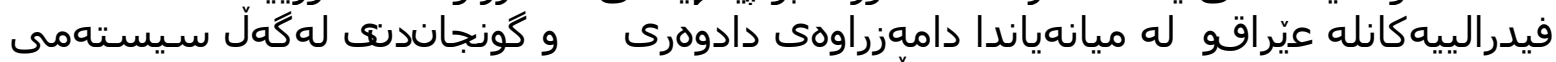

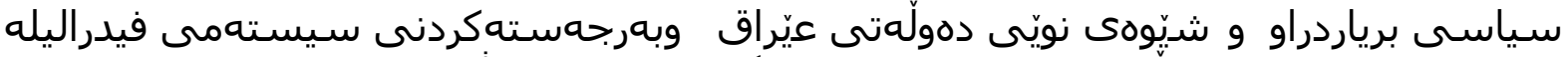

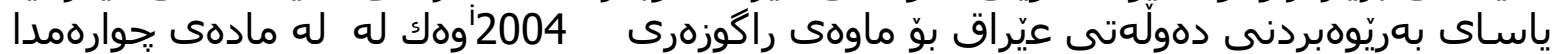

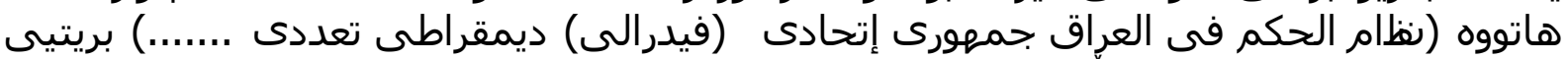

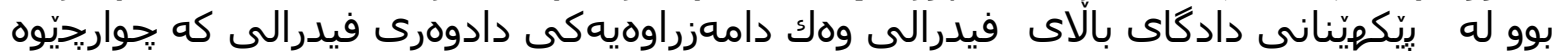

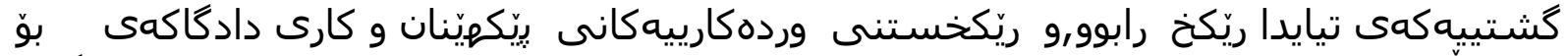

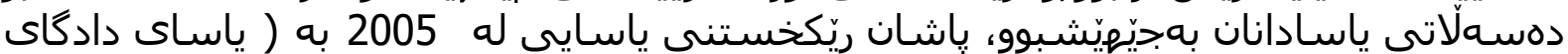
بالآى فيدرالى زماره 30 ى سالنى 2005) و دوواهومينيانيان له ريّكخستنى دهستورى 2005

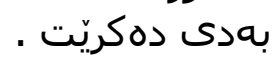

ي دادكاكه روون دمكهينهوهبه جيا بهم شديّوهى خوارموه:

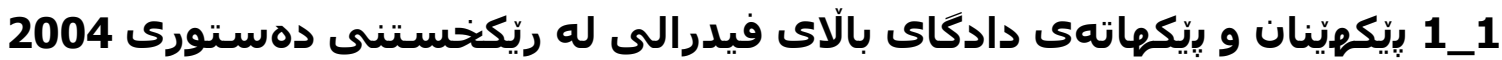

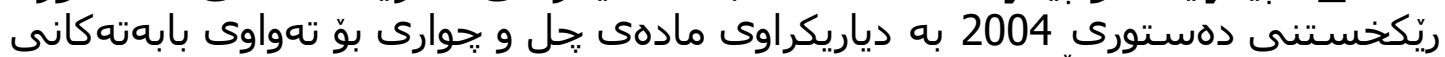

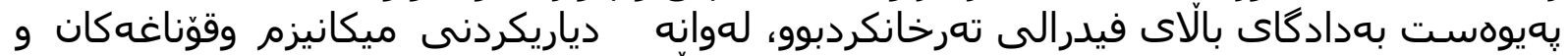

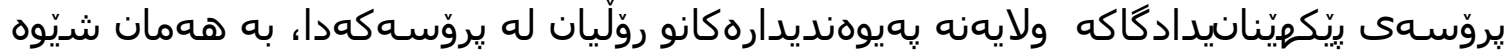

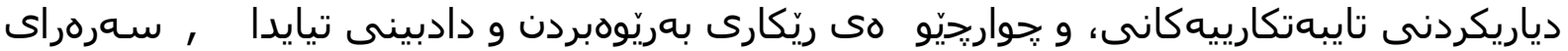

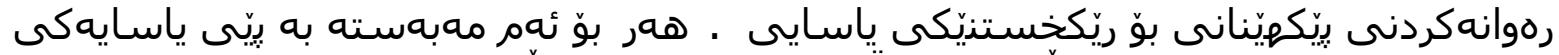

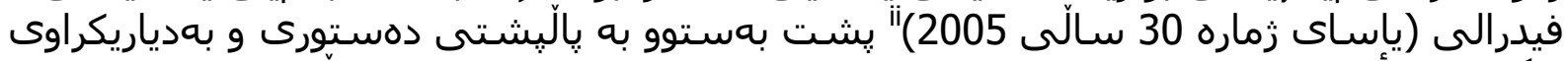

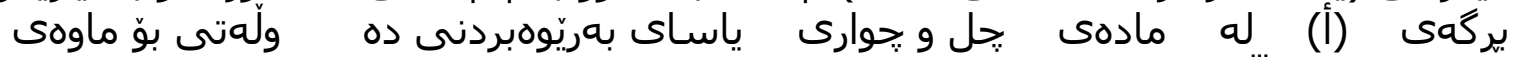

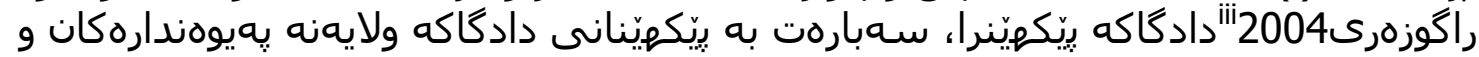

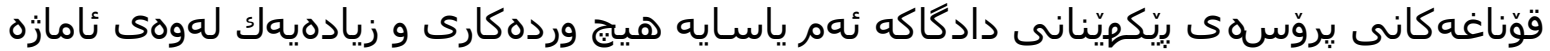

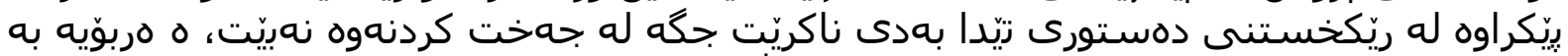

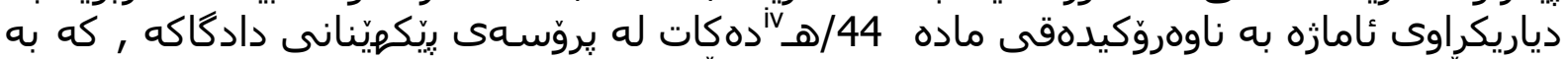

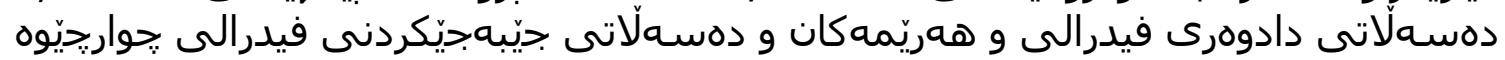
كراوه". بهم شديّوهى خوارهوه :

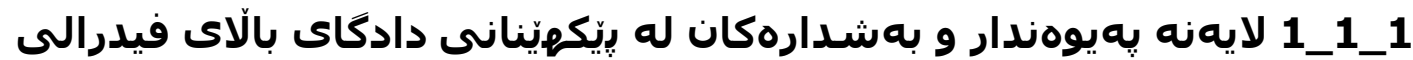

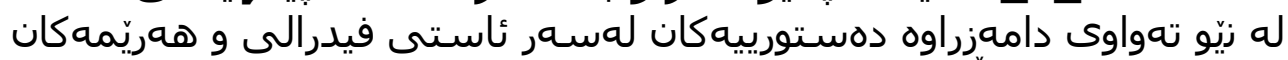

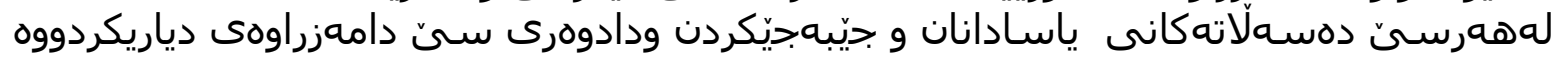

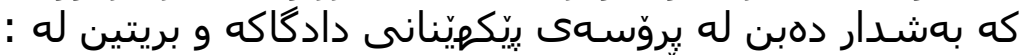
_ _ ئهنومهنى بالآى فيدرالى دادوهرى (فيدرالى). 


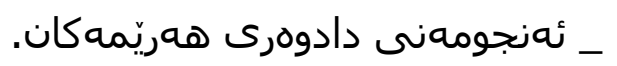

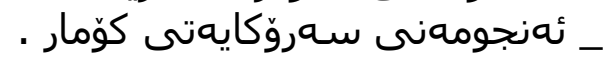

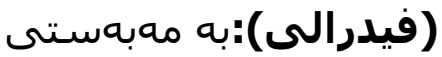

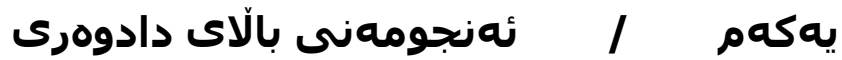

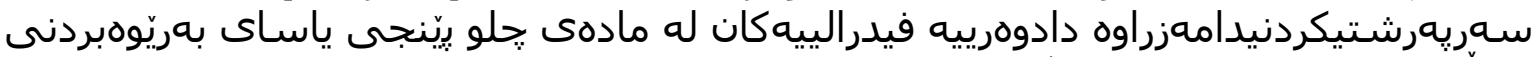

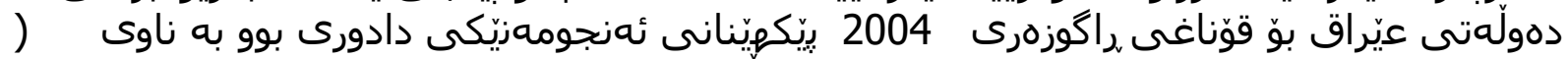

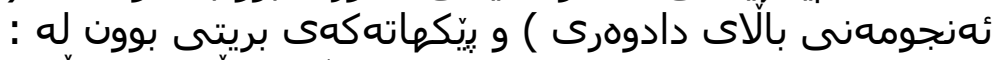

1

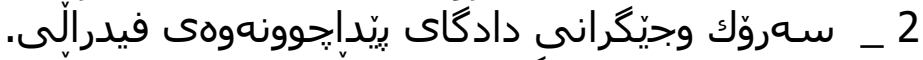

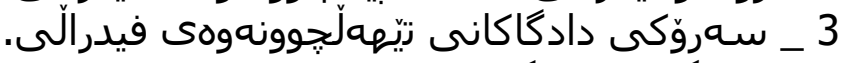

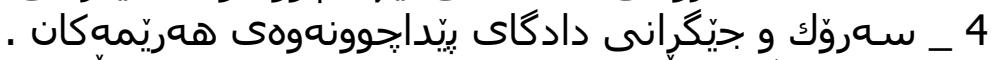

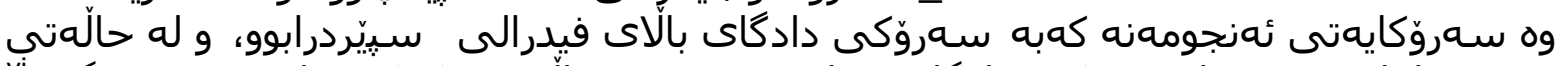

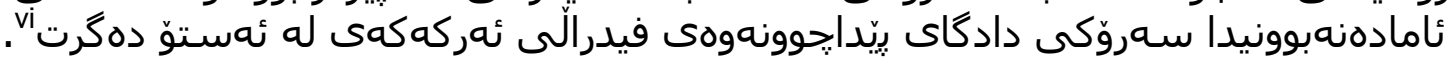

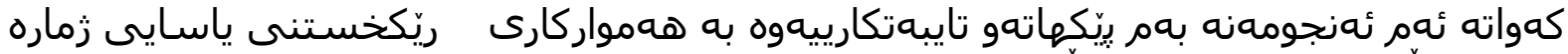

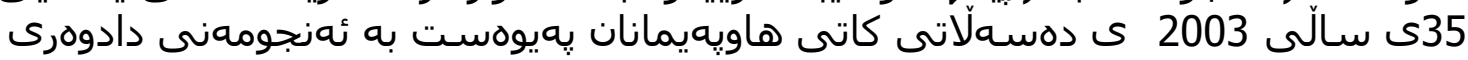

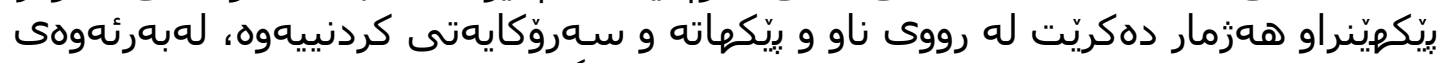

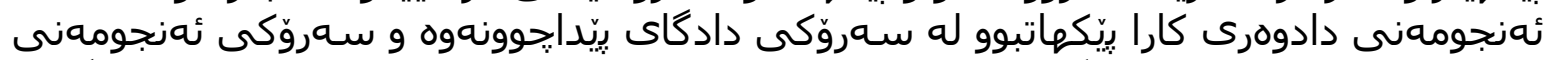

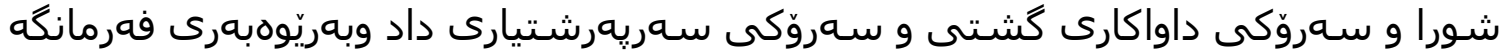

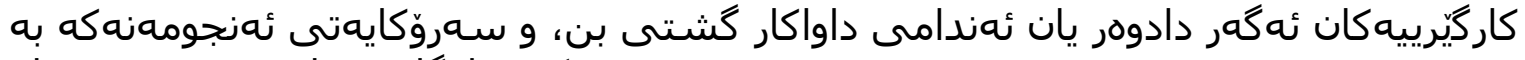

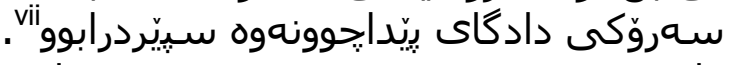

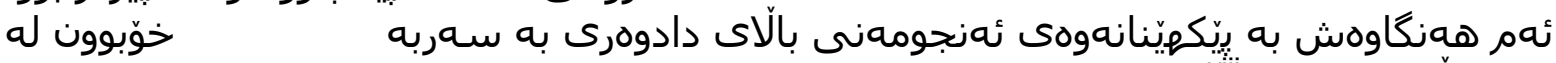

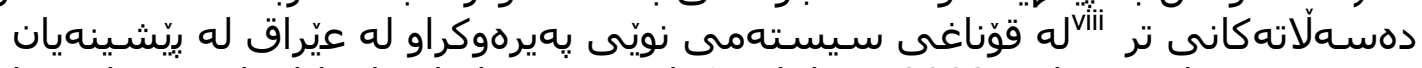

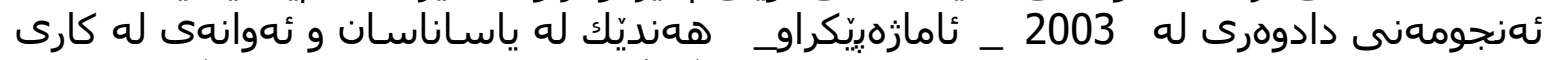

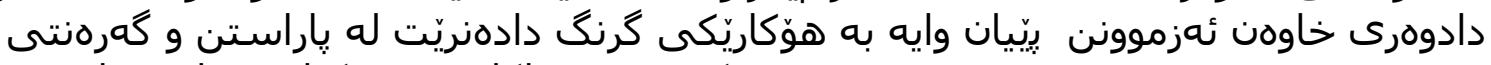

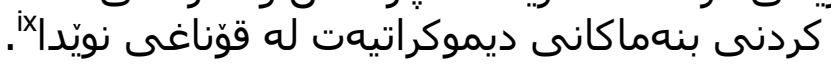

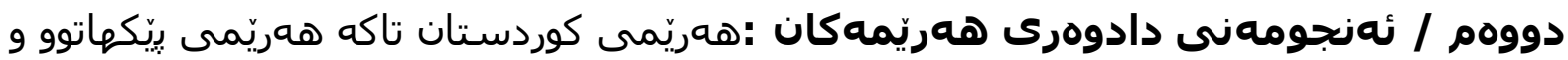

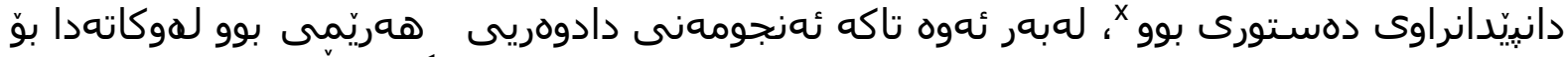

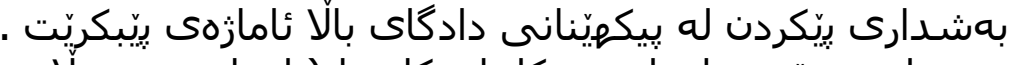

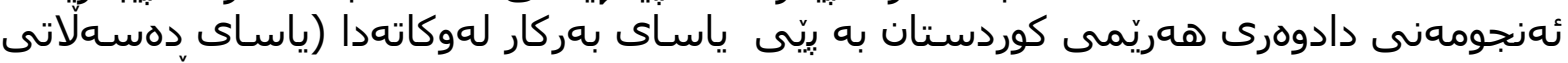

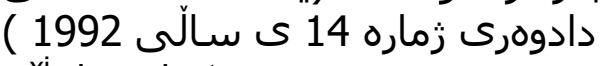

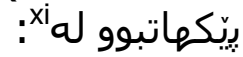

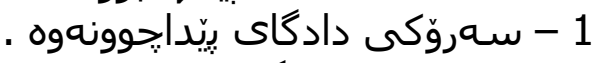

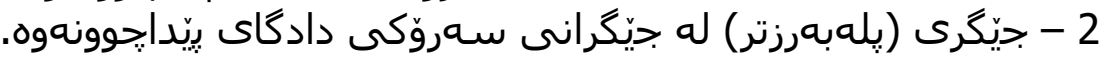

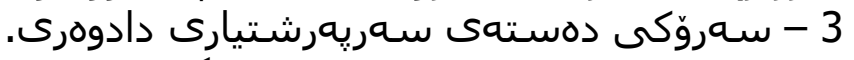

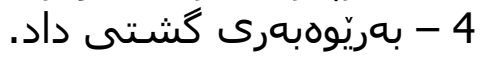

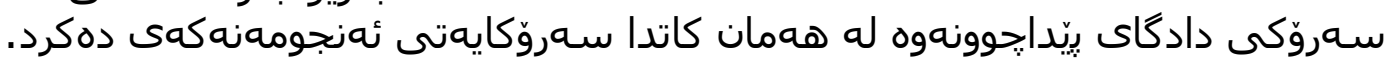

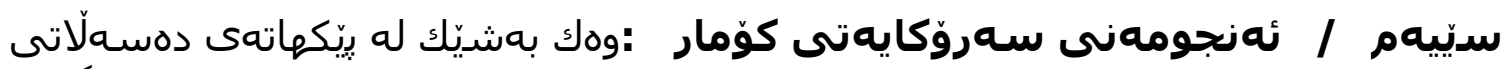

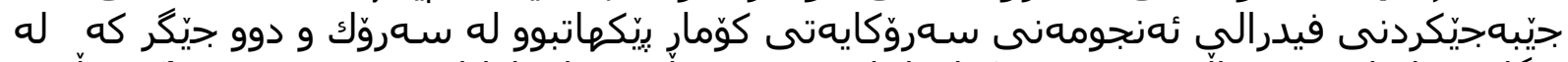

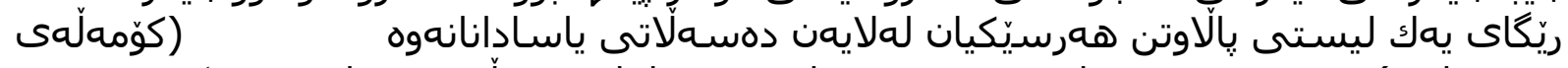

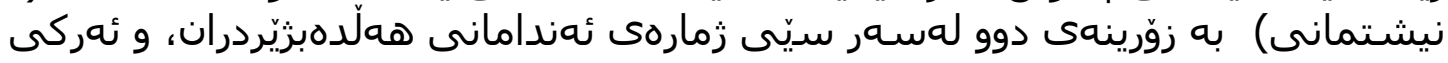

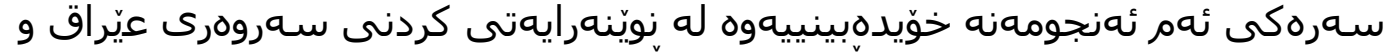

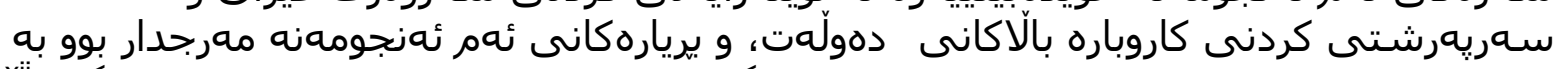

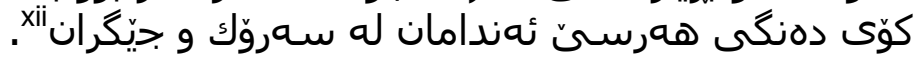

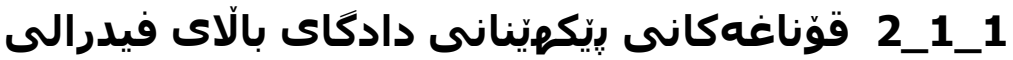




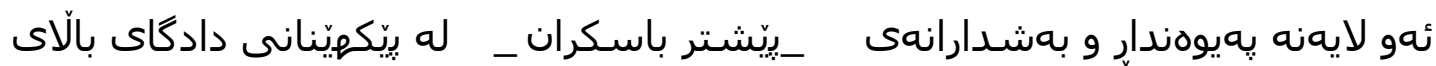

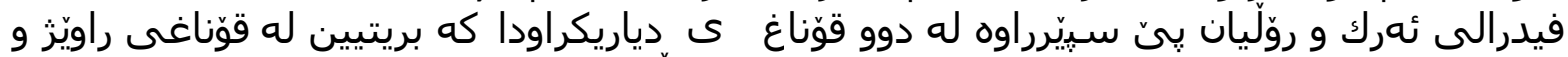
يالاّوتن و قوّناغى دياريكردن و دامصزراندن:

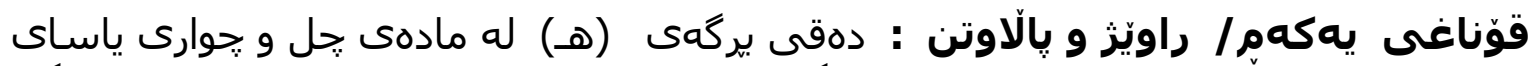

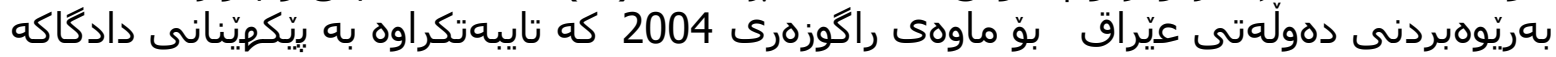

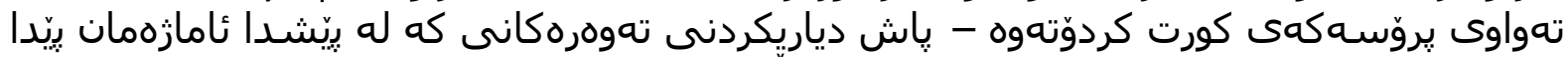

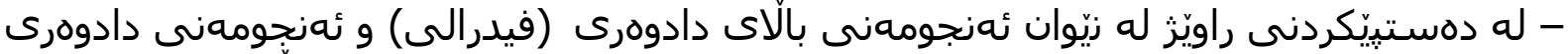

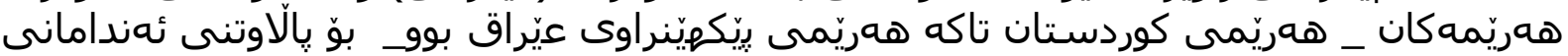

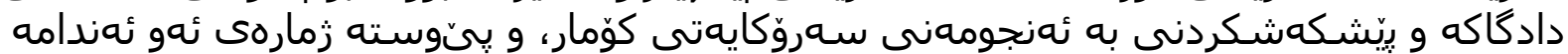

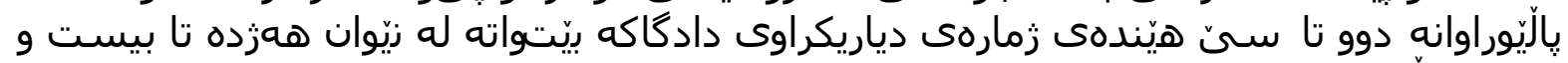

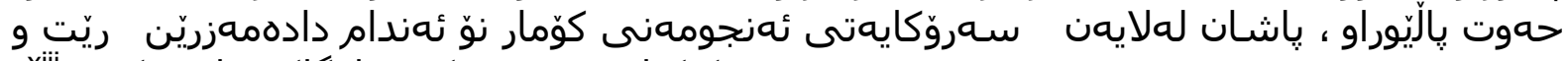

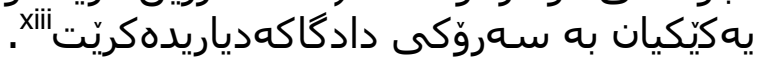

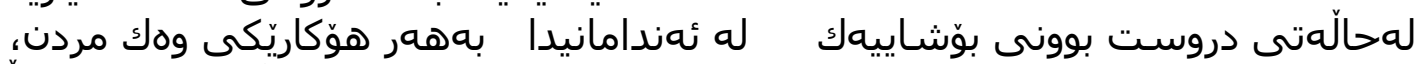

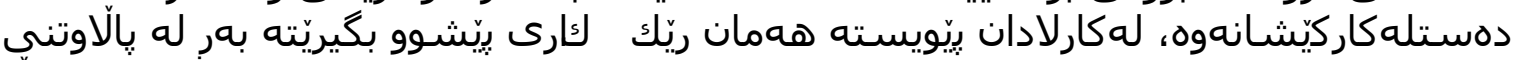

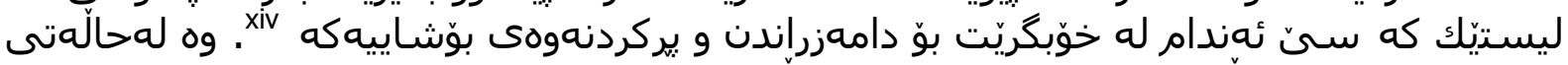

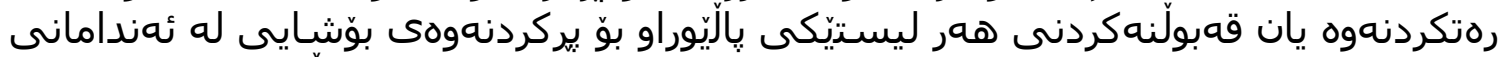

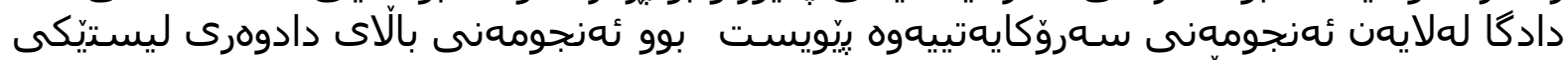

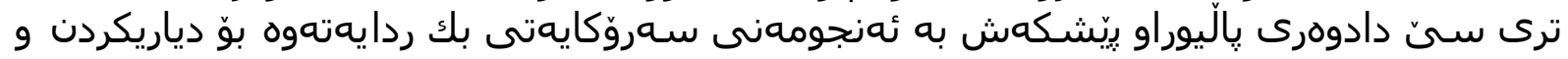
دامهزراندنى يهو يكيكيان.

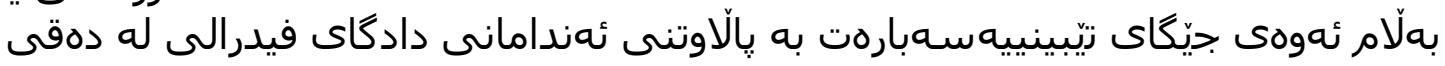

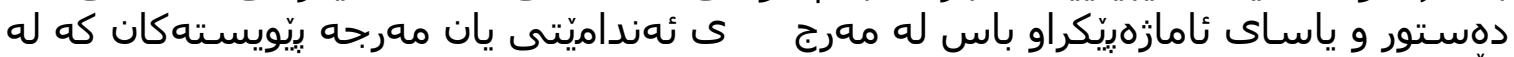

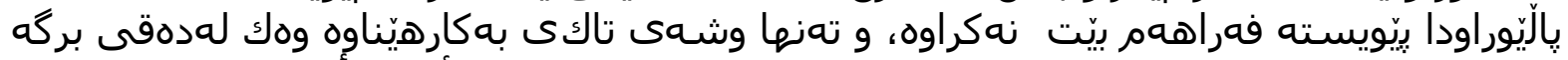

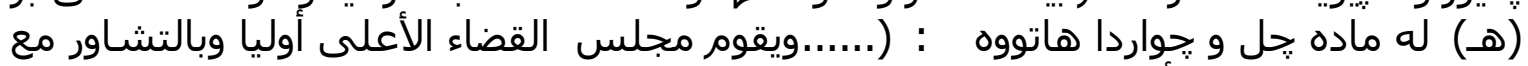

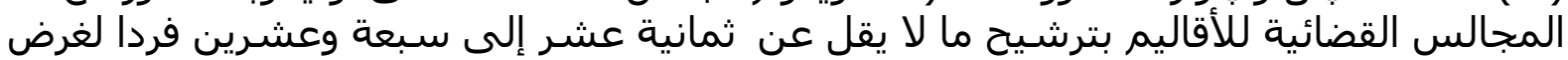

ملء الشواغر فى المحكمة المذكورة

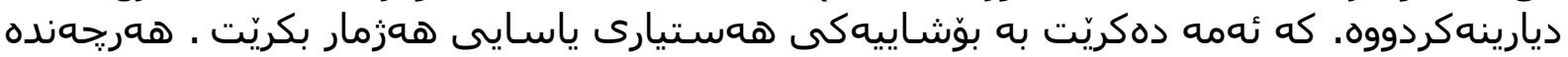

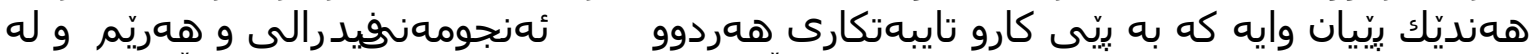

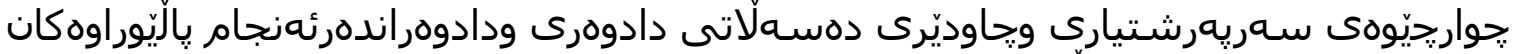

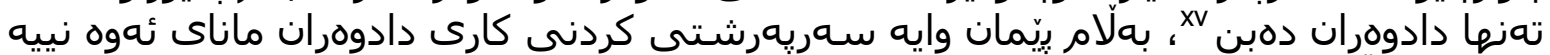

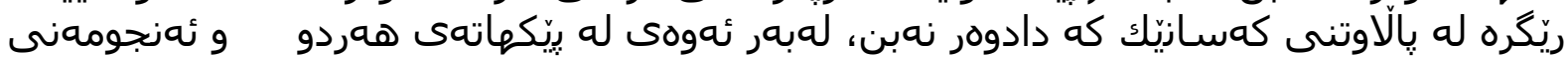

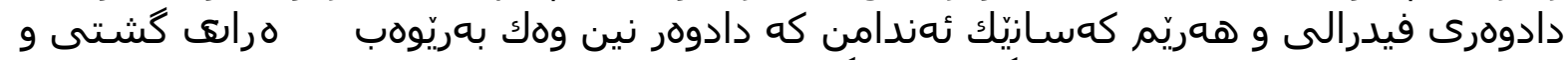

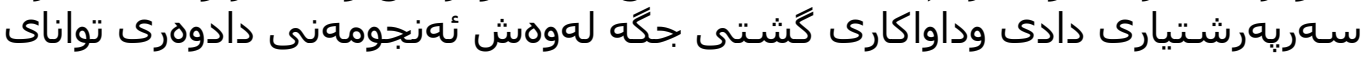

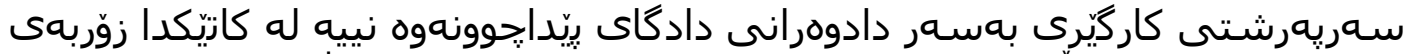

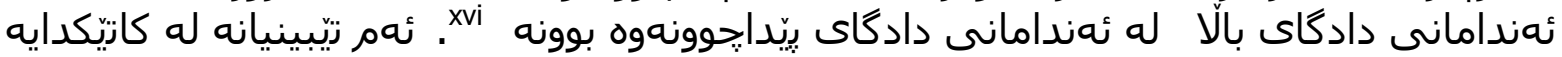

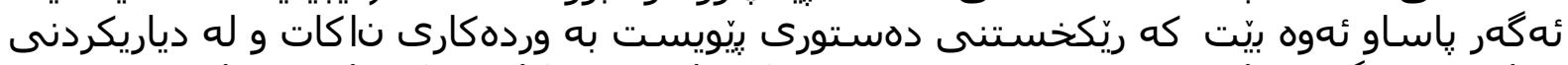

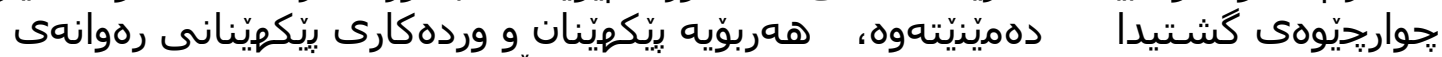

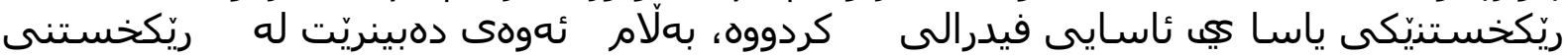

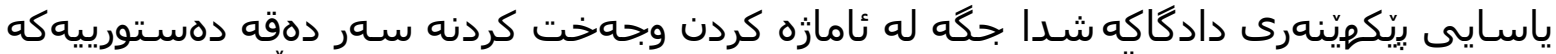

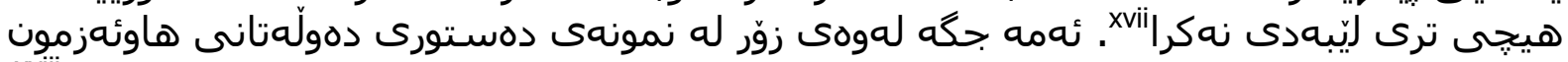

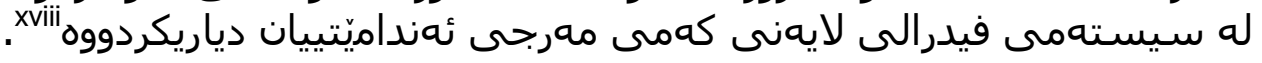

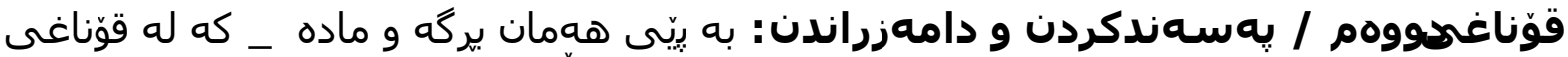

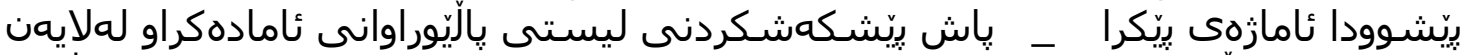

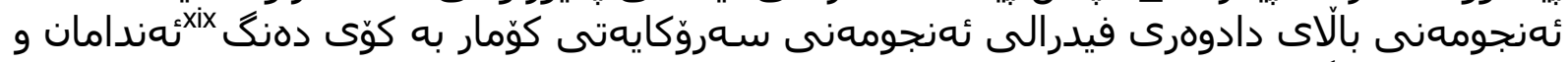

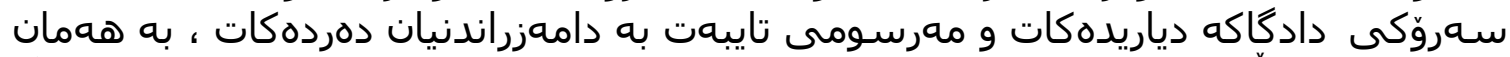

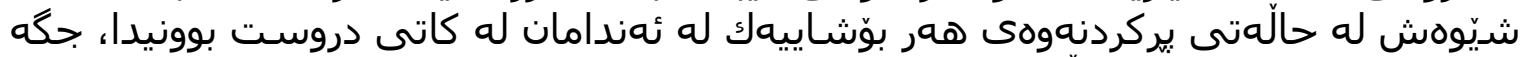

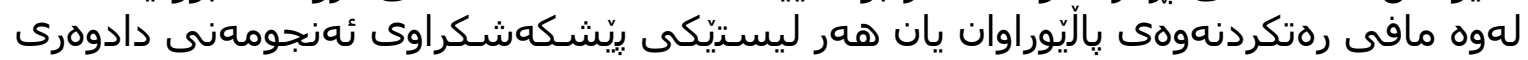
همبوو. 


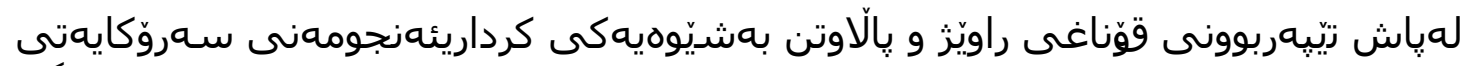

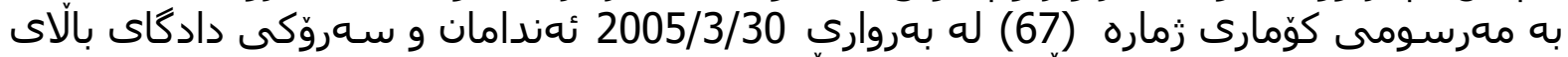

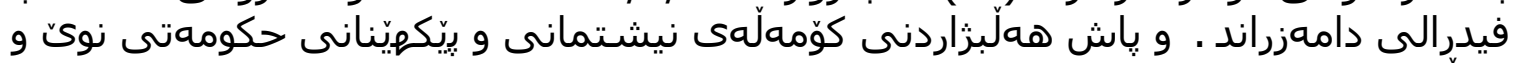

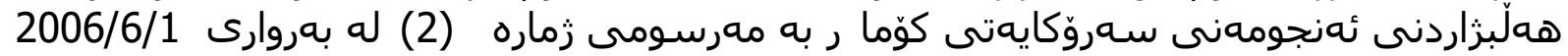

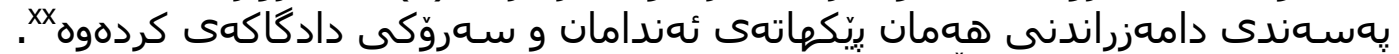

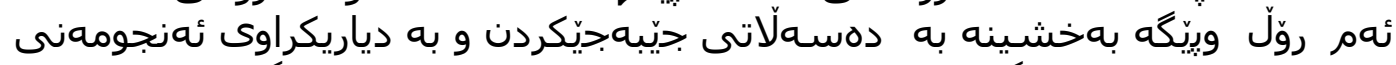

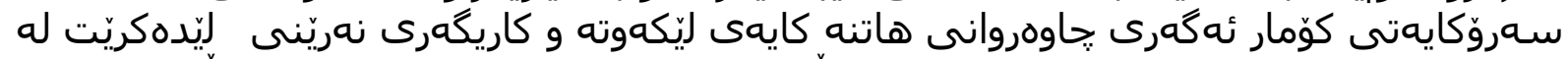

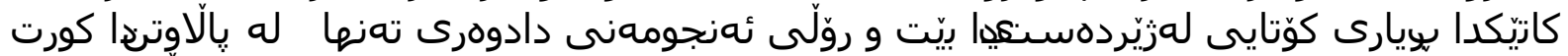

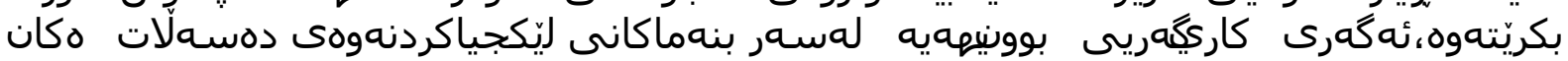

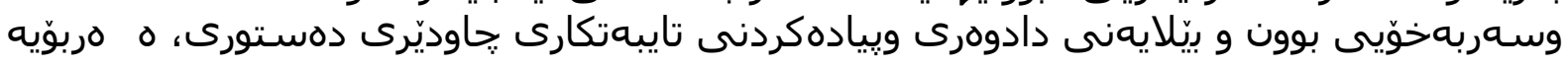

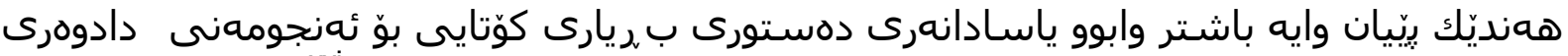

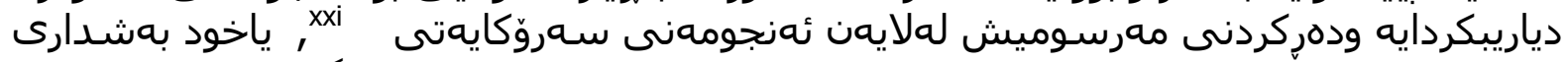

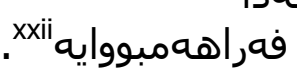

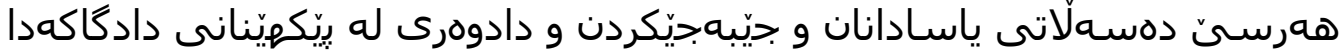

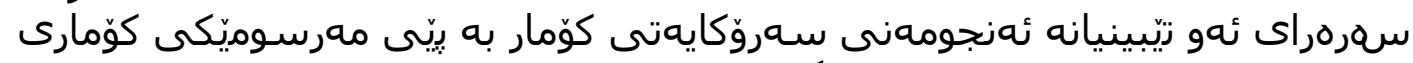

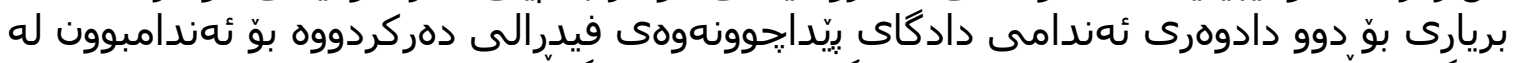

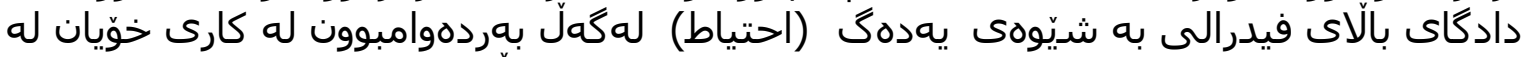

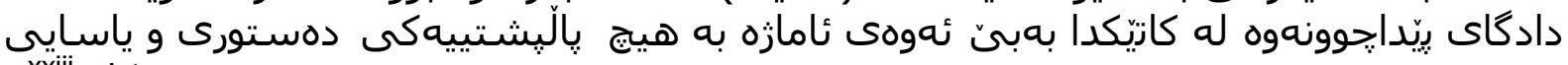

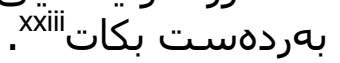

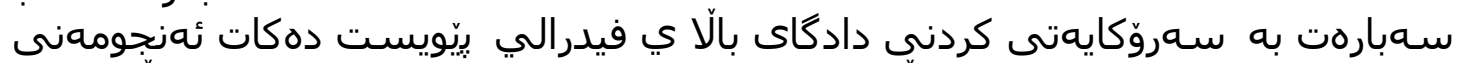

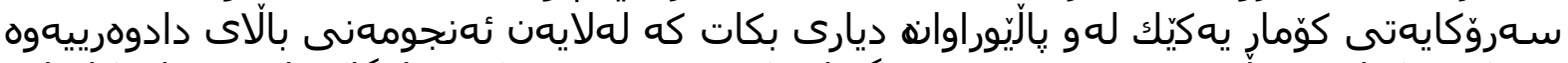

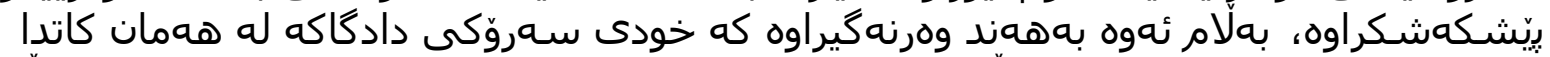

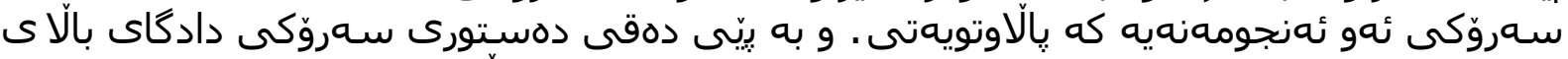

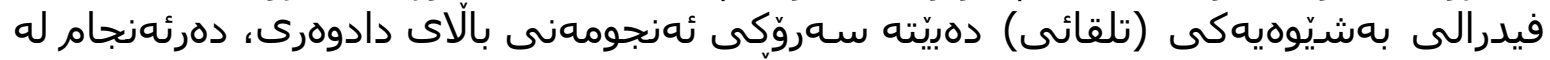

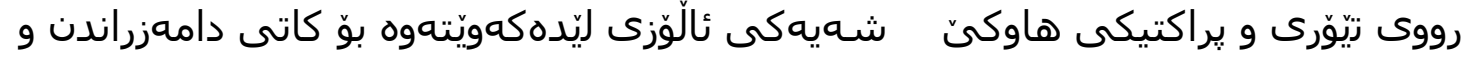

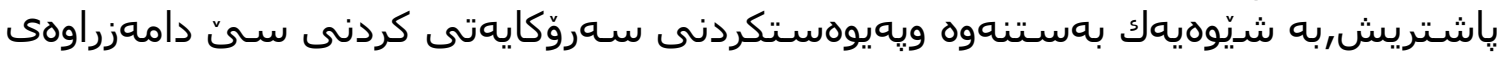

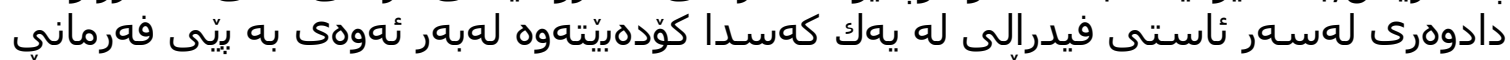

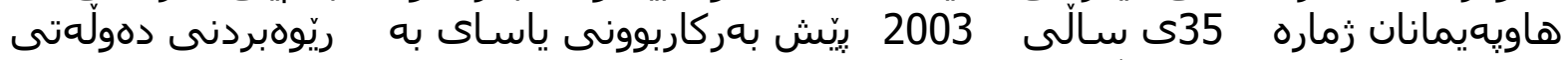

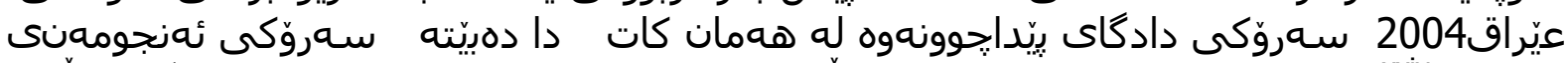

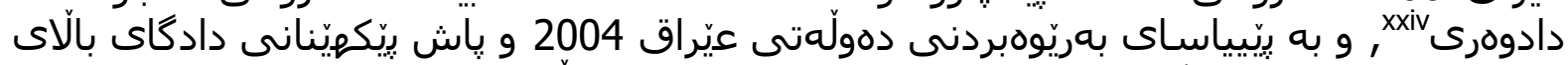

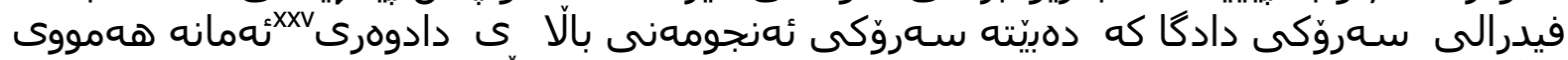

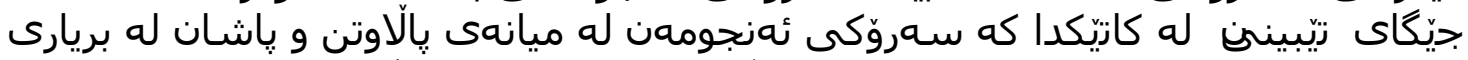

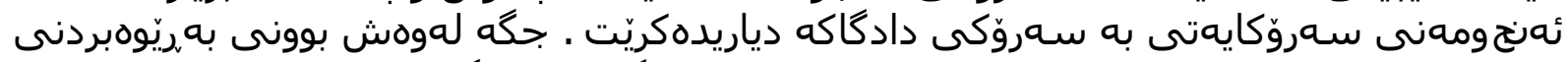

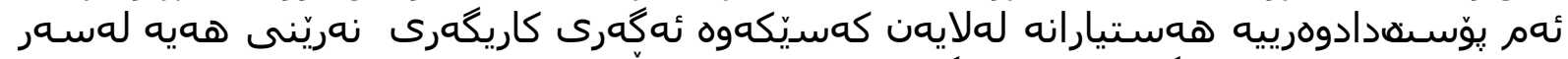

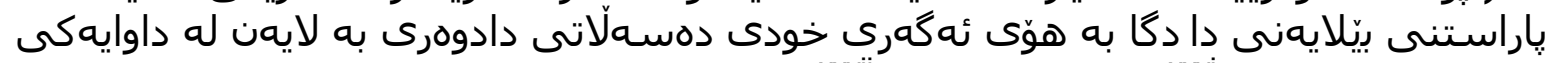

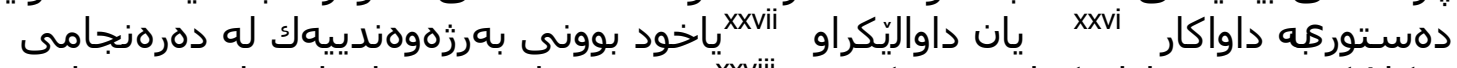

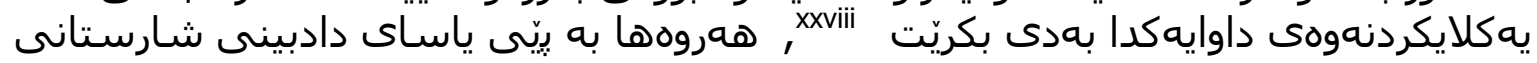

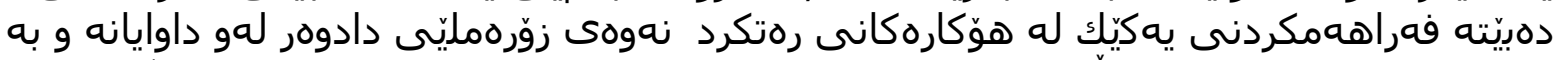

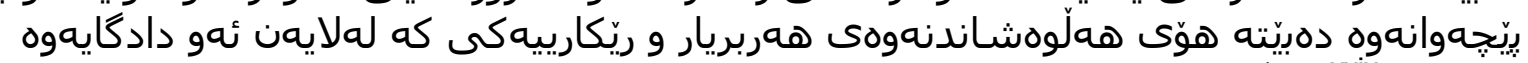

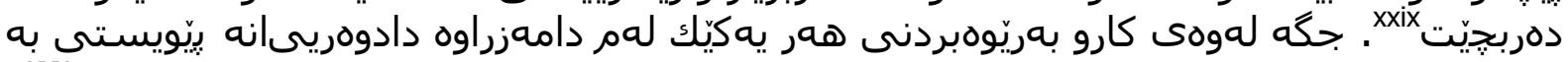

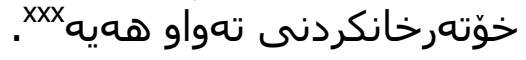

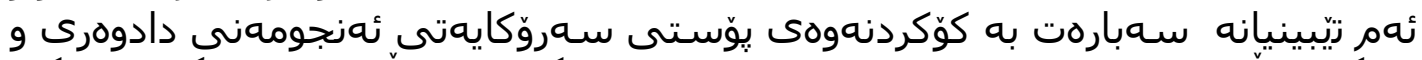

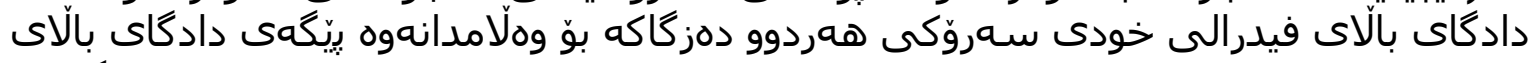

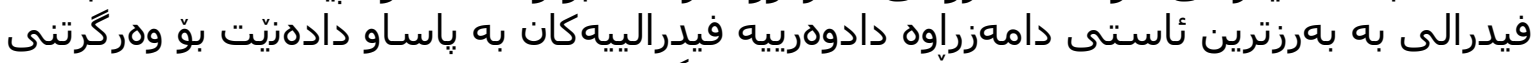

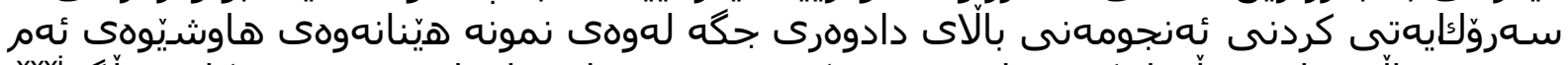

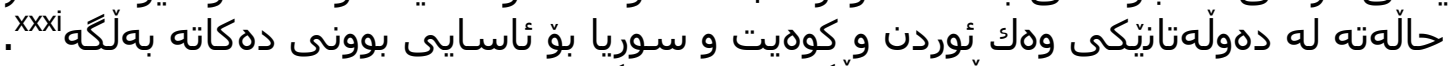

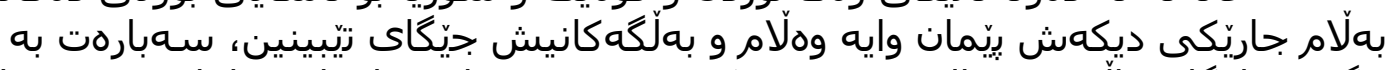

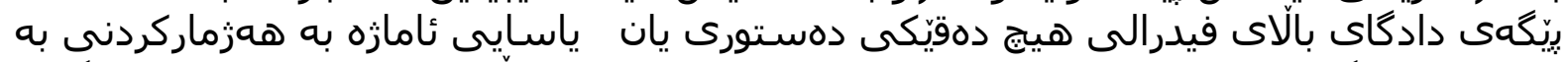

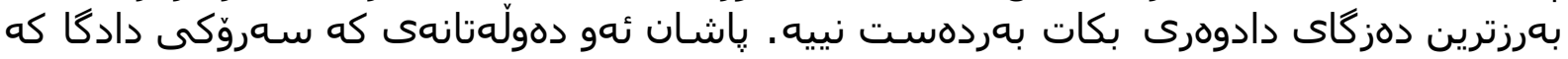




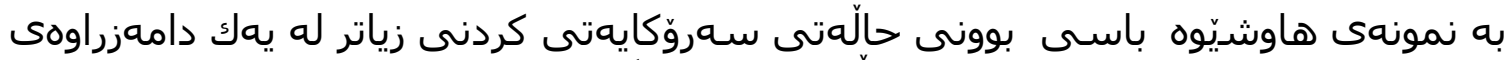

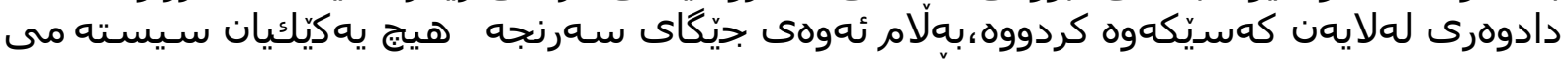

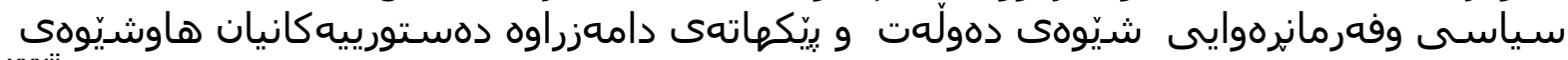

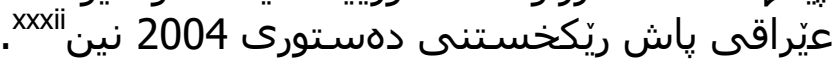

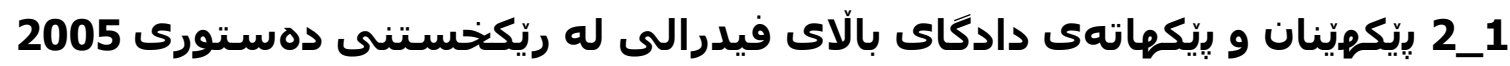

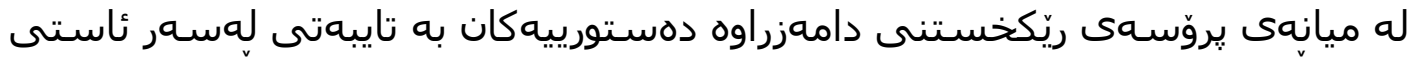

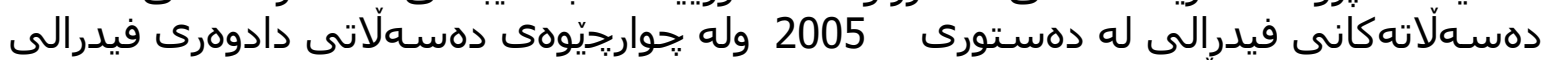

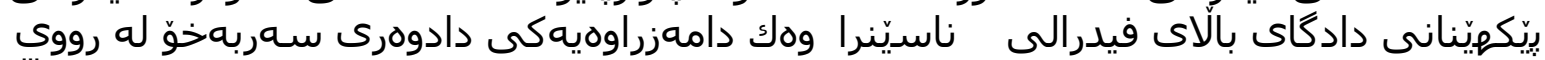

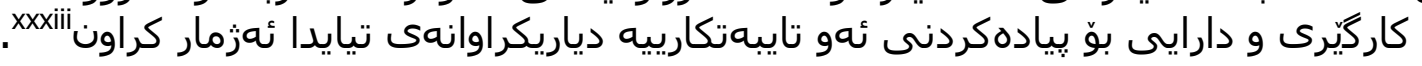

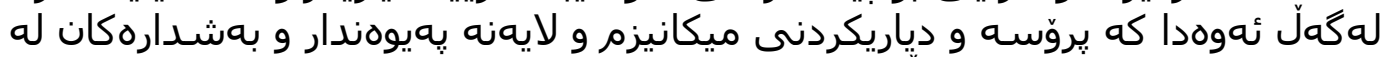

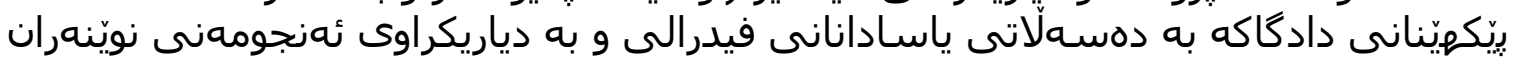

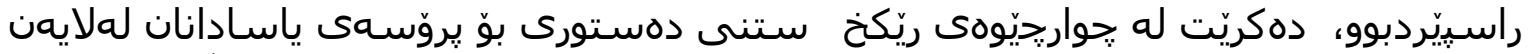

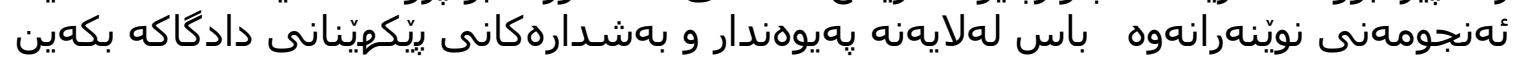
ياشان له بِينكهاتهى ئهندامه كانيى:

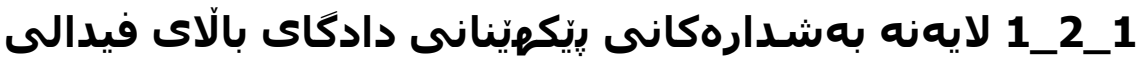

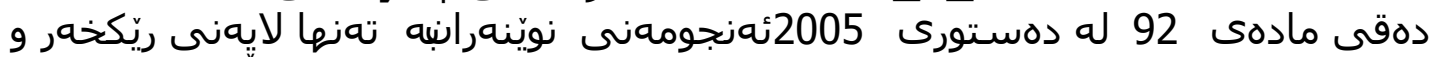

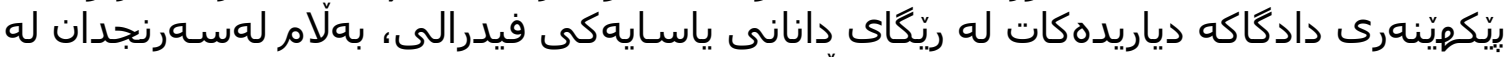

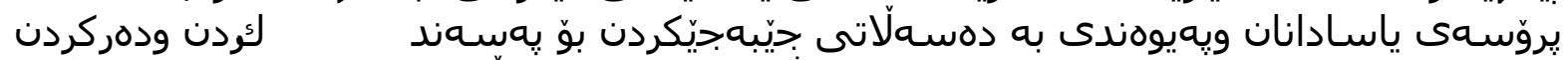

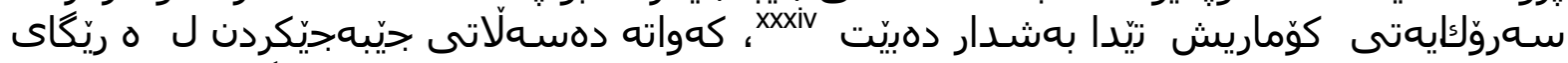

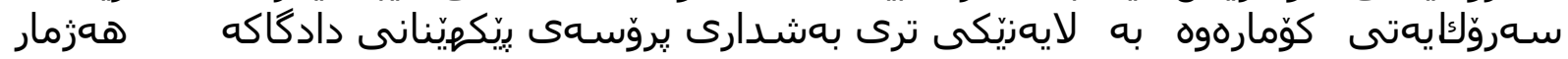
دمكريَت.

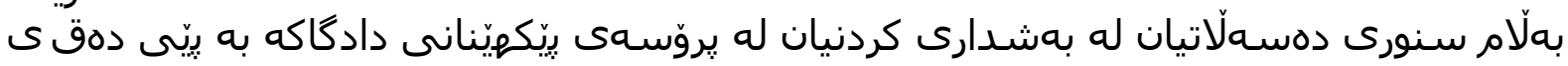

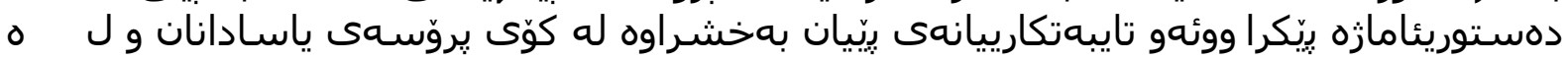

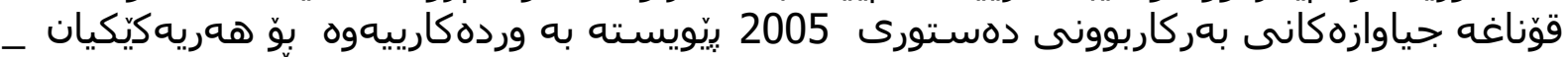

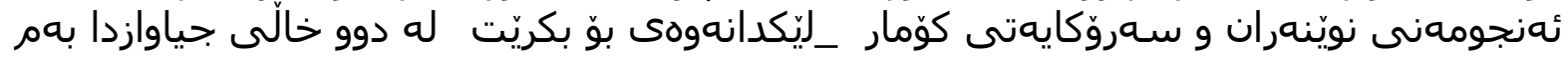
شيُّوهى خوراهوه:

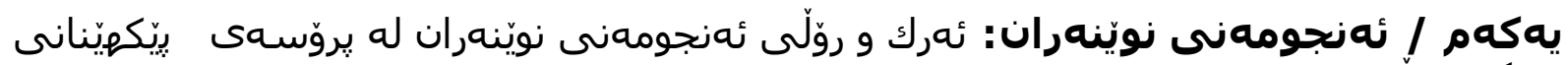

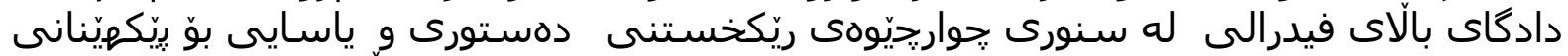

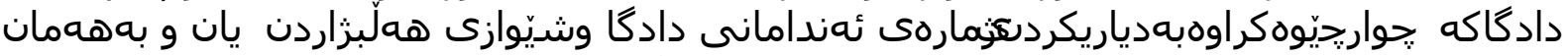

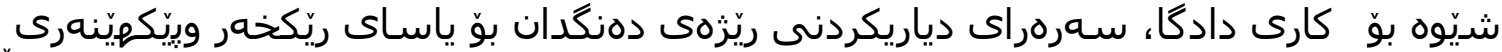

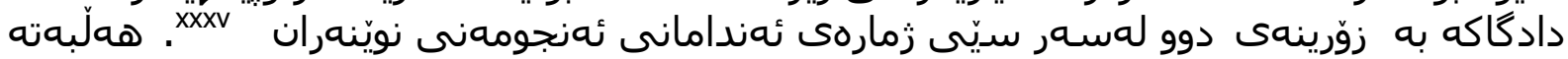

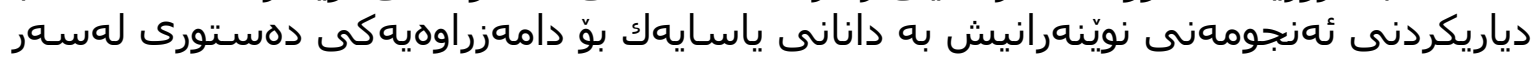

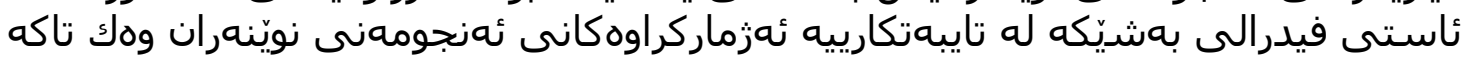

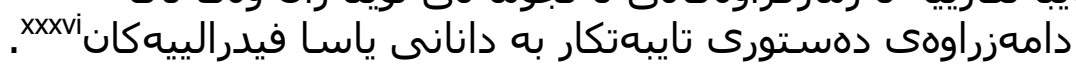

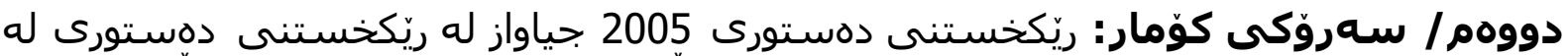

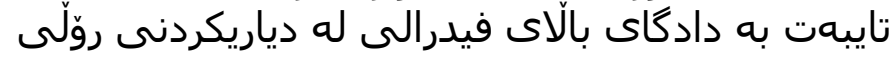

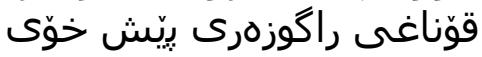

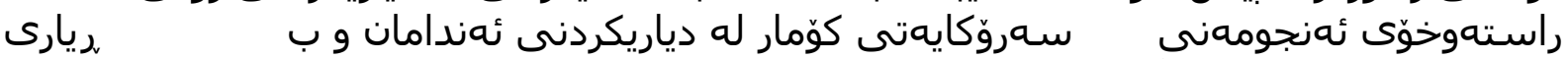

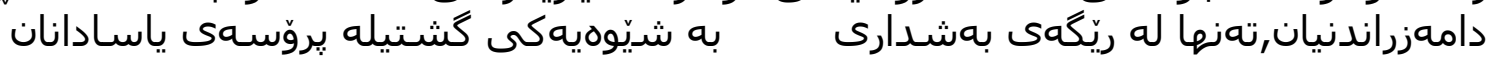

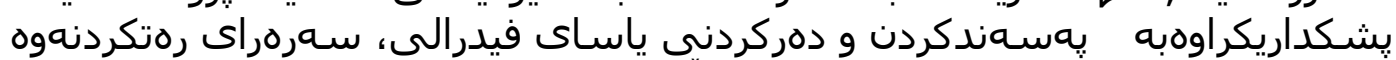

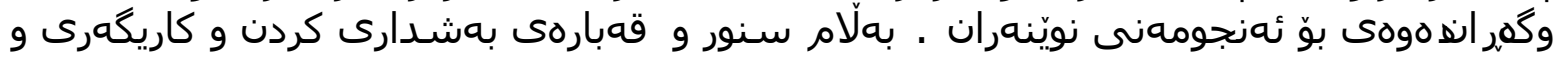

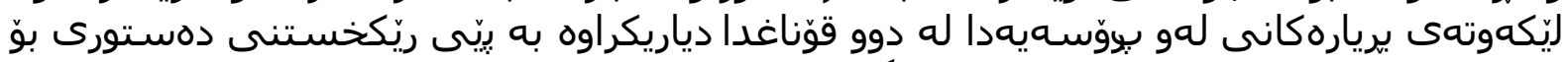

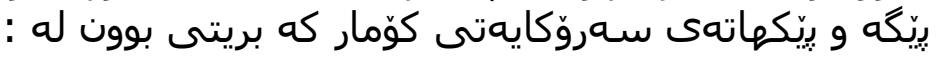




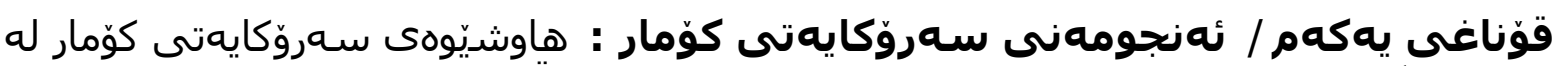

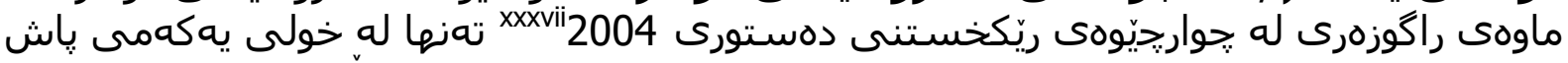

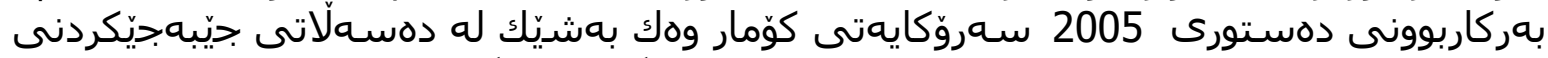

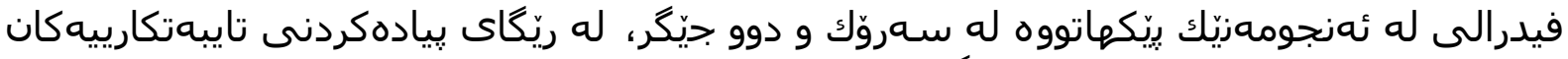

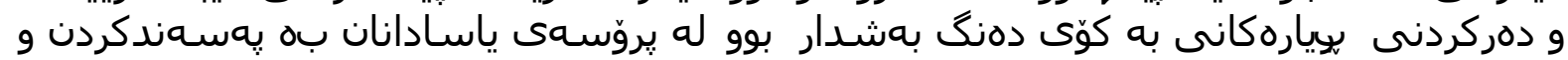

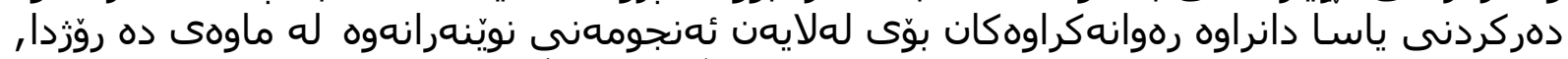

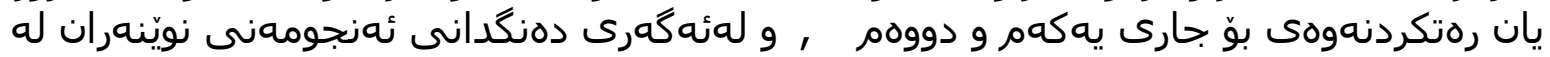

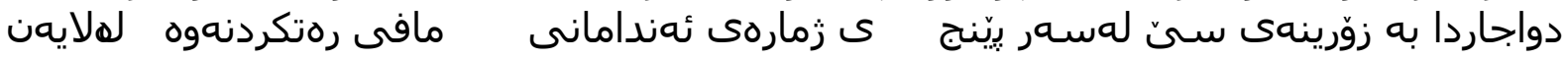

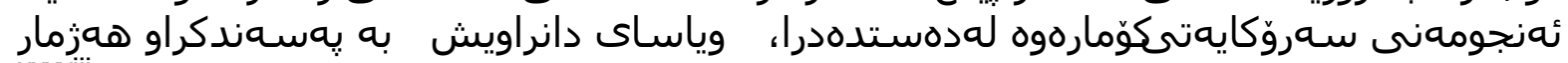
.xxviiii

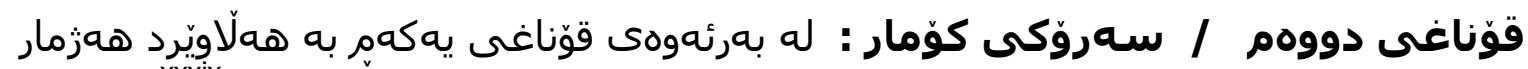

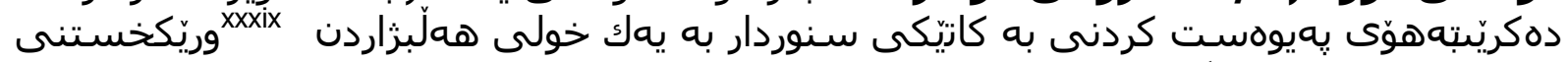

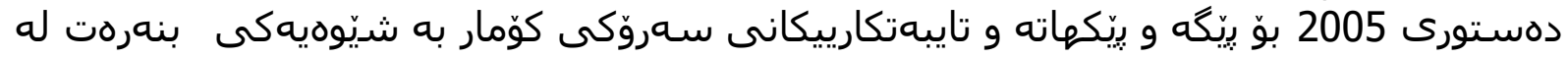

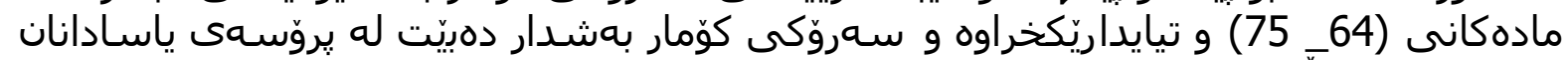

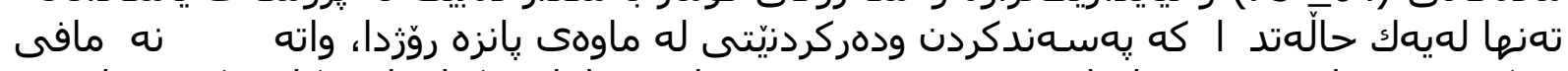

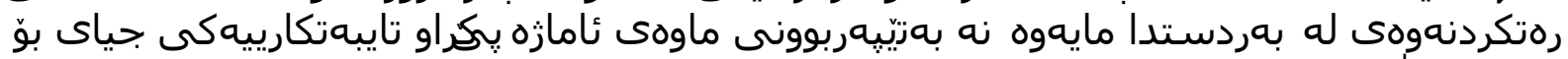

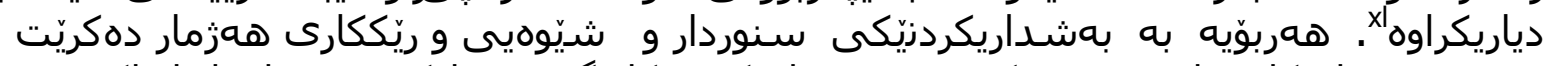

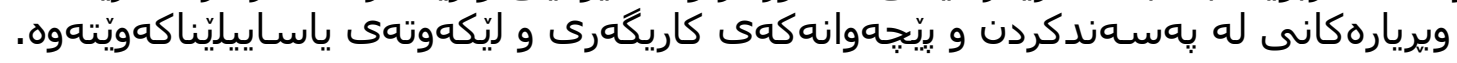

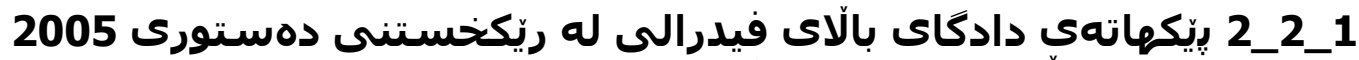

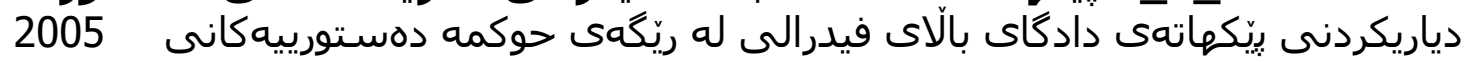

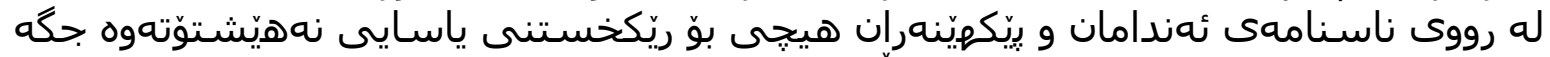

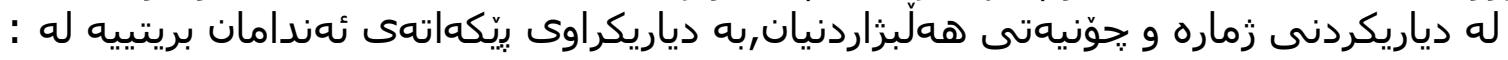

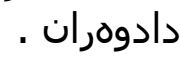

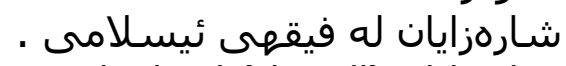

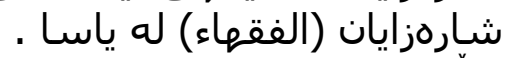

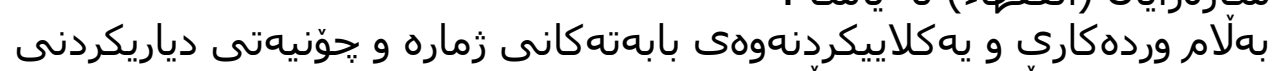

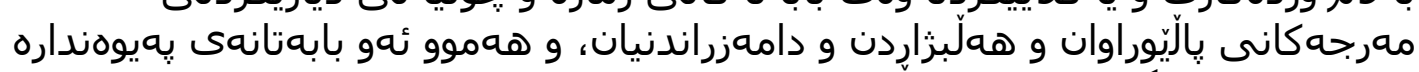

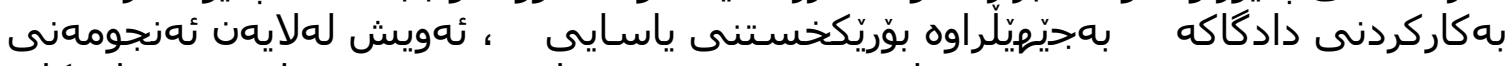

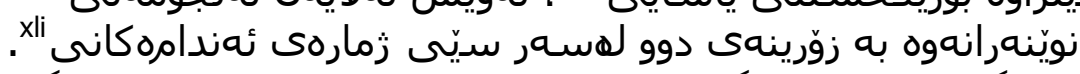

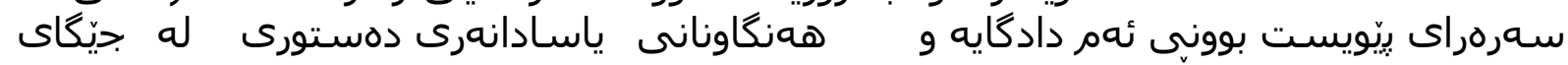

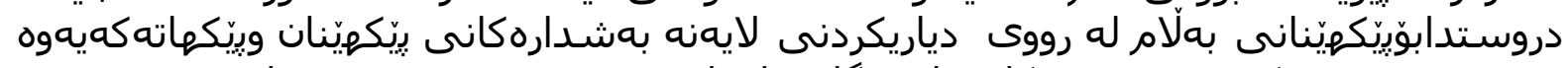

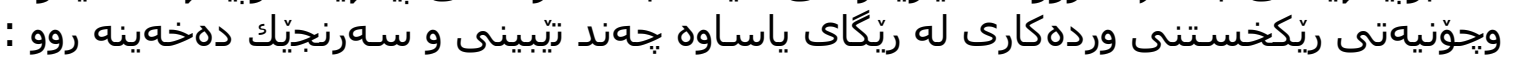

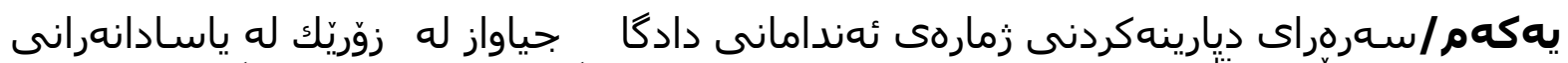

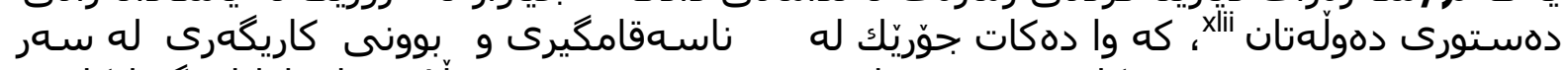

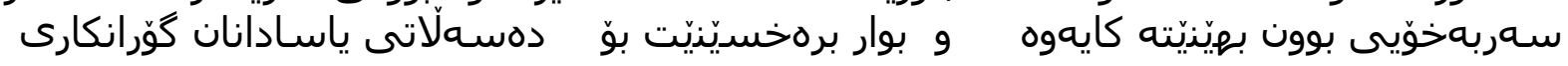

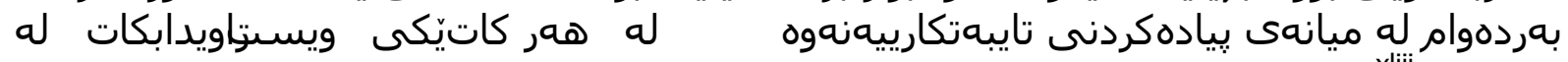

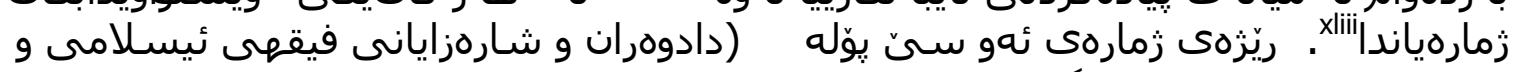

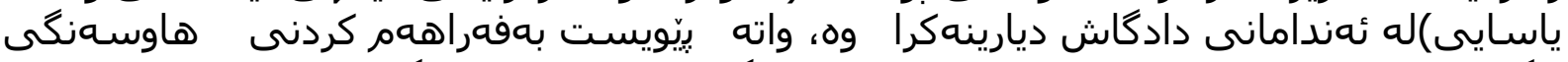

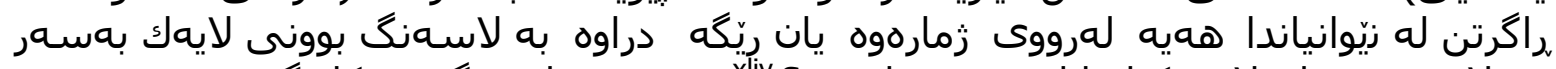

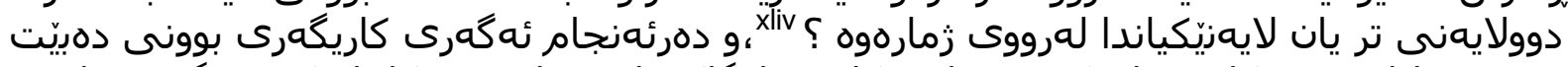

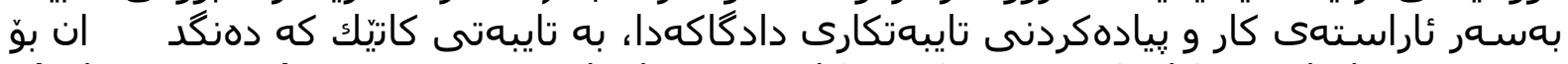

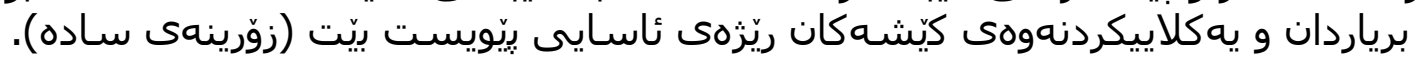

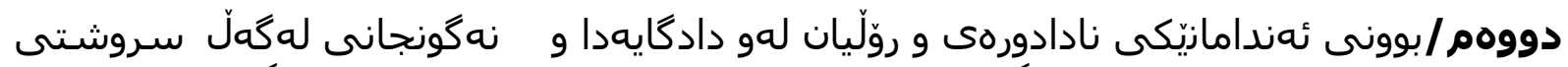

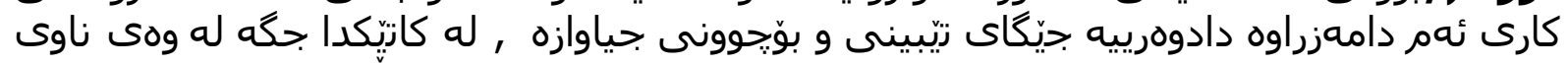

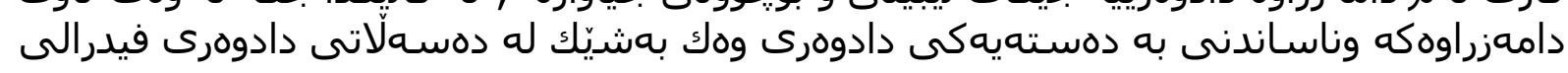




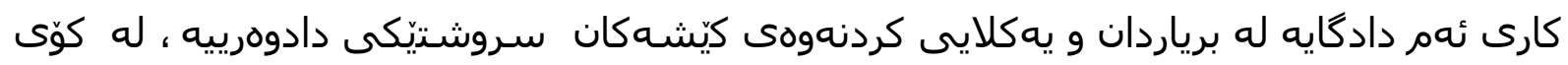

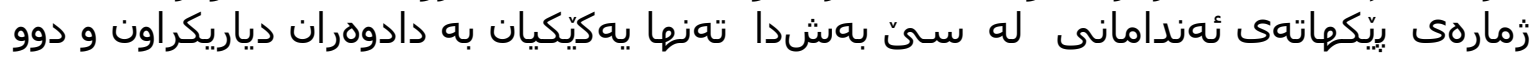

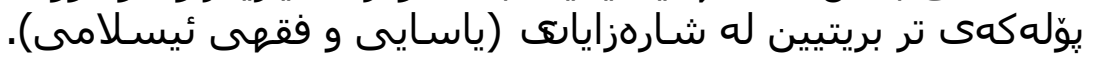

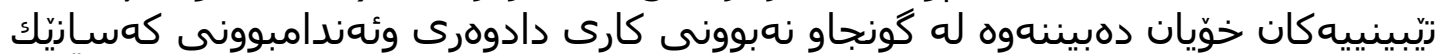

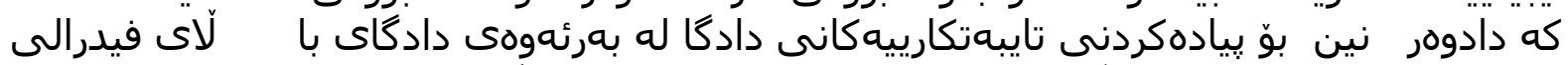

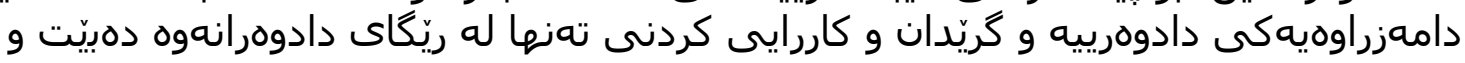

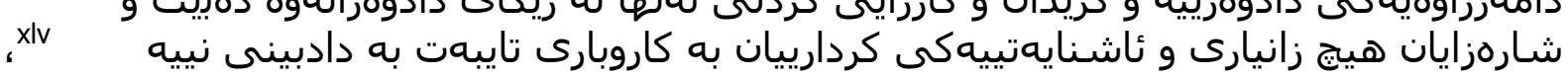

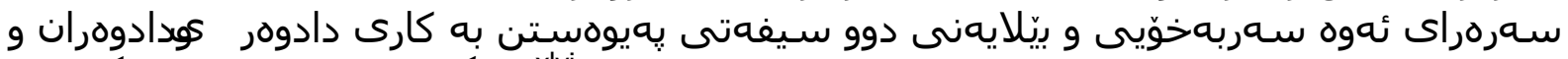

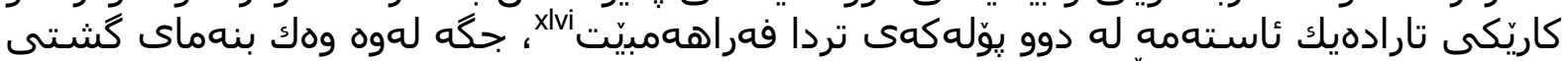

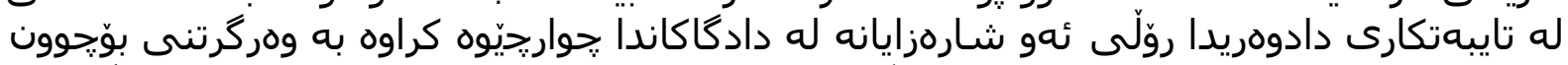

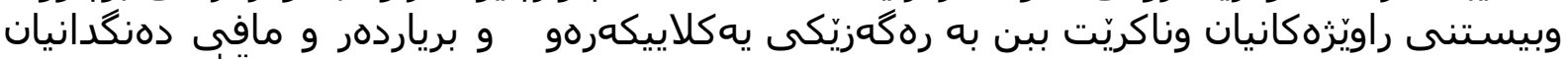

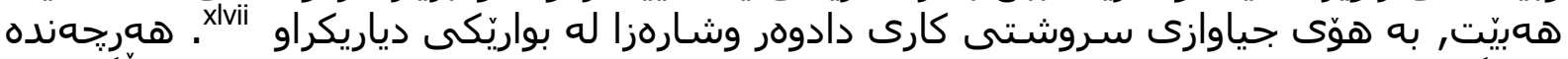

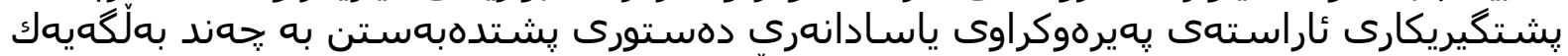

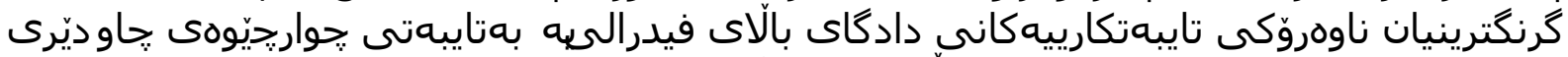

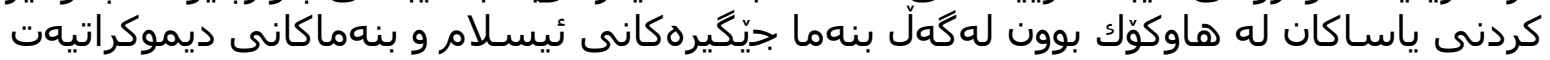

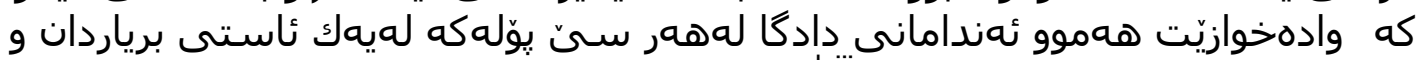
بيادهكردنى تايبهتكارييهكاندا بن

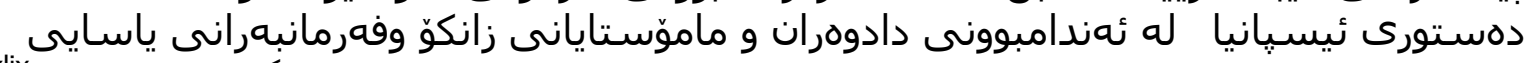

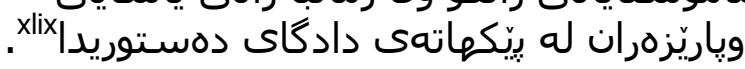

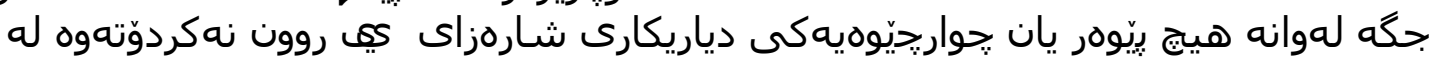

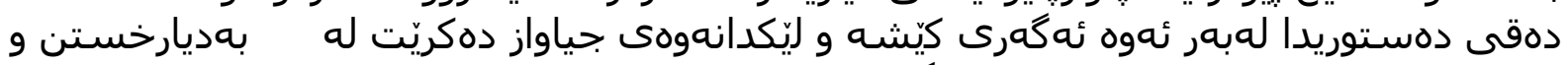

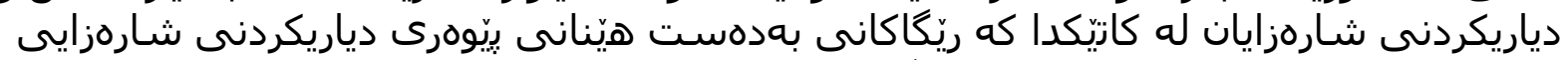

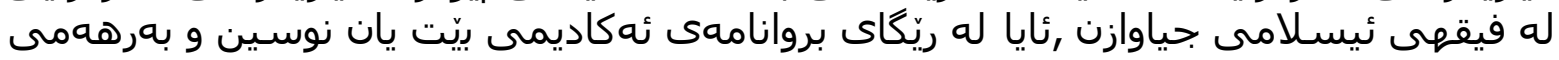

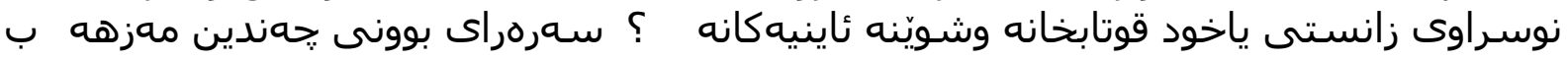

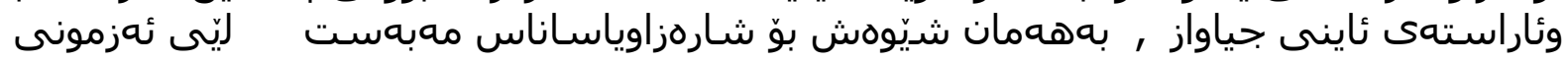

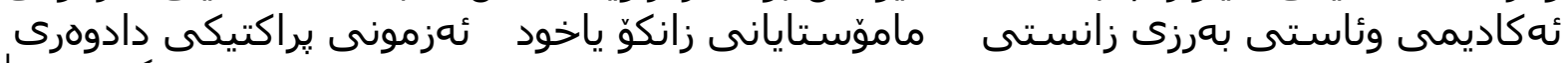

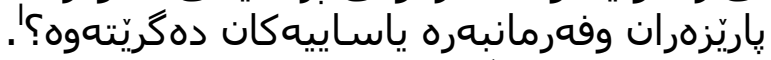

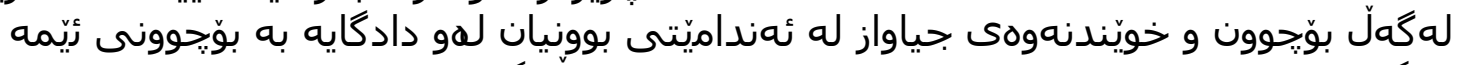

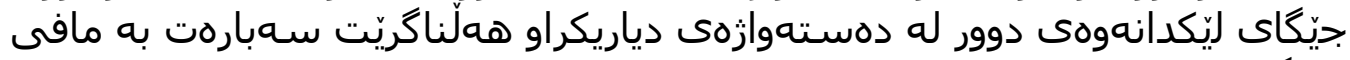

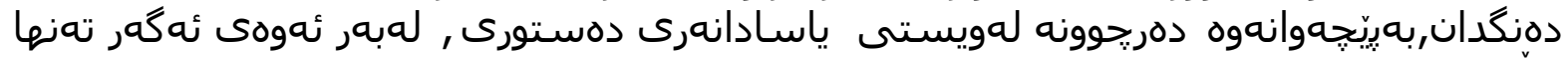

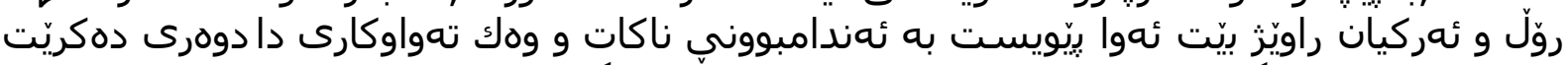

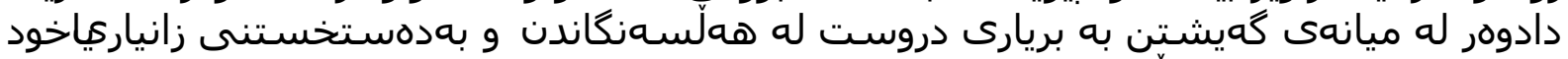

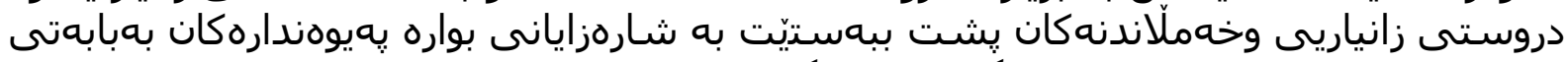

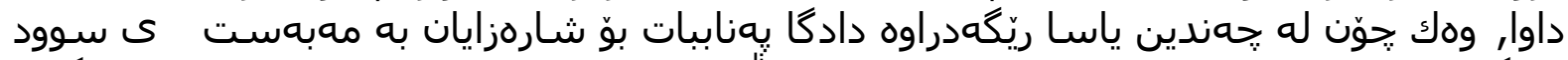

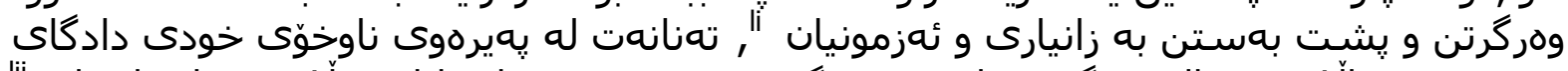

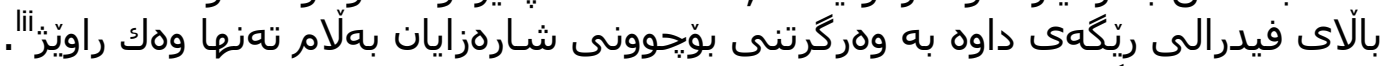

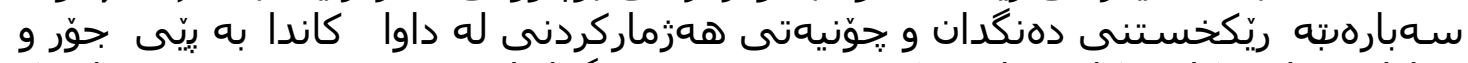

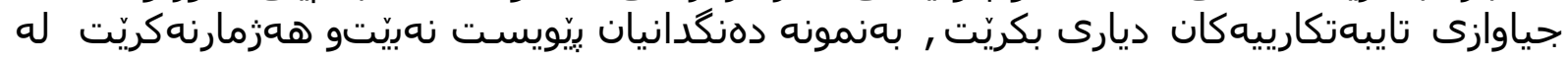

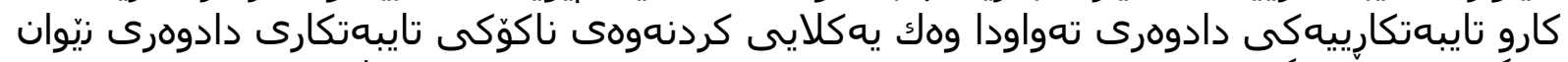

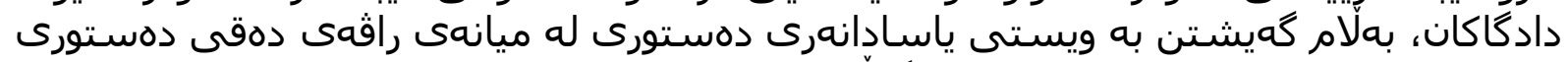

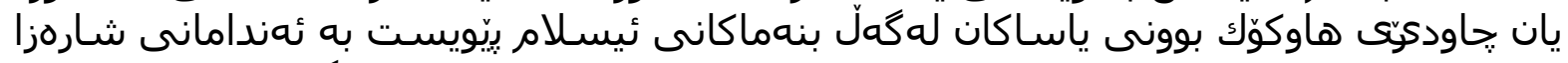

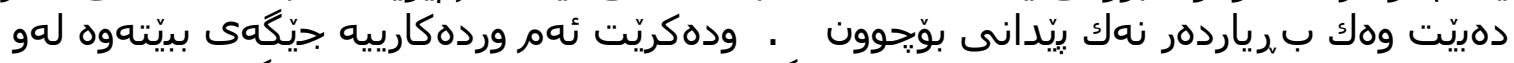

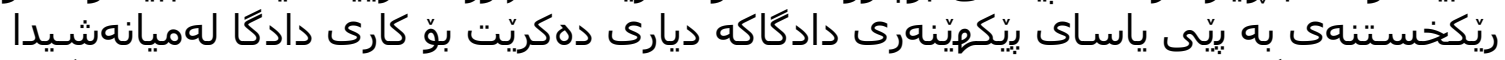

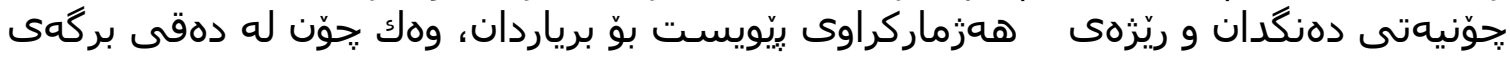

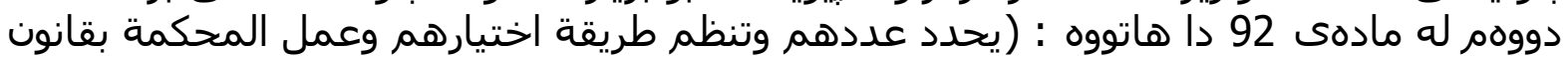
. (

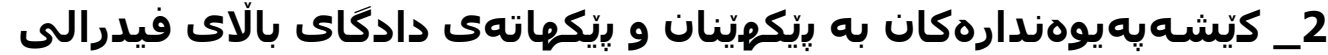




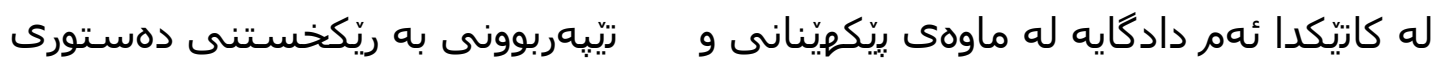

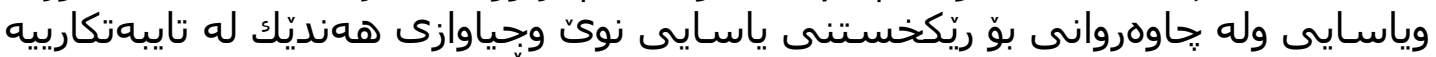

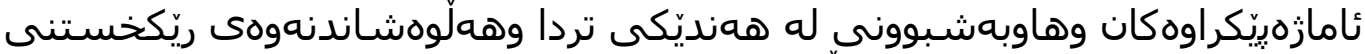

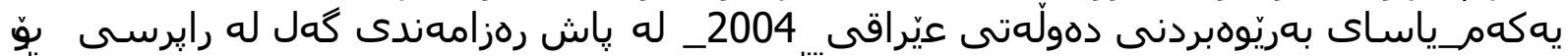

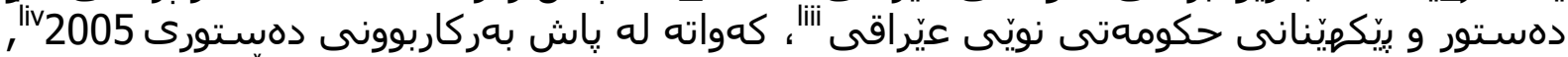

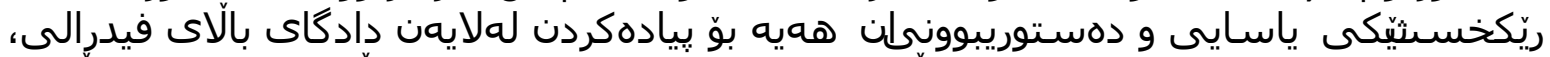

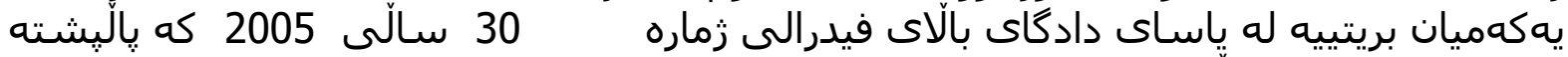

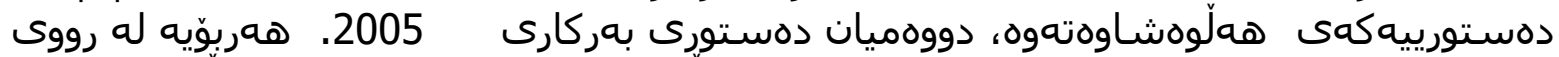

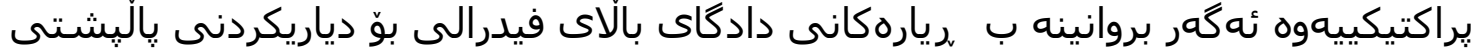

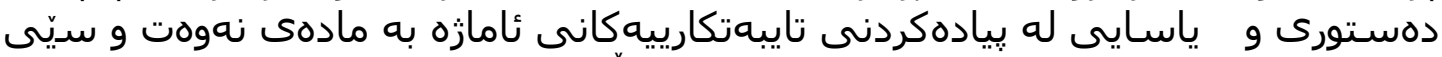

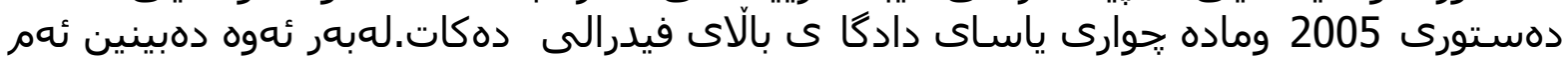

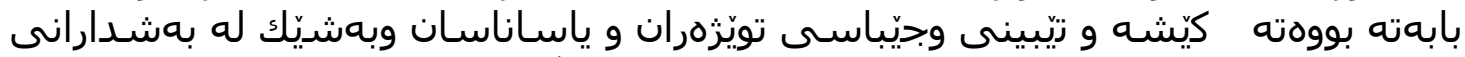

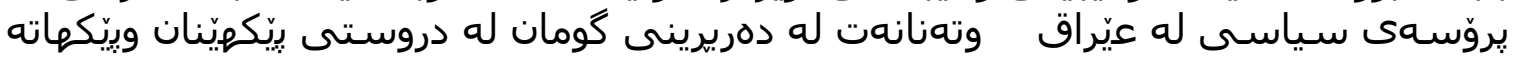

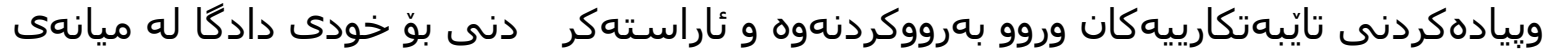

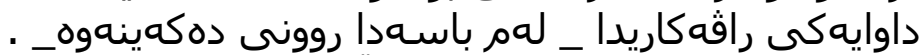

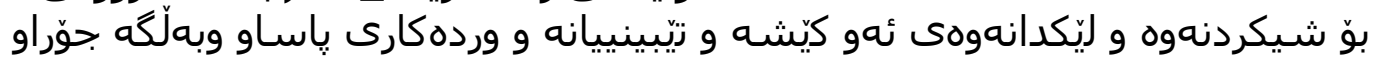

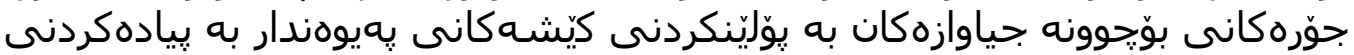

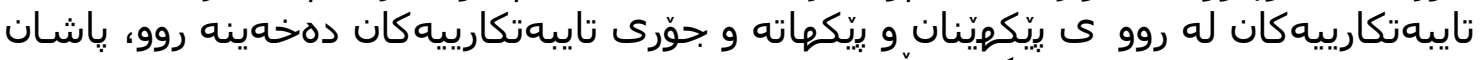

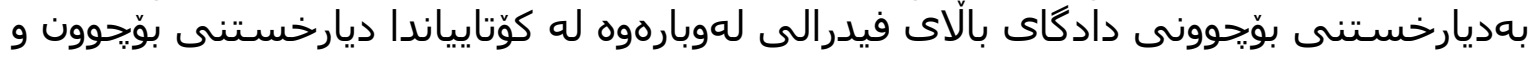

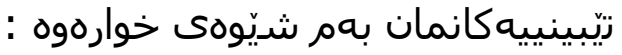

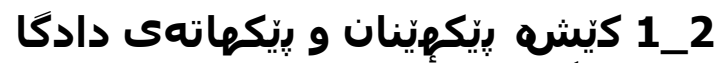

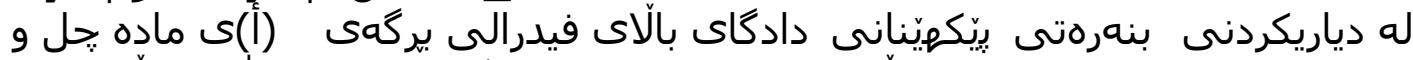

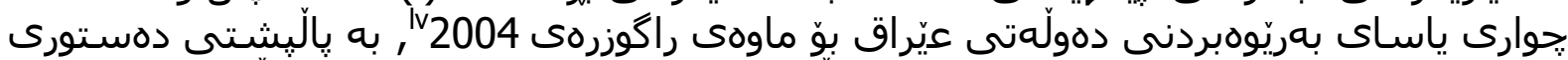

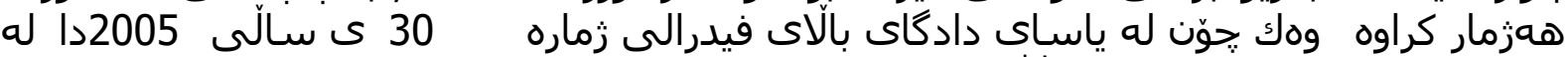

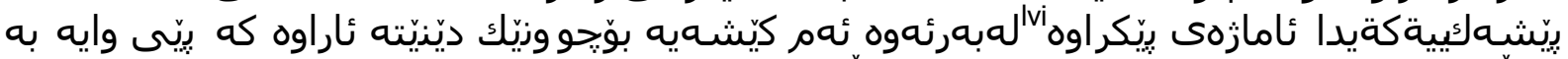

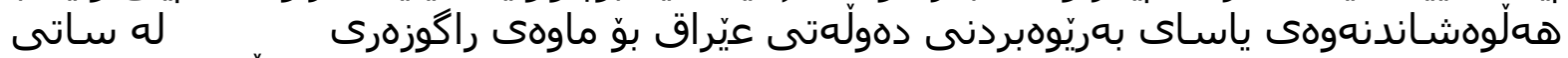

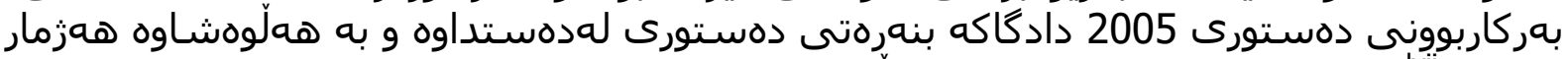

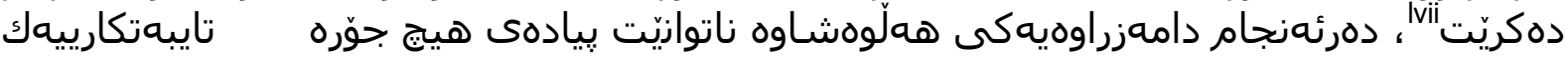
بكات .

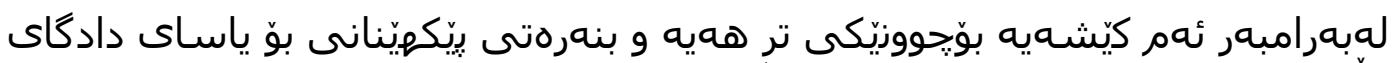

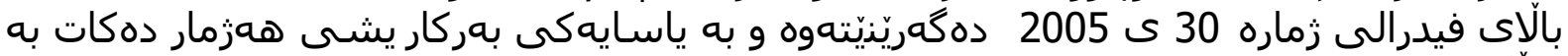

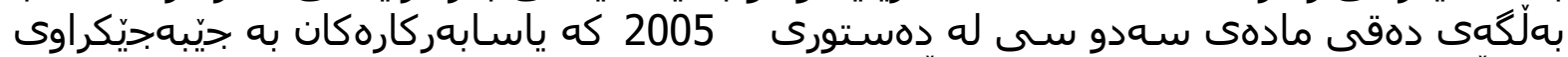

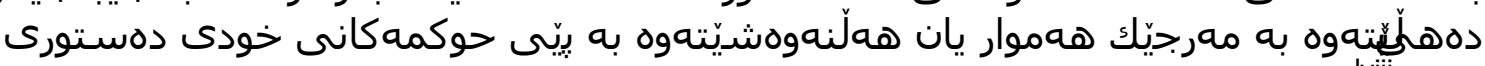

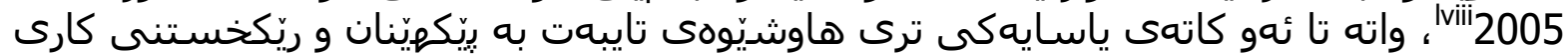

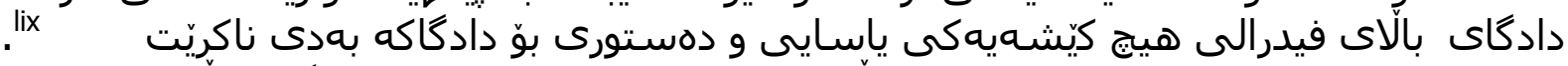

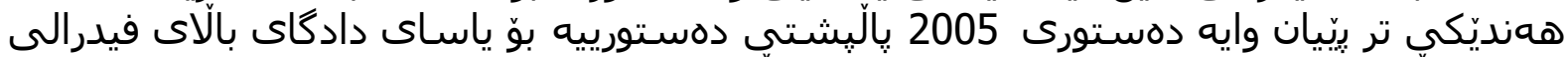

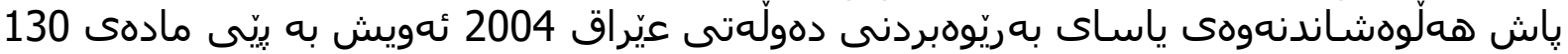

ى دهستورى 2005 كه رِيّشتر

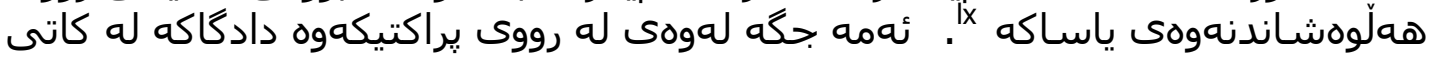

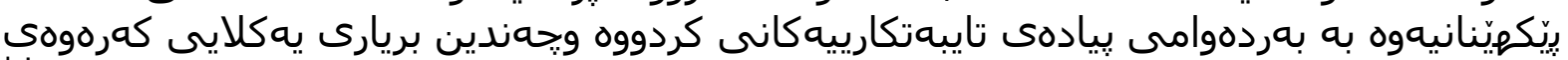

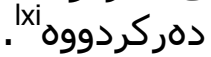

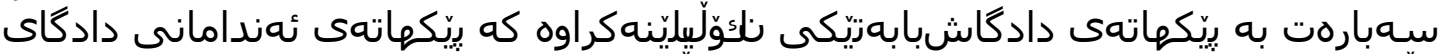

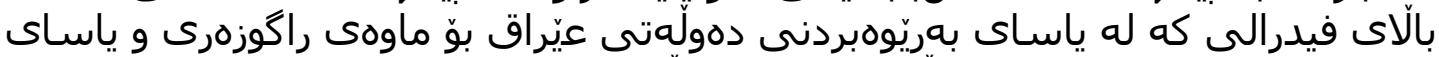

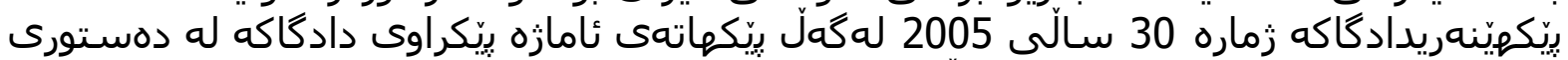

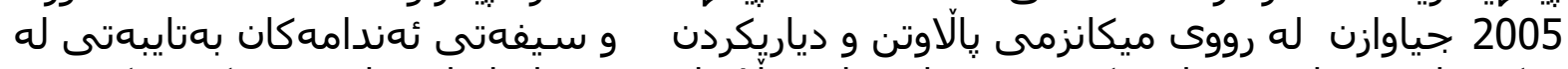

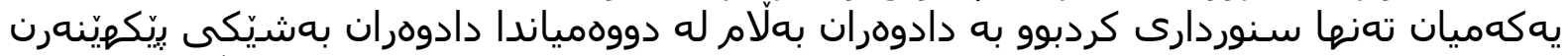

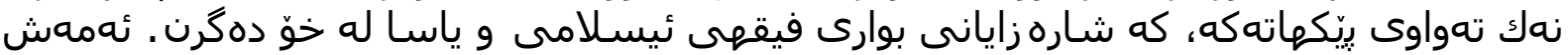

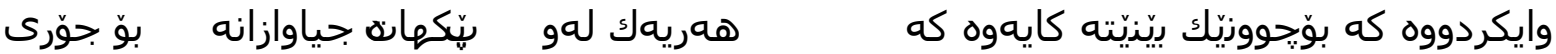




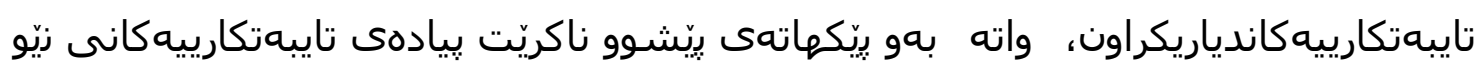

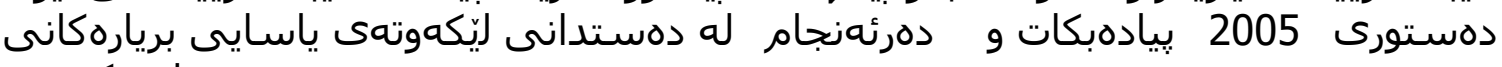

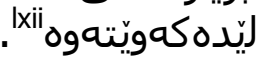

\section{اني}

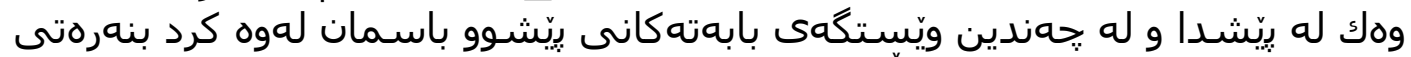

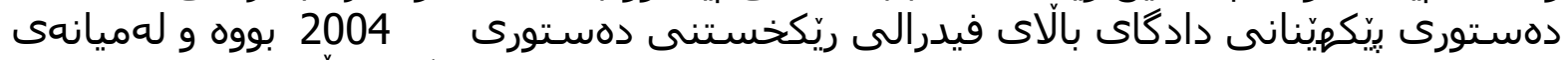

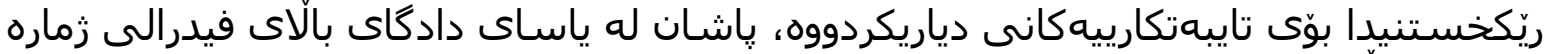

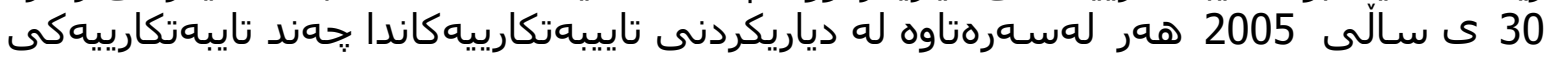

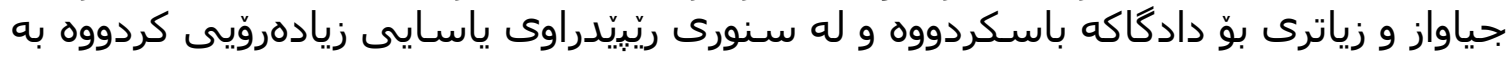

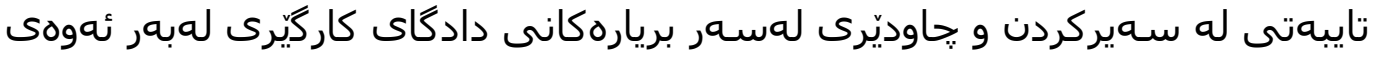

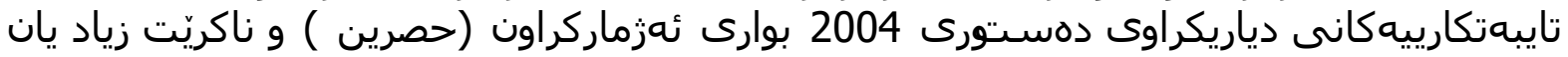

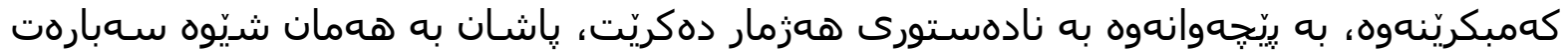

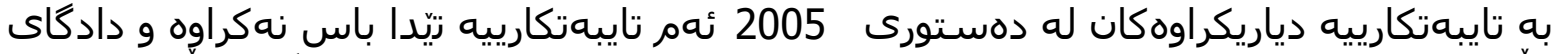

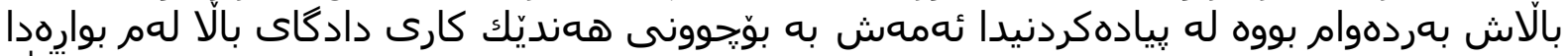

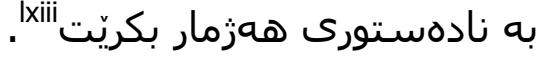

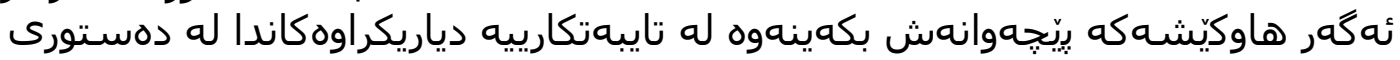

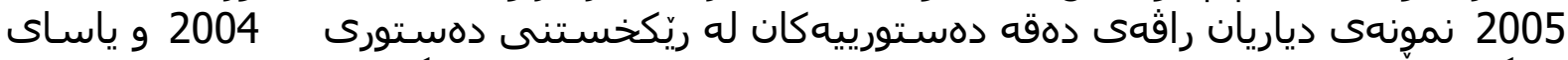

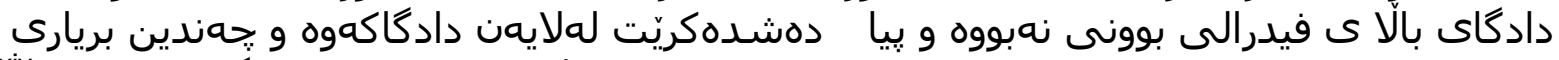

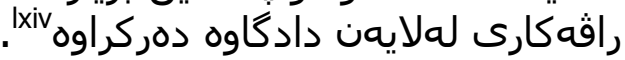

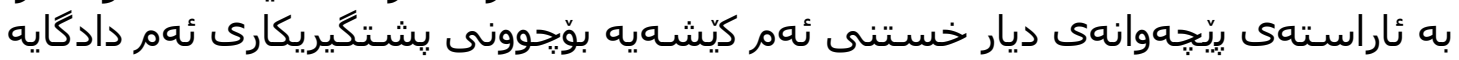

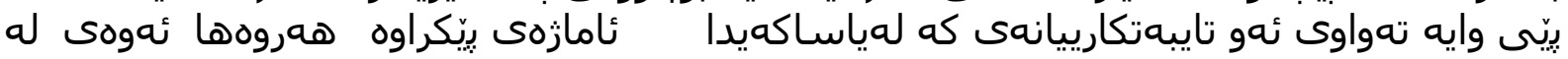

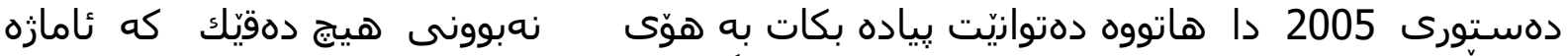

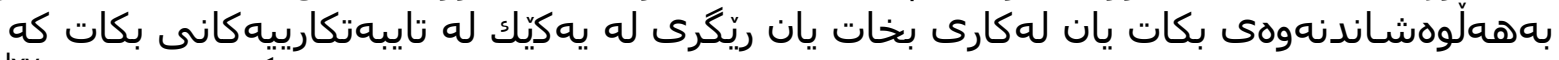

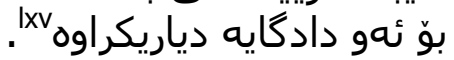

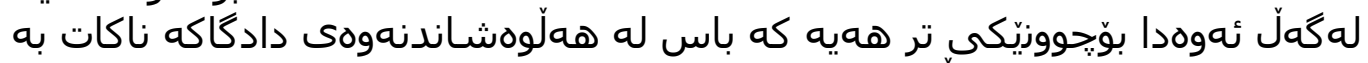

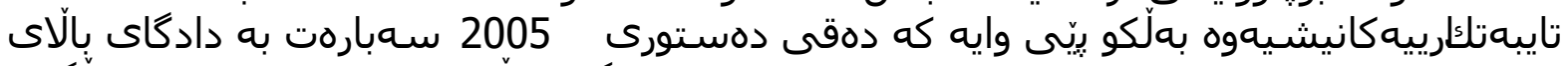

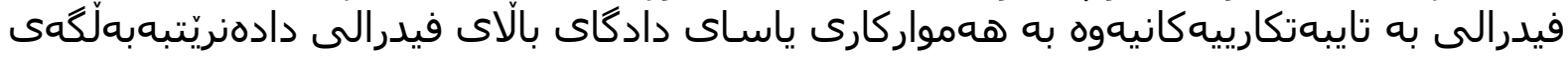

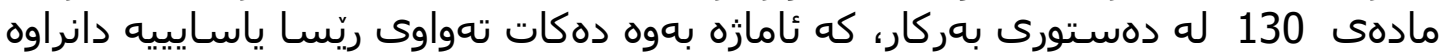

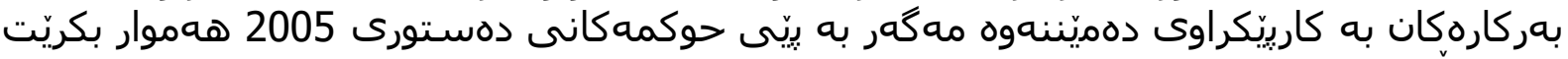

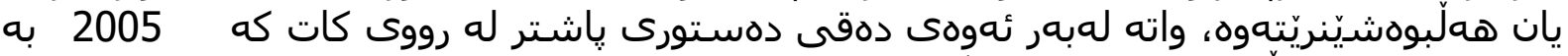

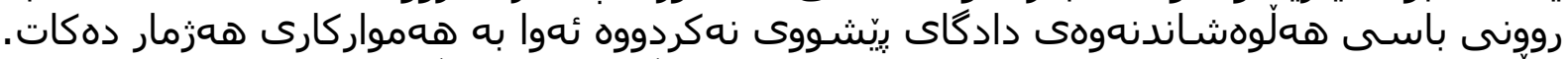

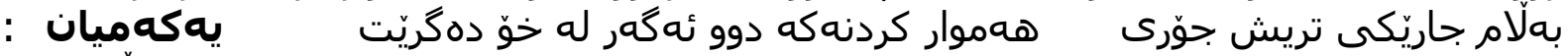

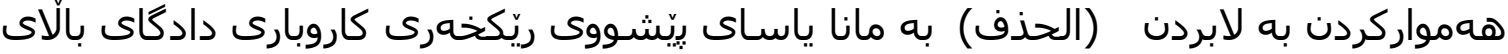

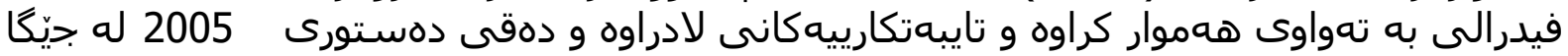

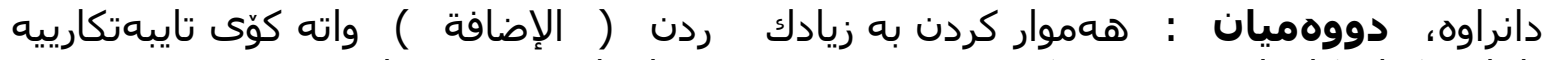

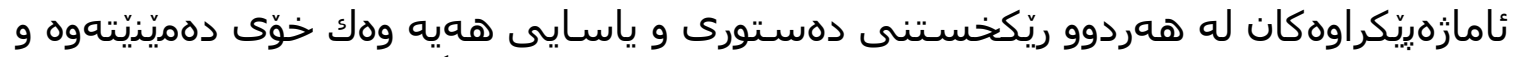

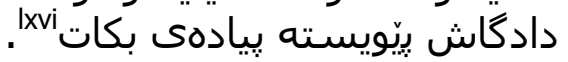

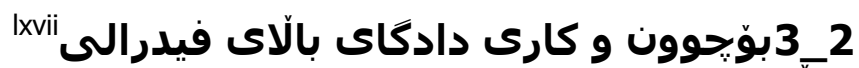

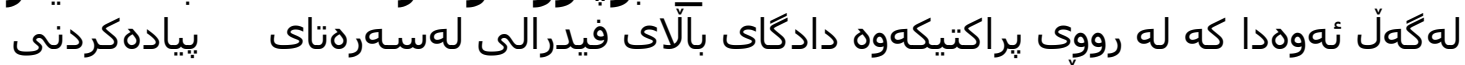

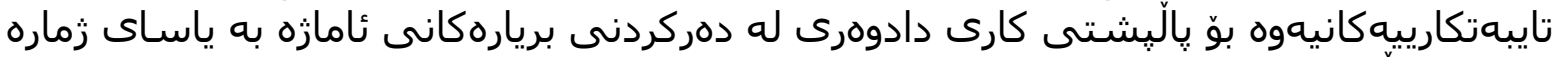

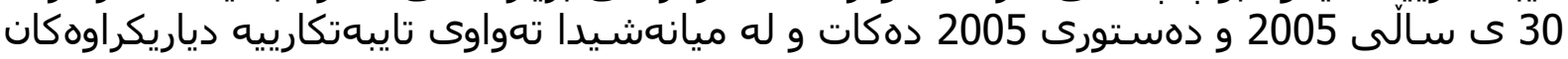

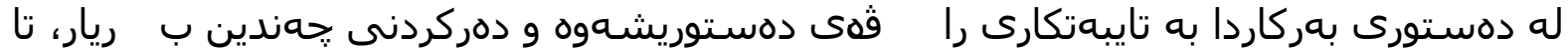

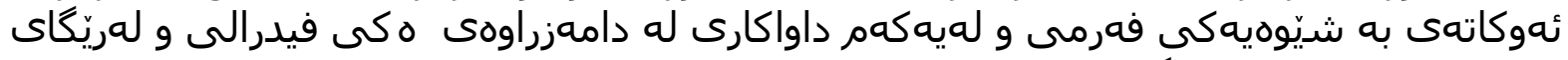

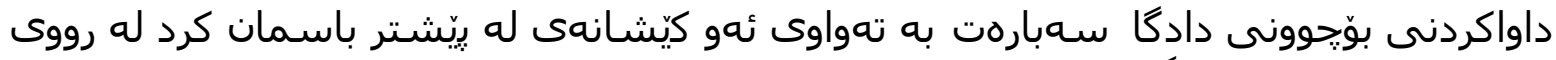

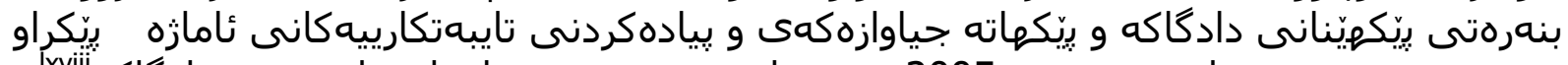

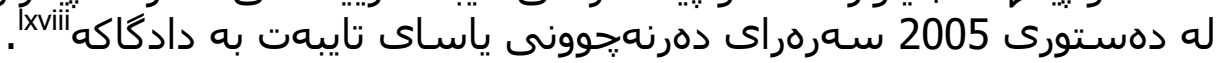




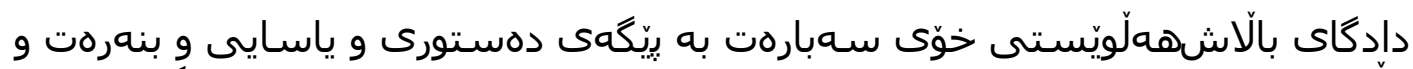

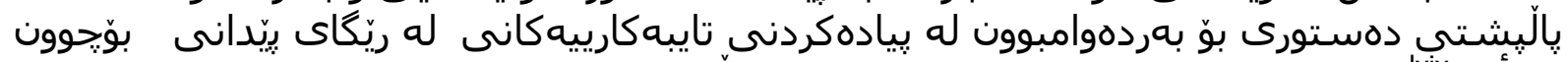

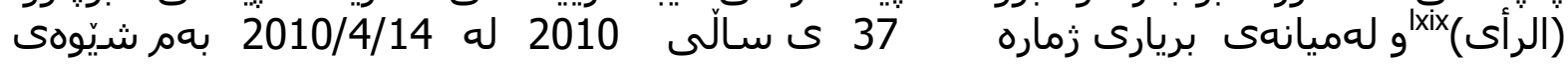

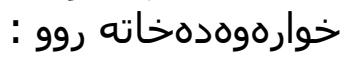

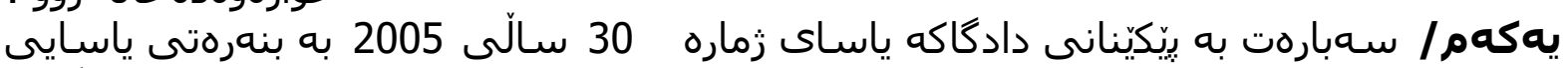

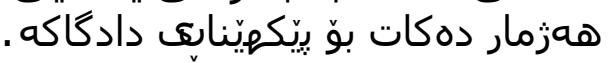

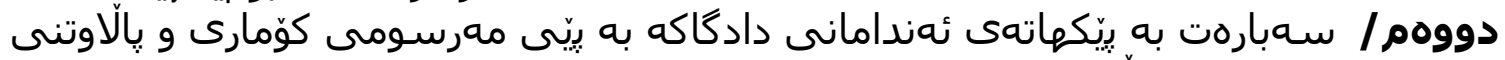

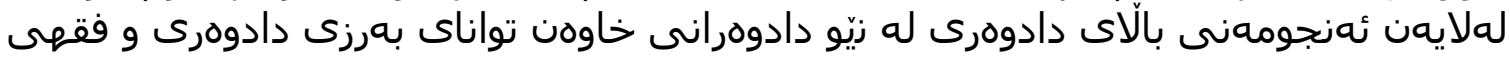

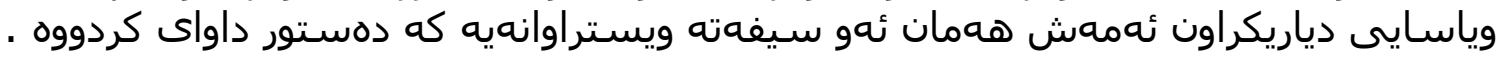

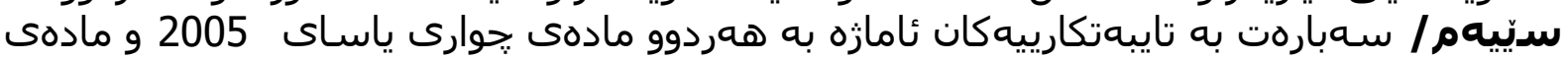

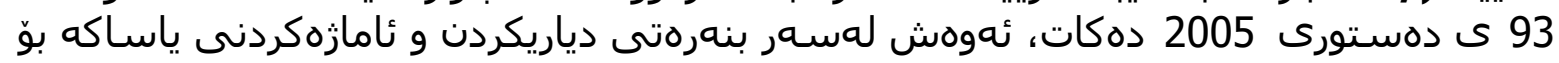

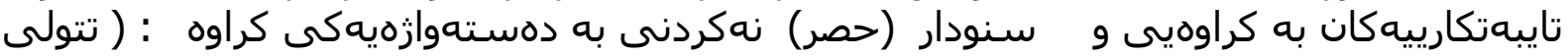

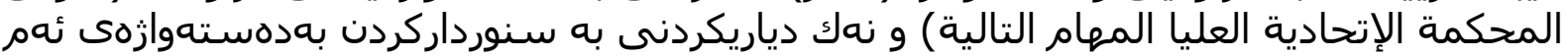

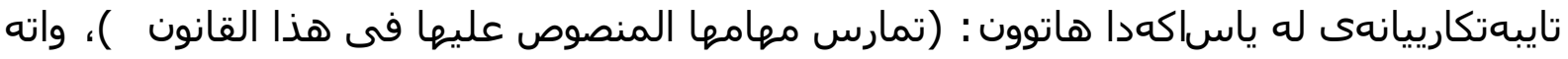

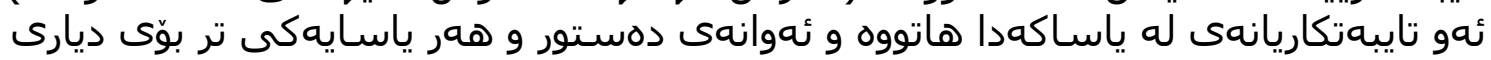

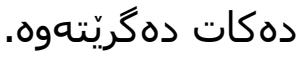

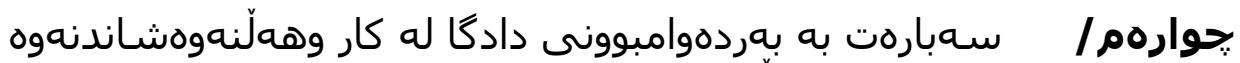

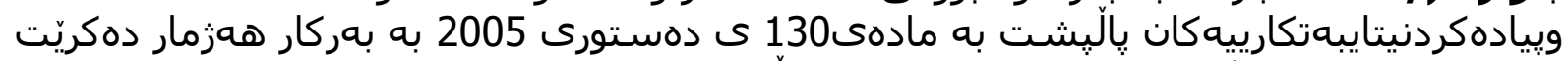

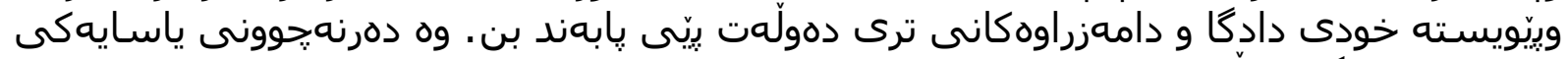

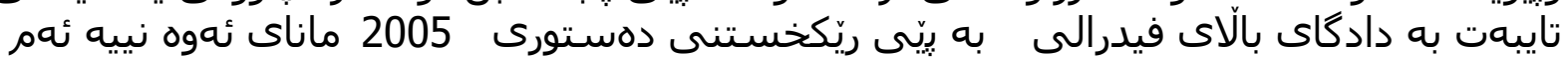

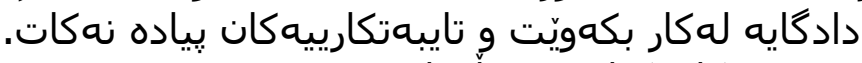

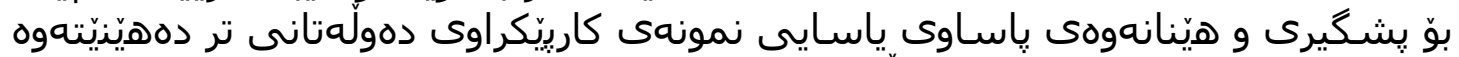

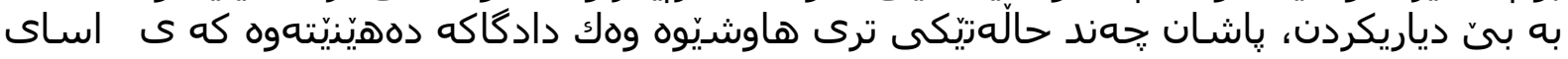

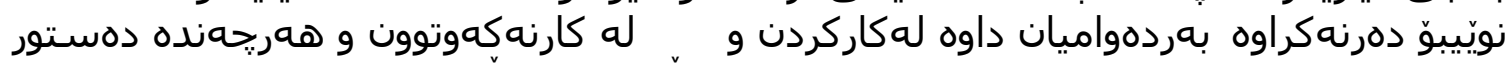

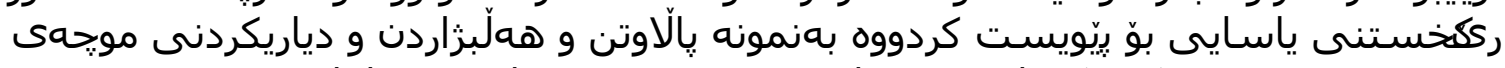

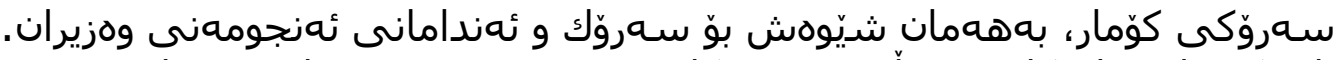

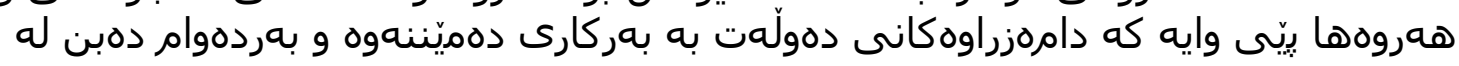

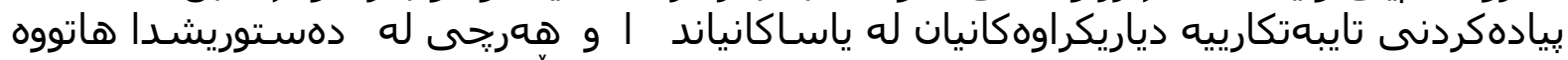

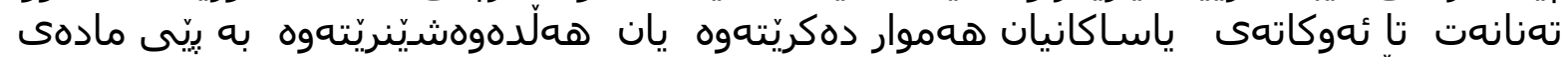

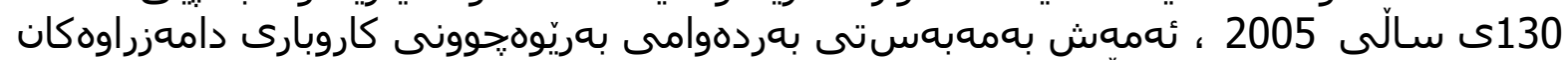

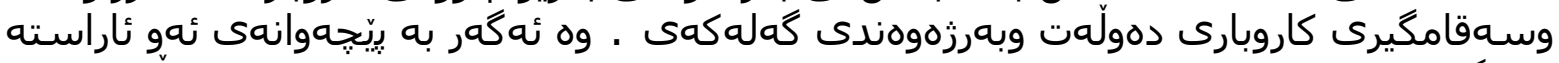

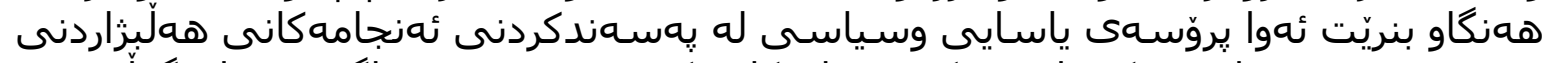

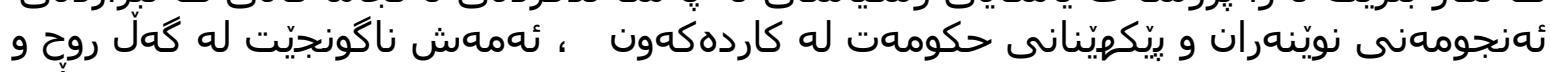

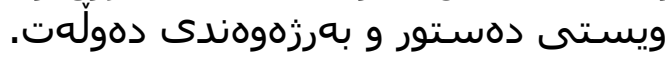

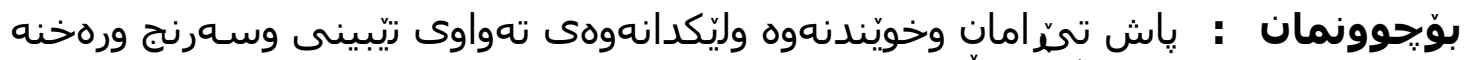

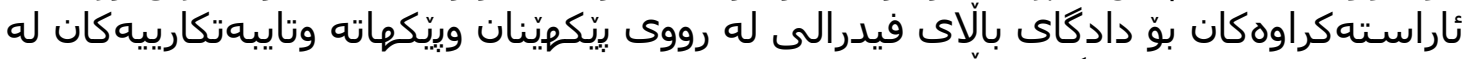

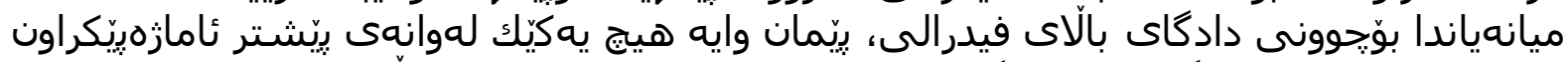

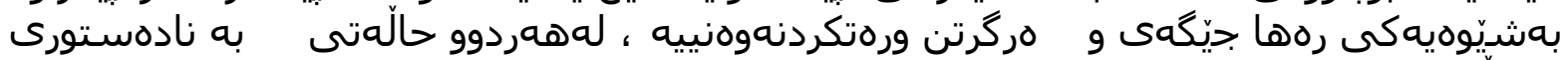

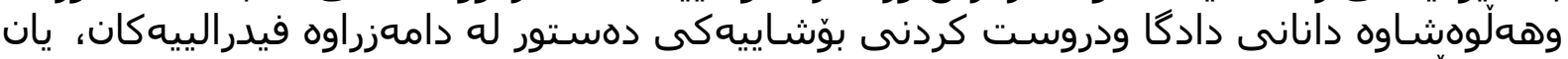

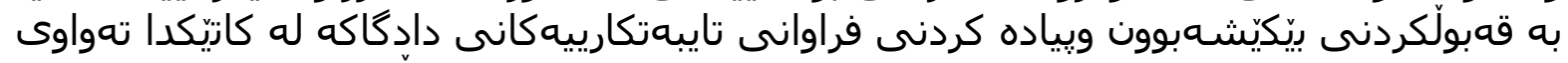

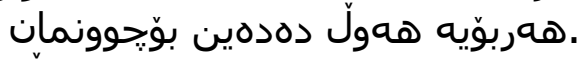

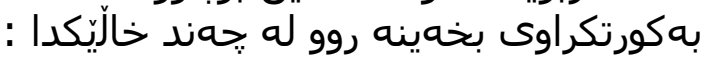

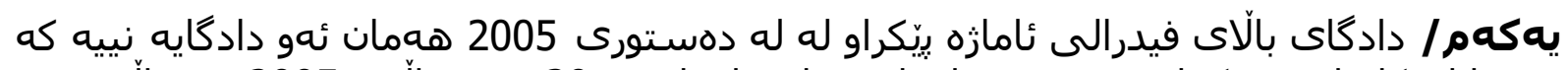

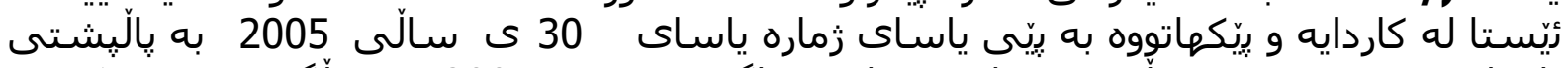

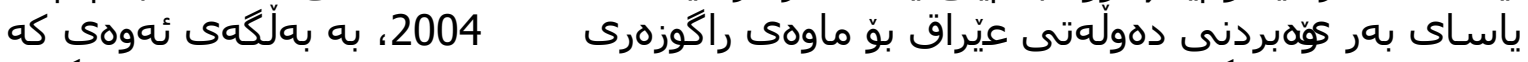

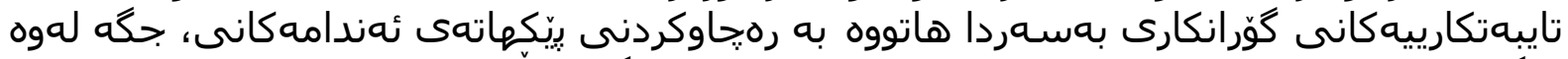

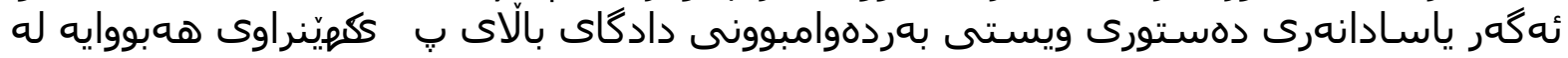




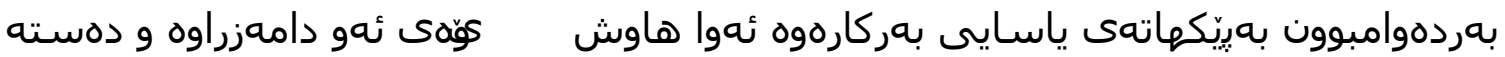

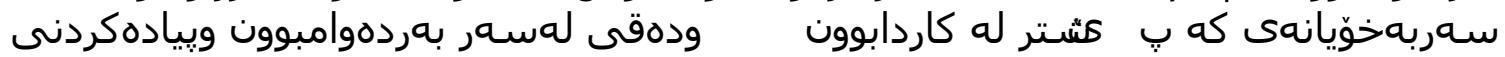

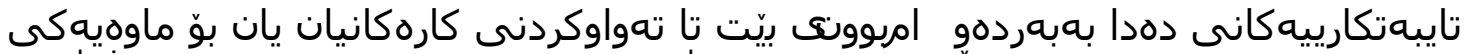

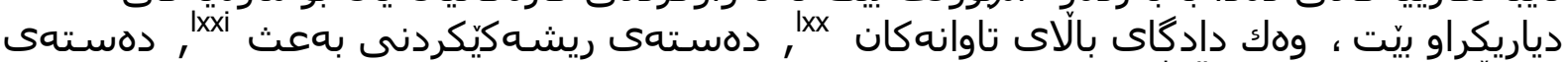

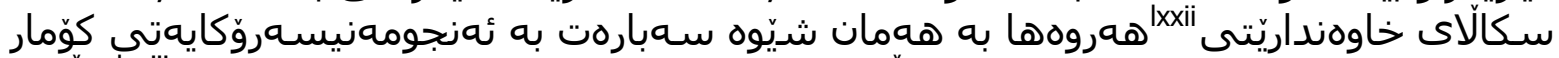

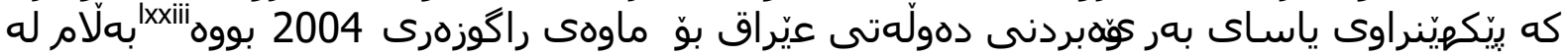

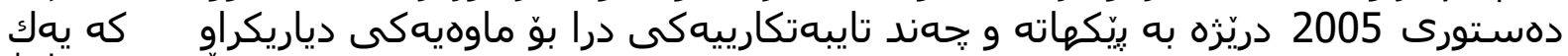

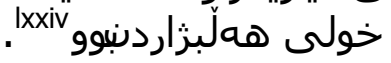

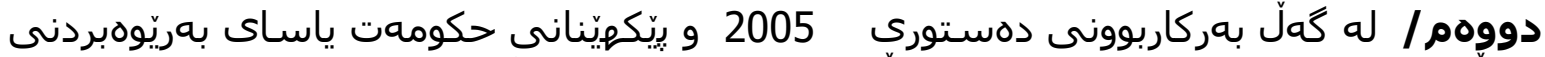

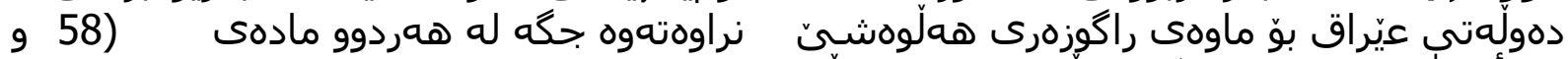

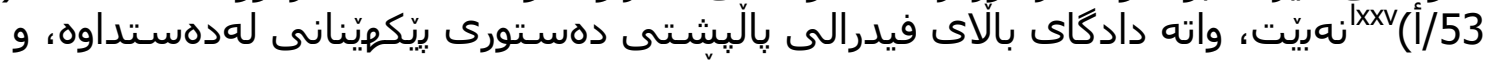

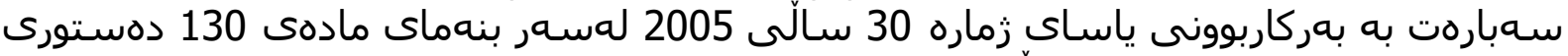

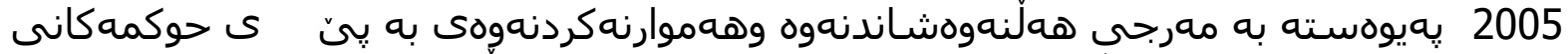

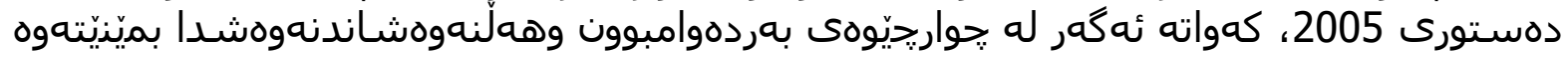

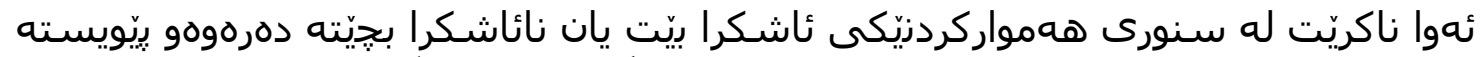

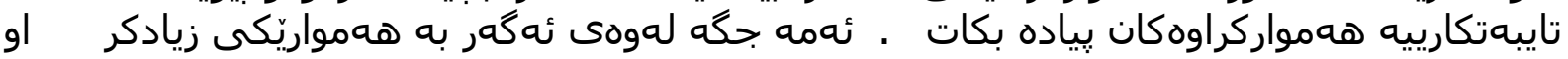

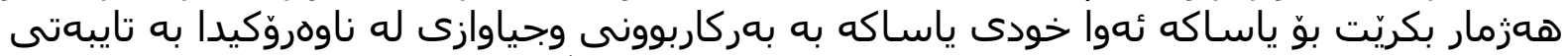

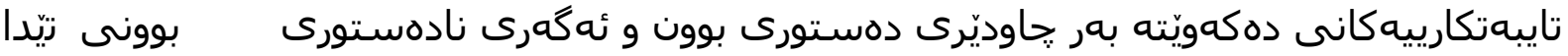
بههيزه.

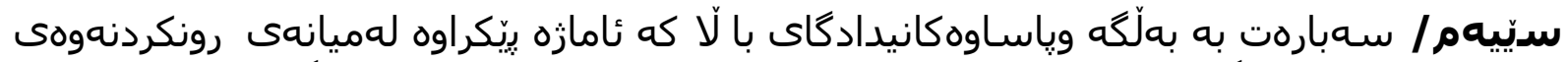

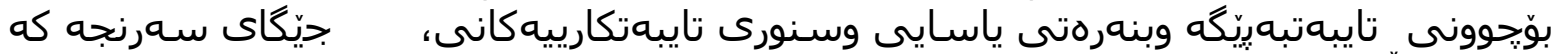

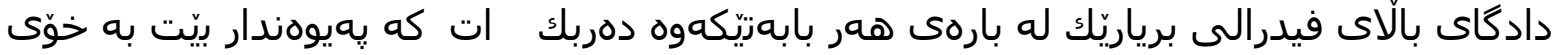

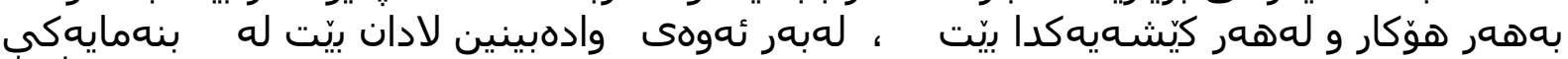

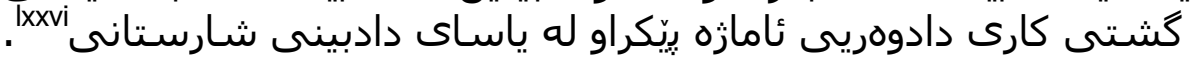

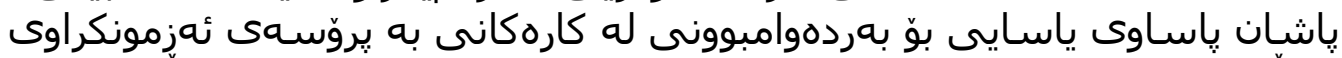

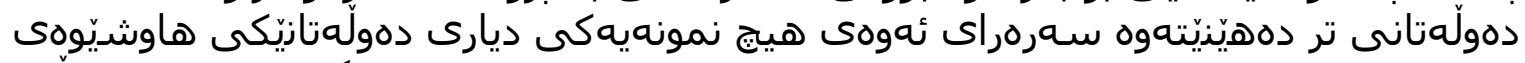

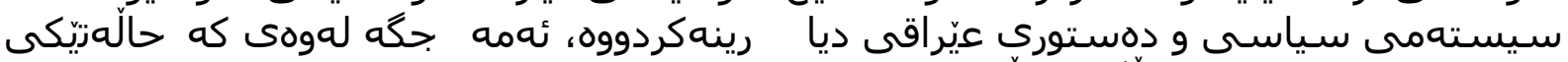

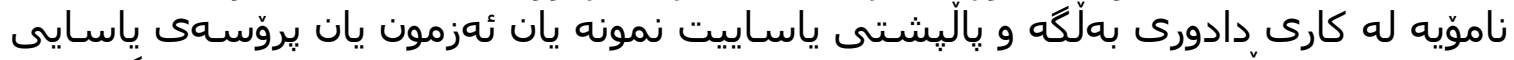

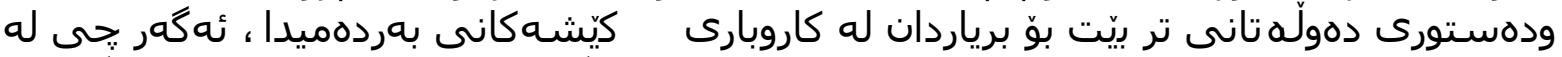

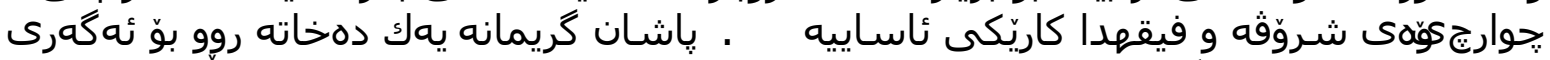

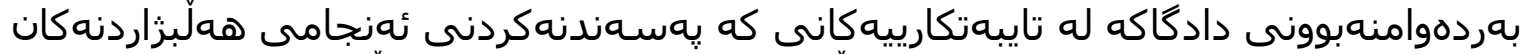

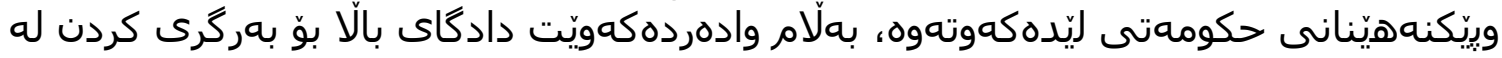

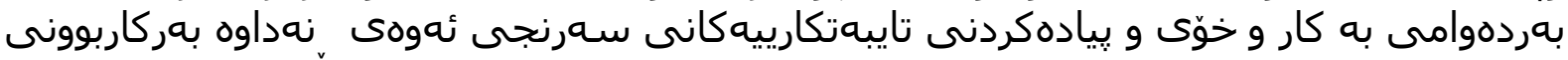

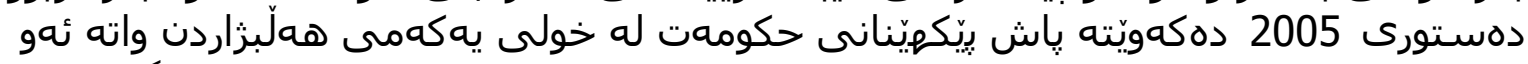

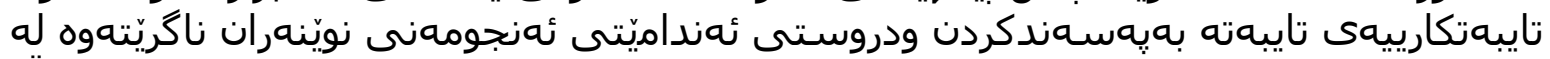
خولى يمكهمر Ixvii

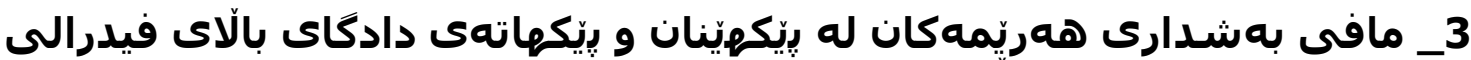

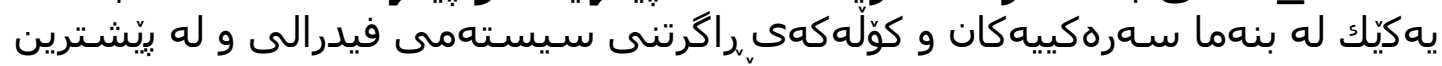

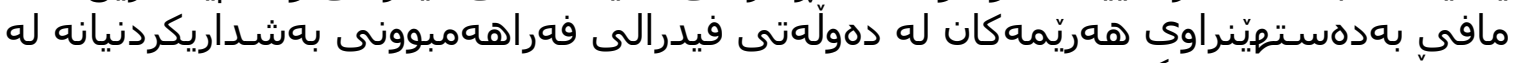

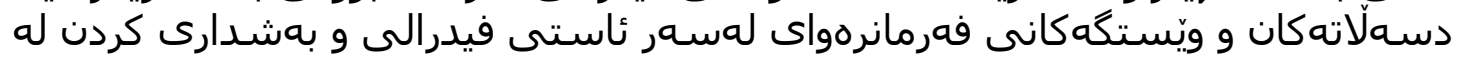

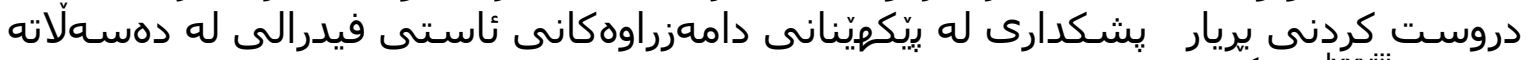

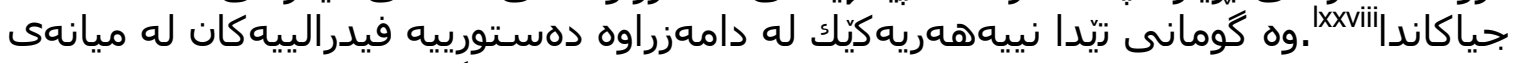

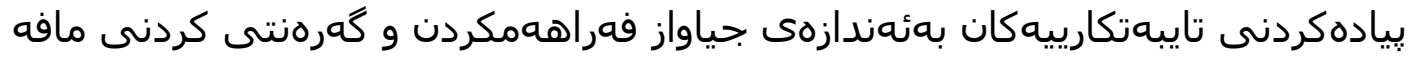

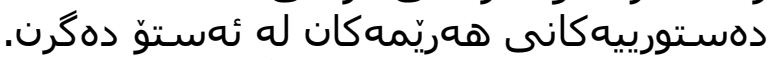

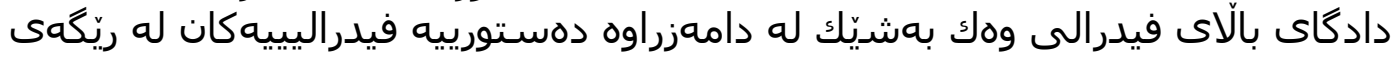

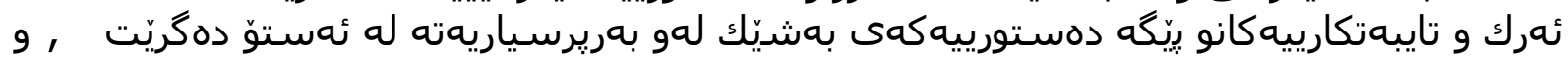




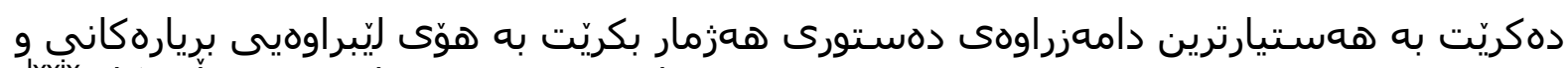

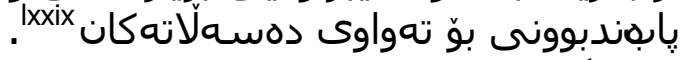

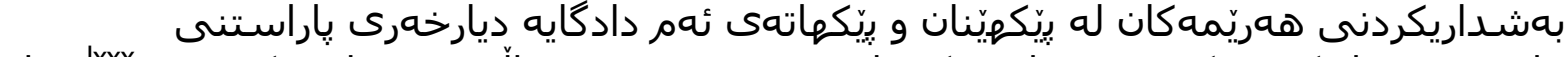

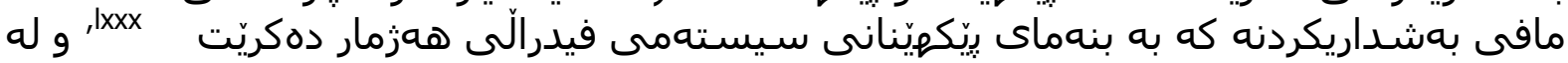

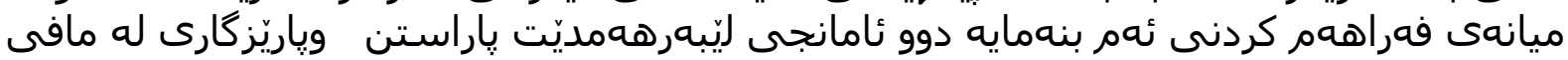

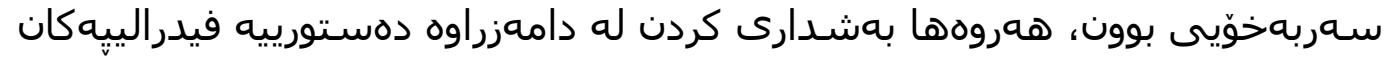

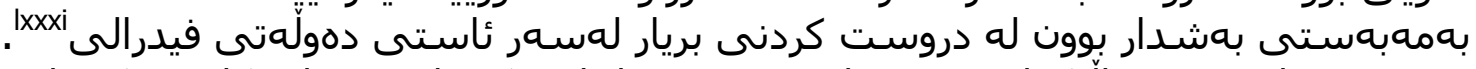

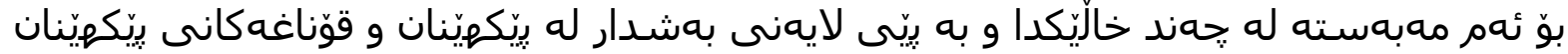

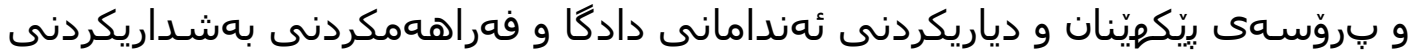
هوريّمهكان تيايانداله ههريهك له ريّكخستنى دهستورى 2004 و 2005 دهخهينه بهر باسكر باس :

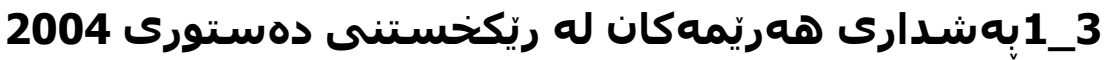

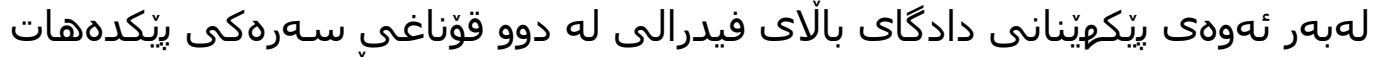

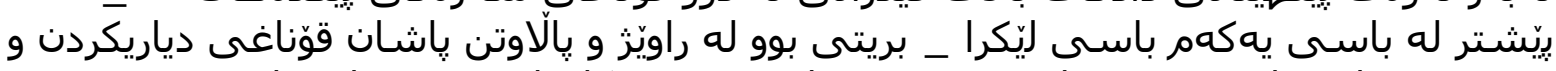

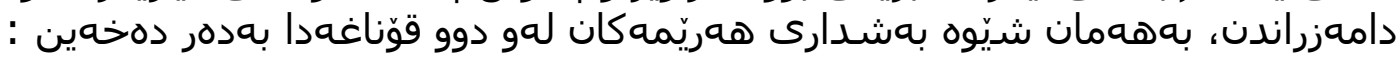

\section{له}

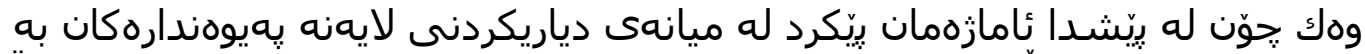

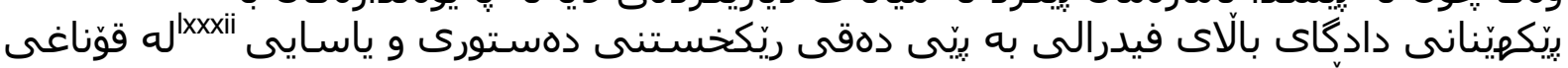

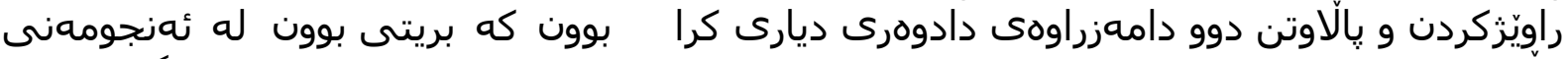

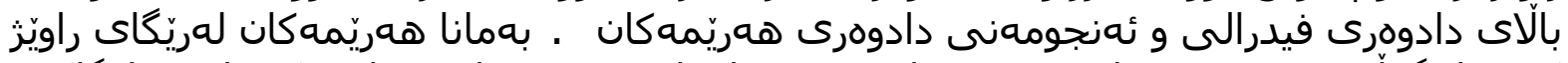

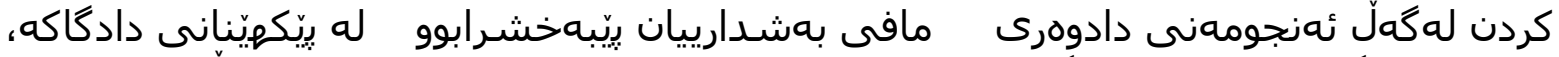

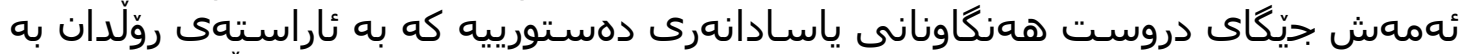

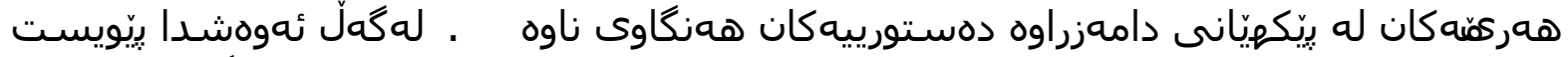

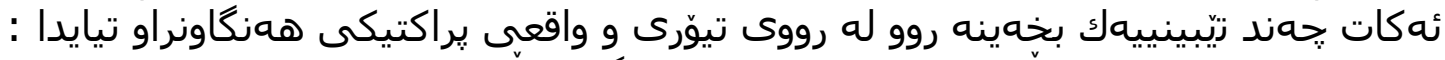

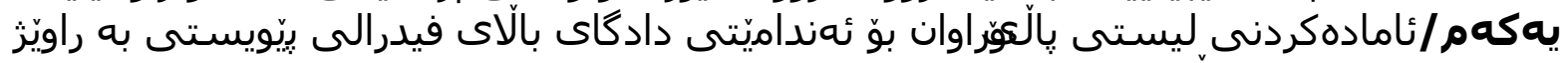

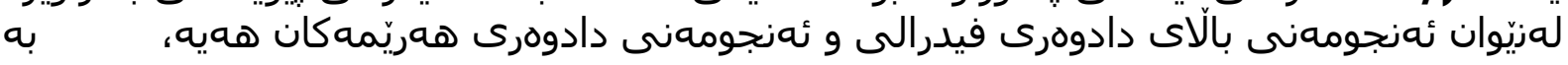

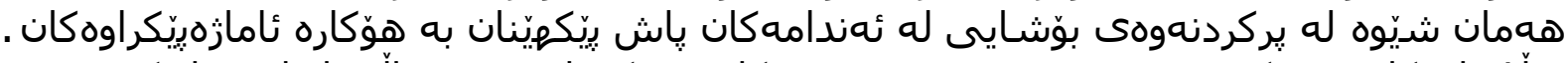

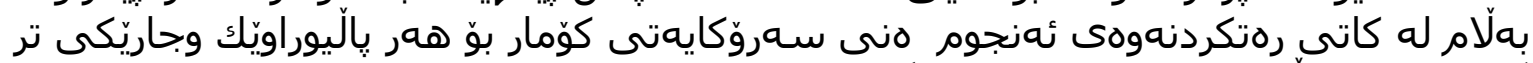

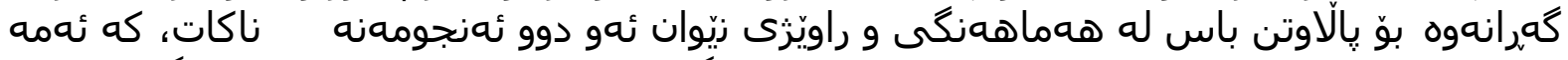

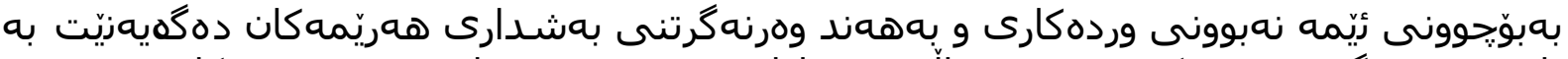

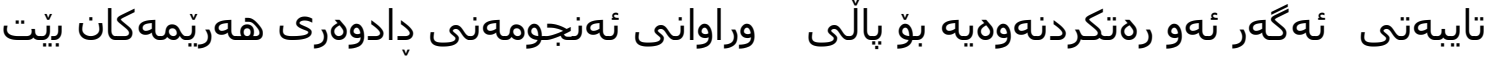

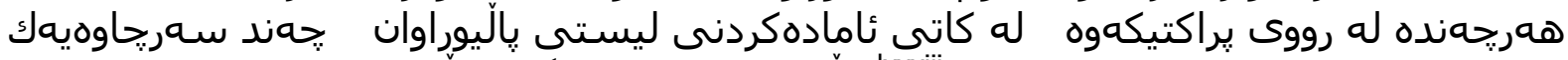

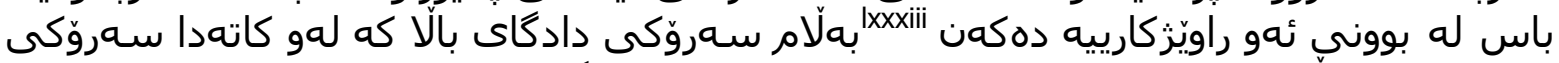

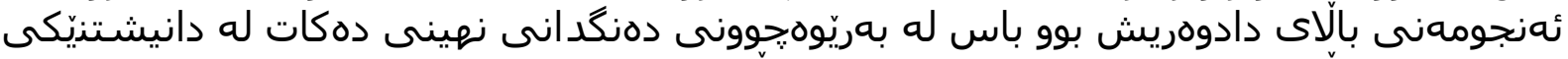

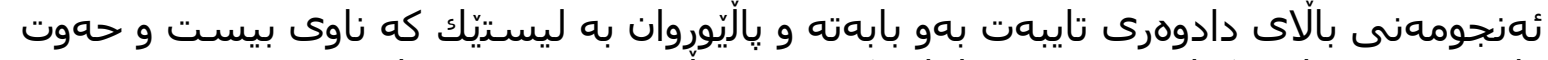

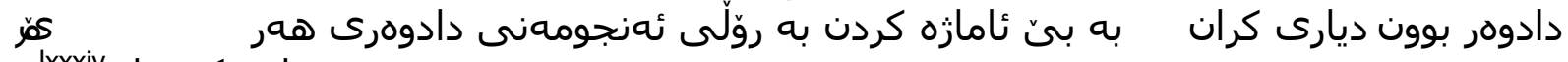

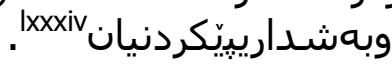

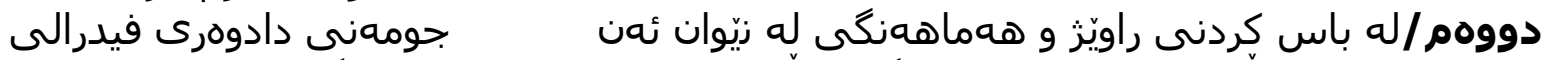

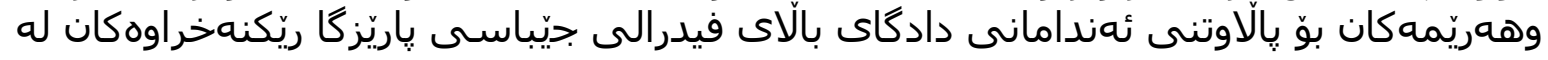

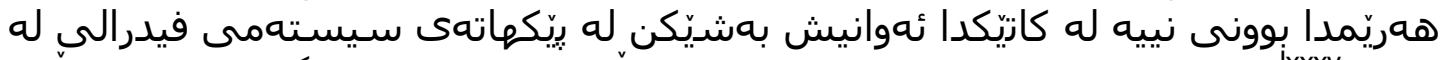

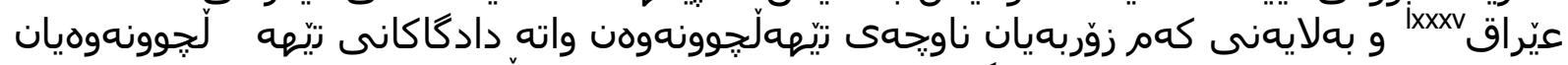

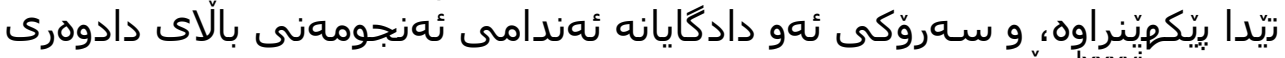

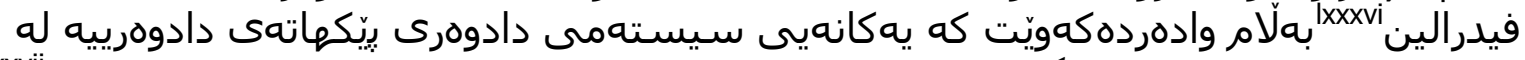

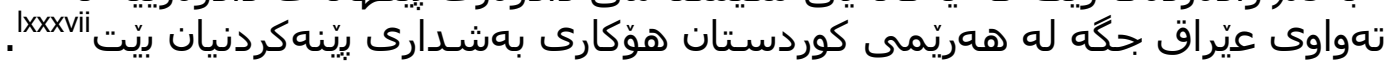

\section{}

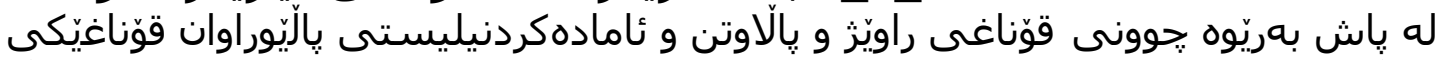

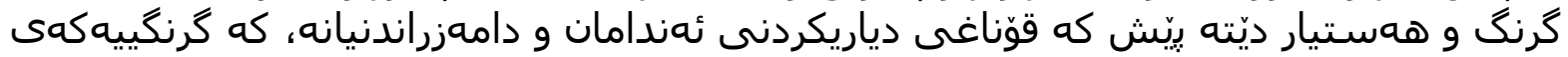




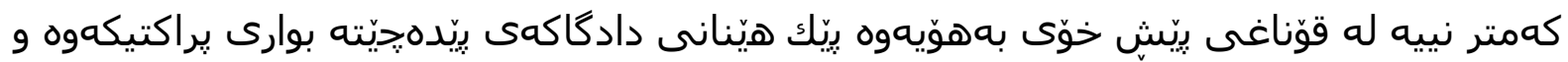

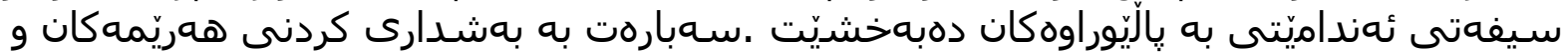

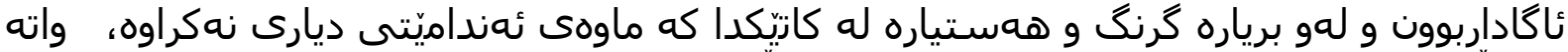

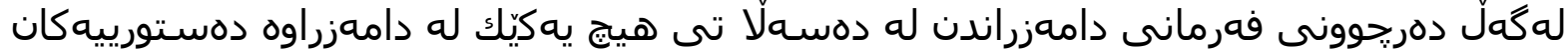

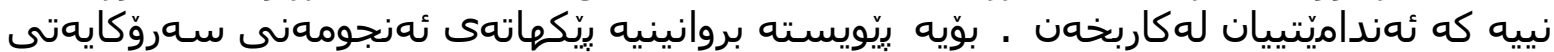

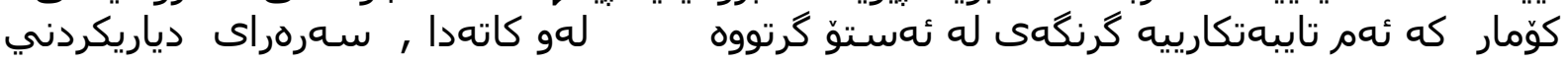

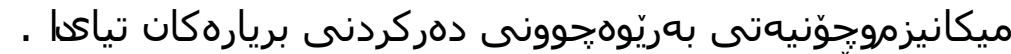

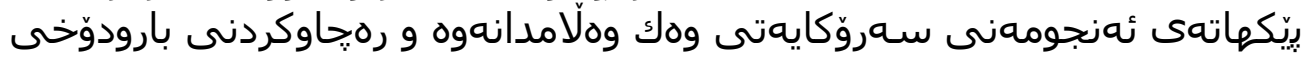

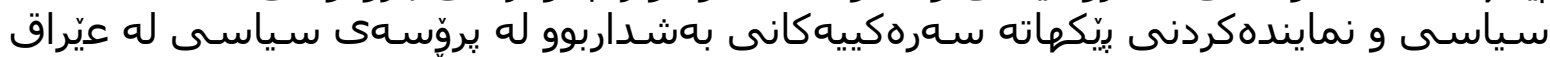

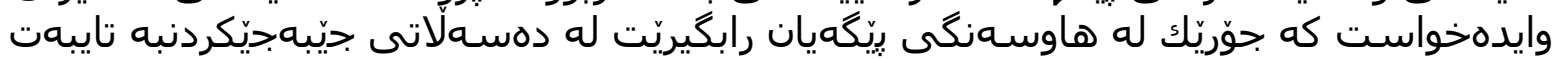

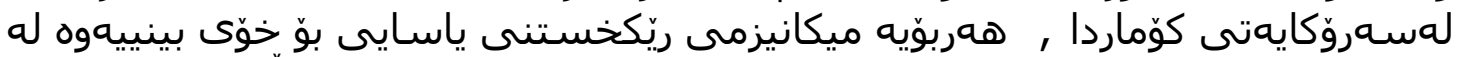

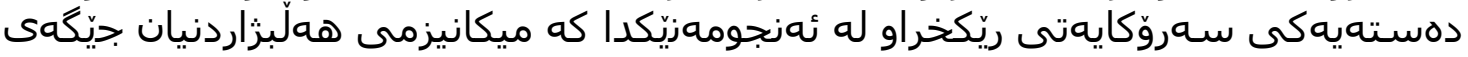

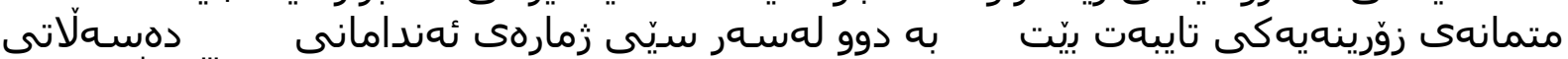

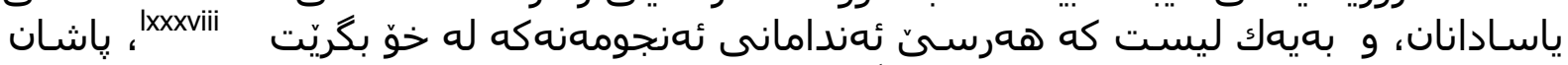

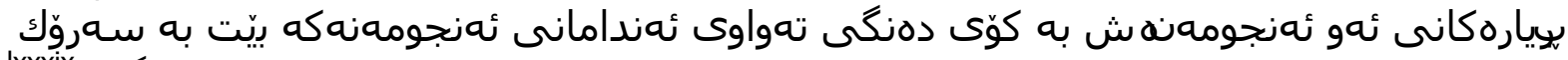

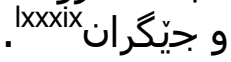

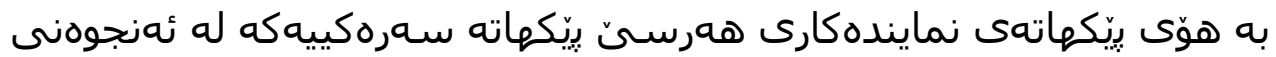

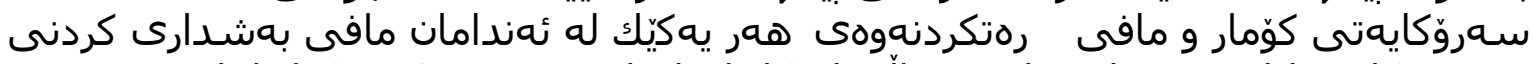

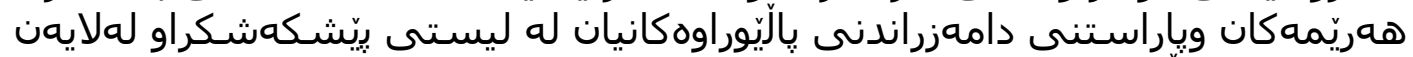

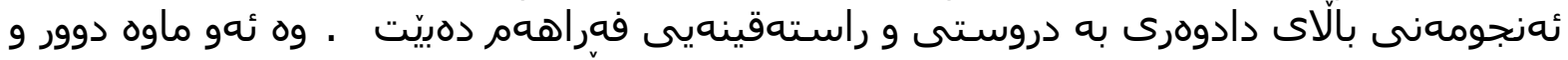

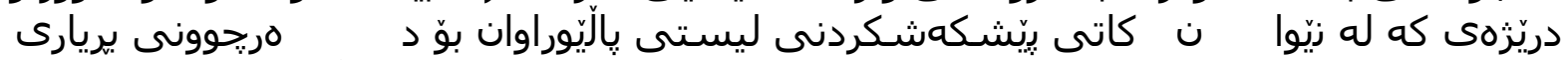

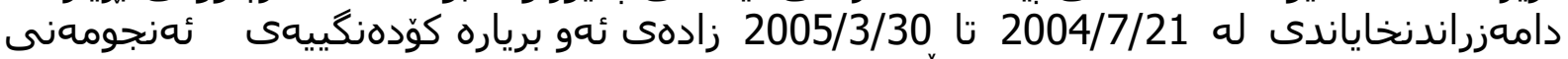

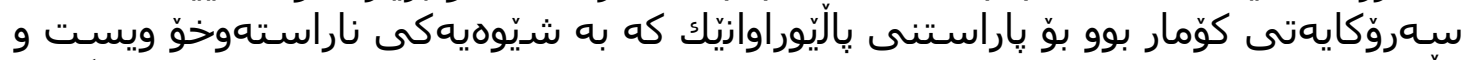

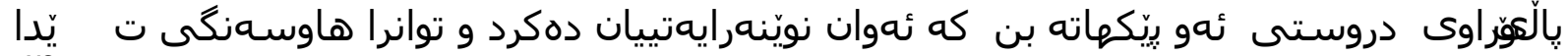

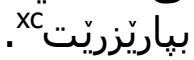

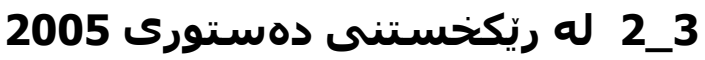

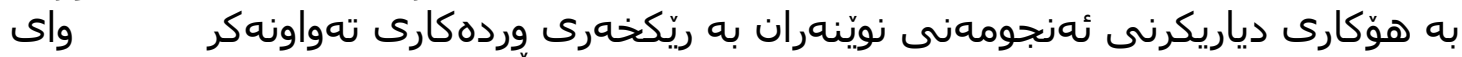

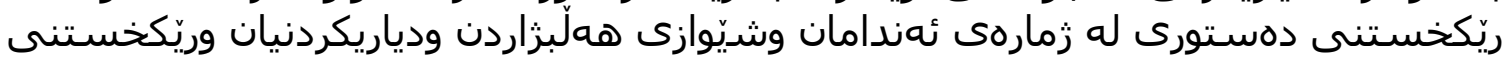

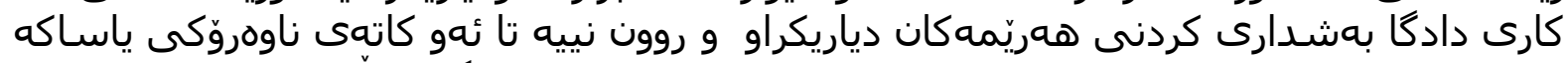

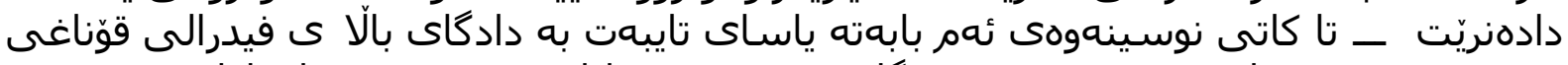

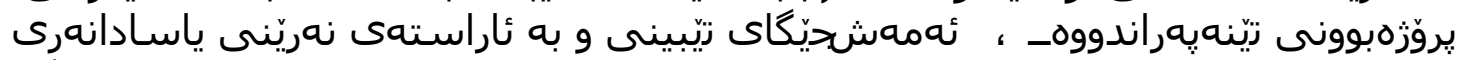

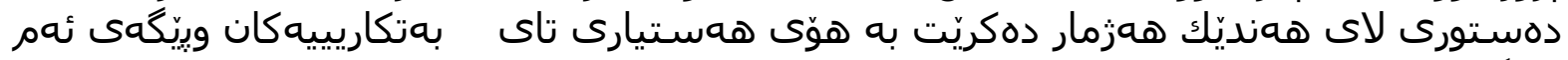

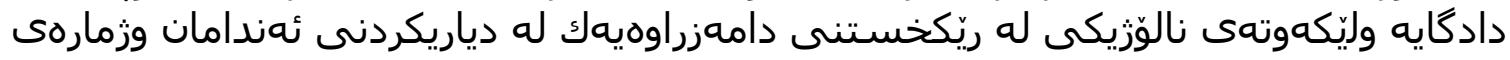

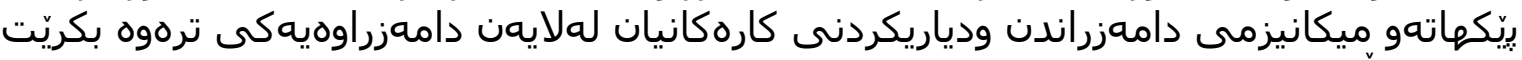

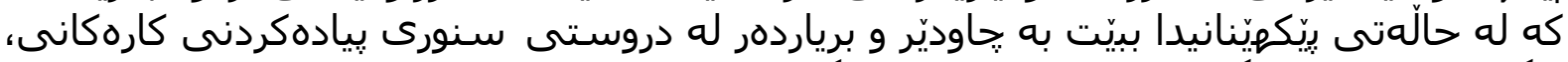

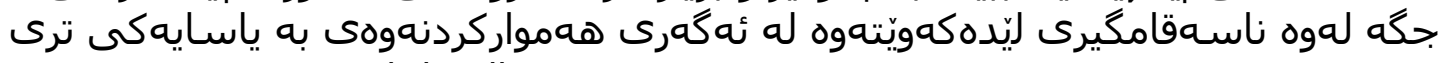

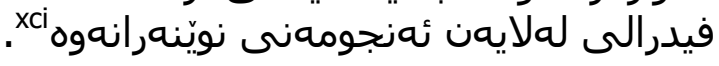

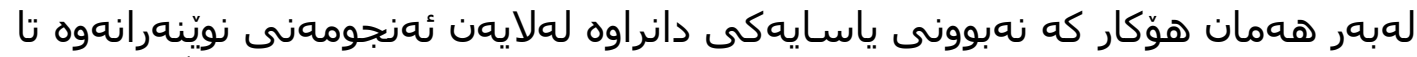

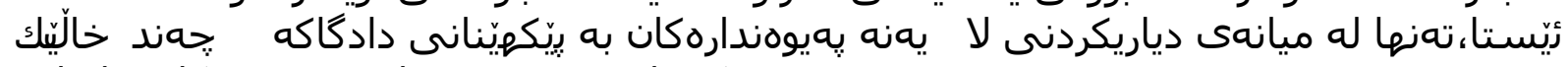

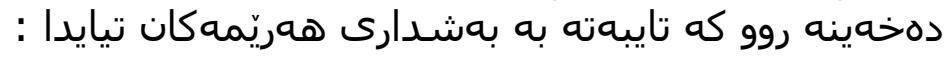

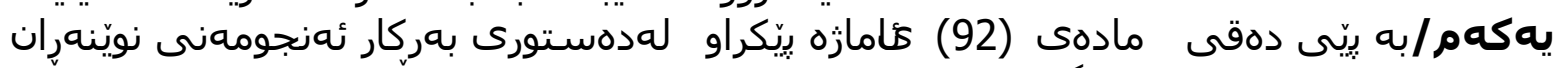

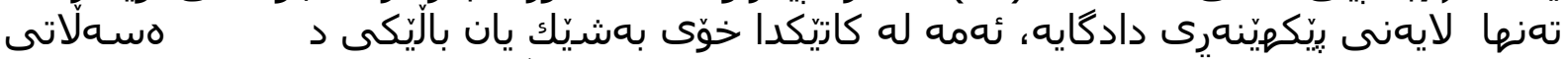

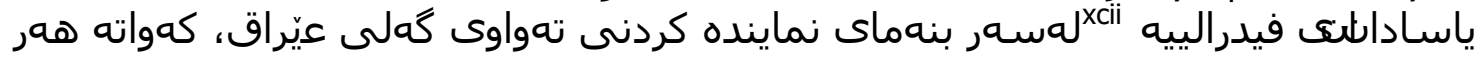

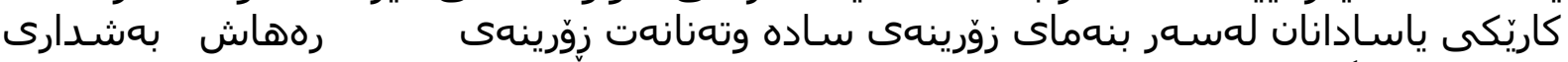

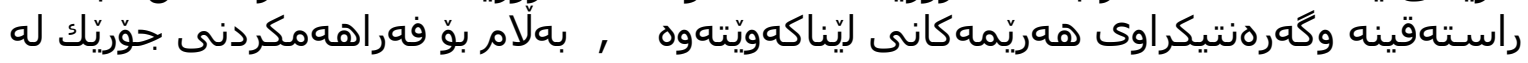

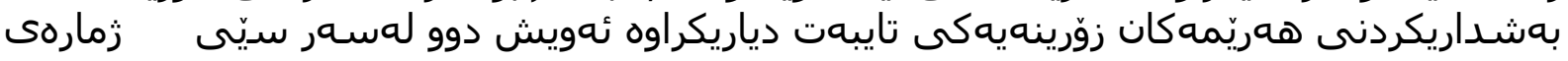

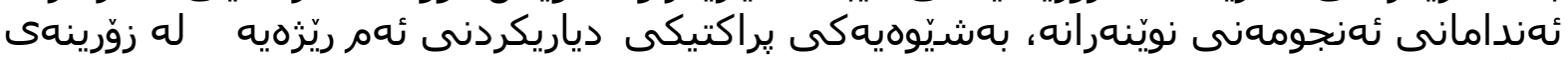

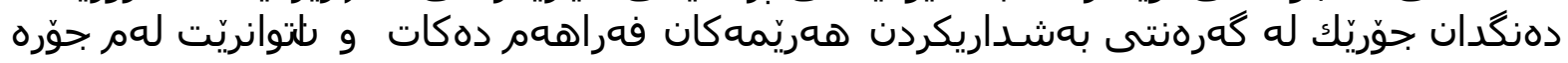




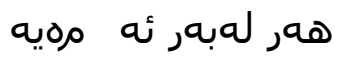

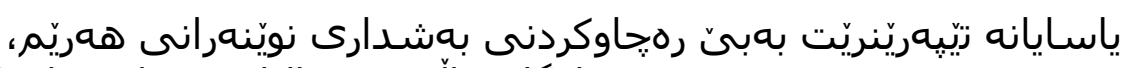

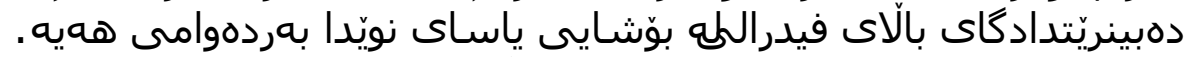

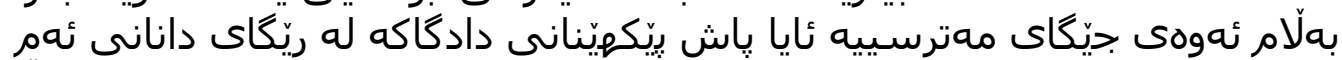

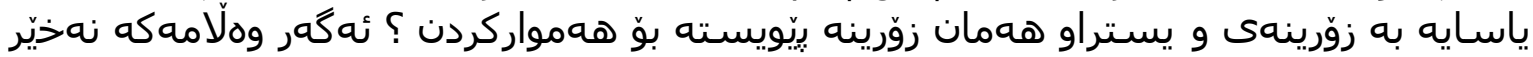

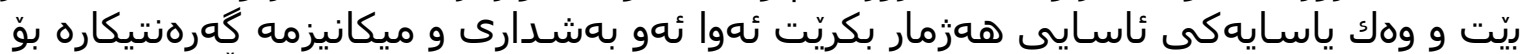

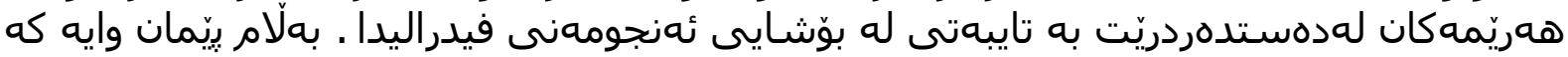

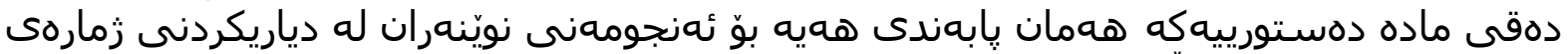

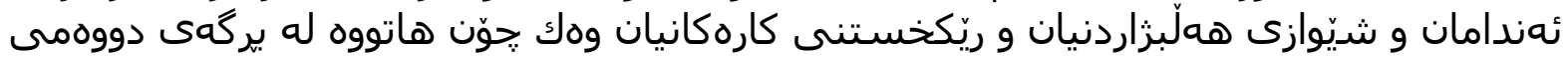

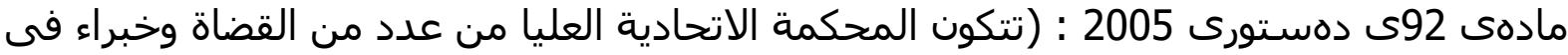

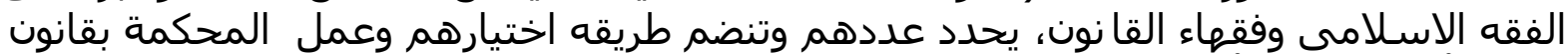

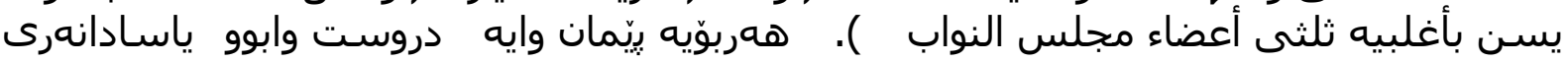

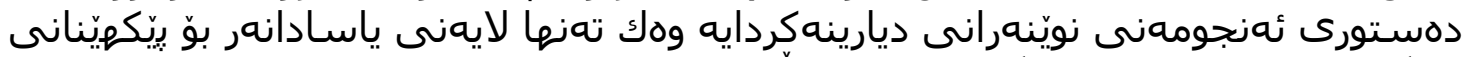

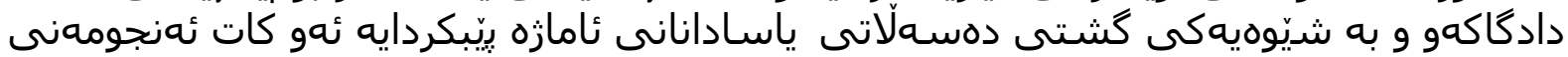

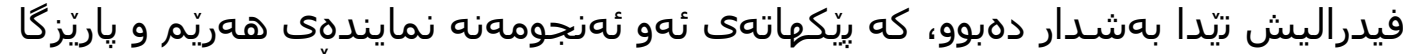

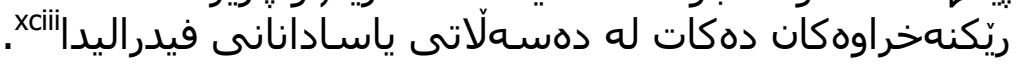

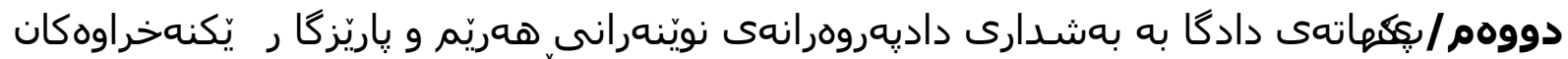

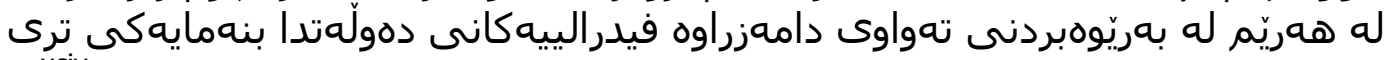

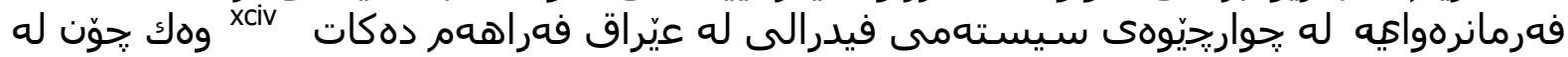

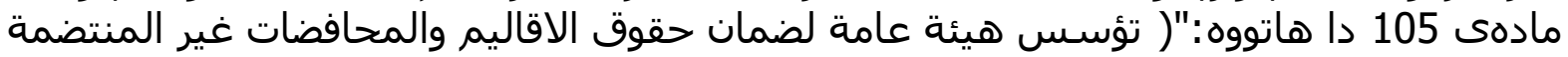

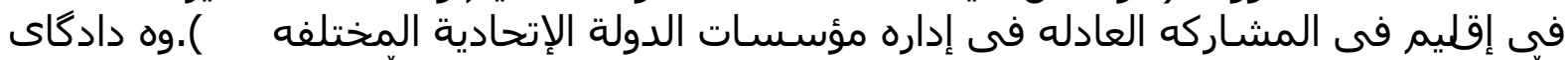

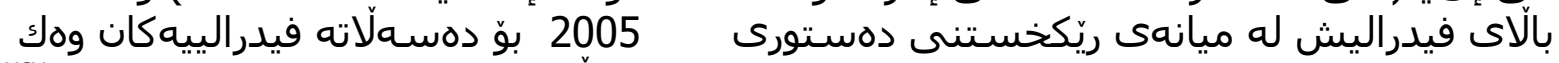

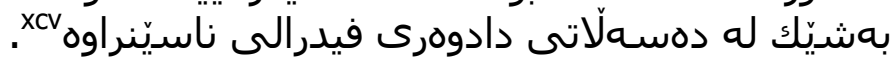

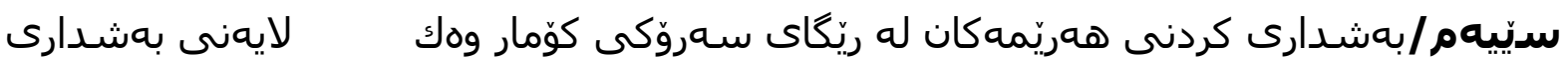

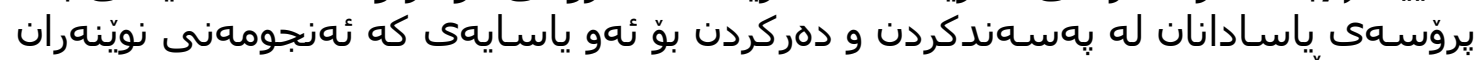

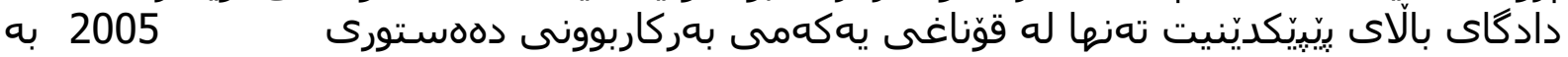

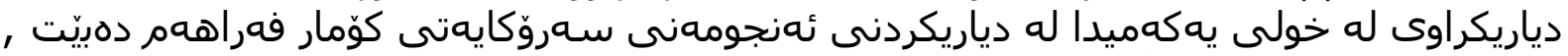

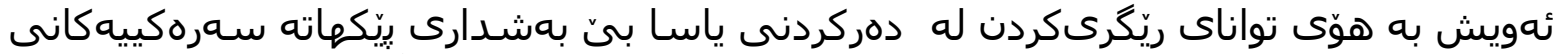

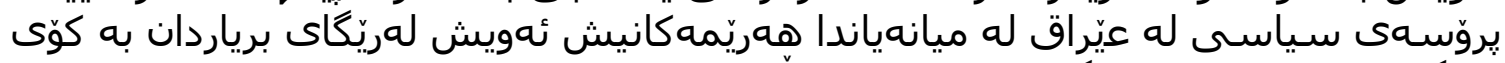

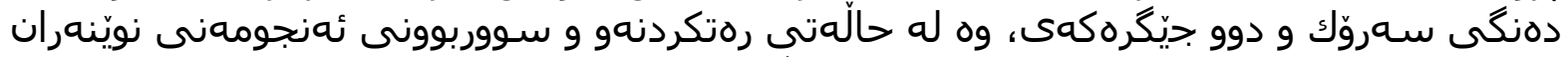

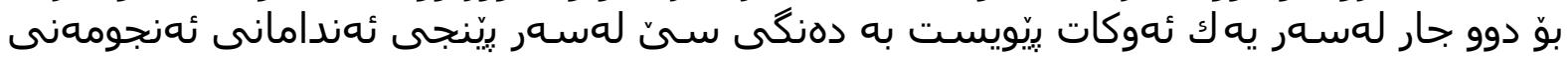

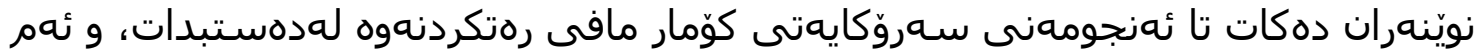

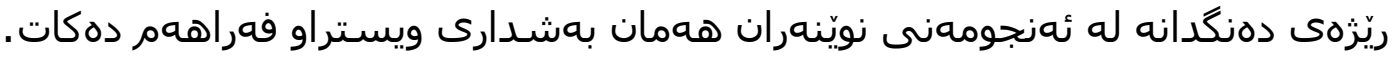

\section{كوّتايى}

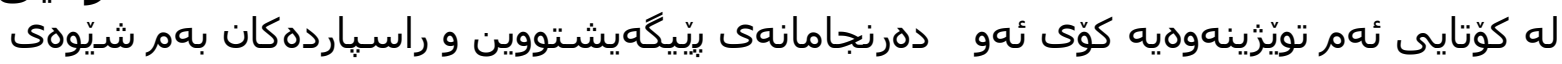

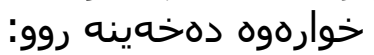

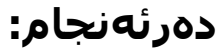

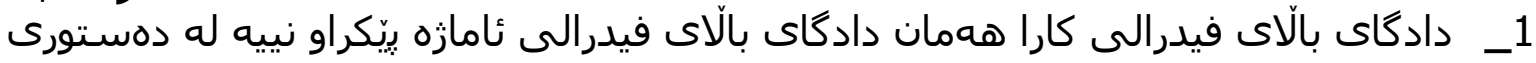

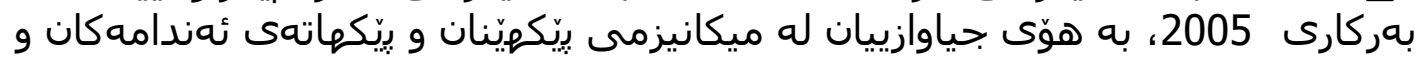

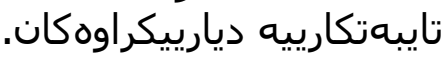

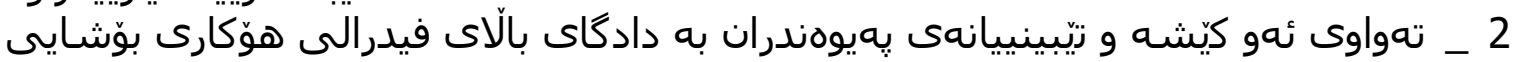

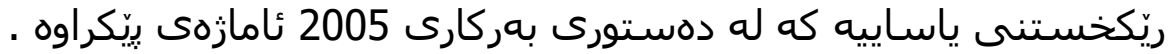

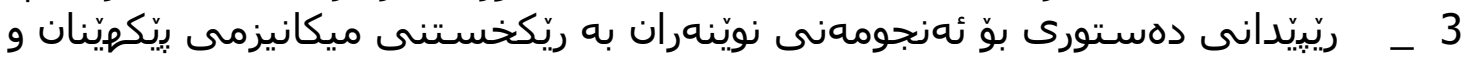

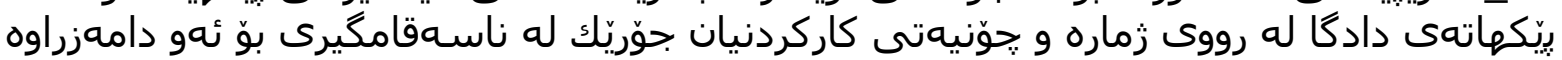

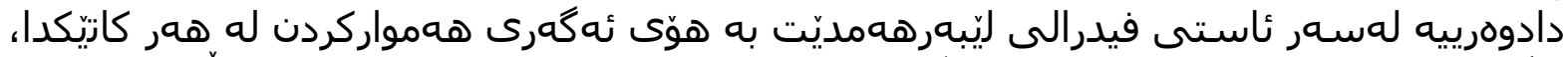

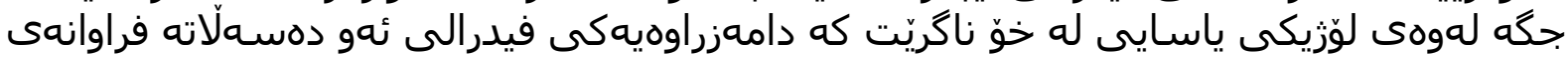




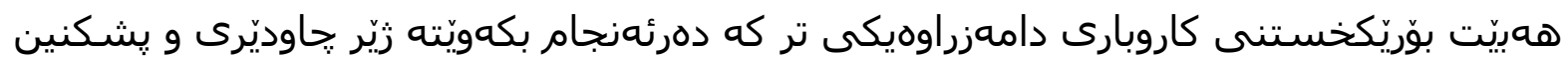

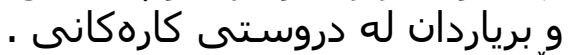

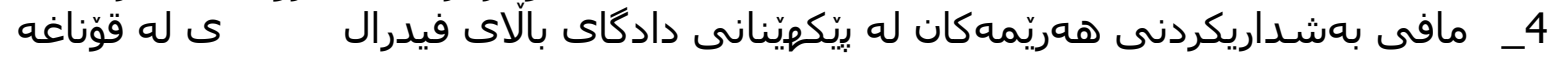

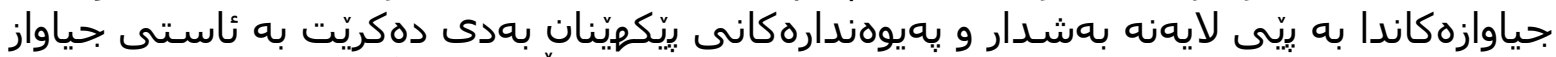

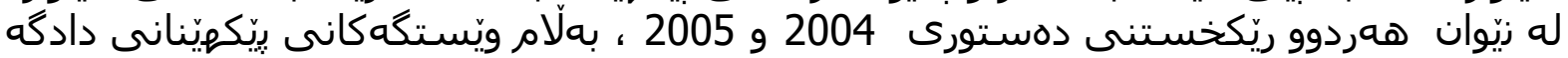

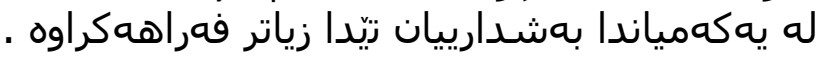

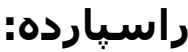

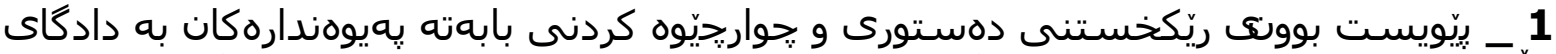

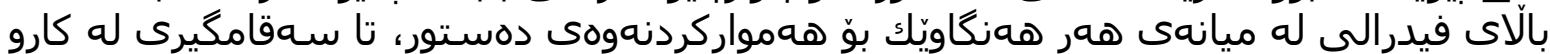

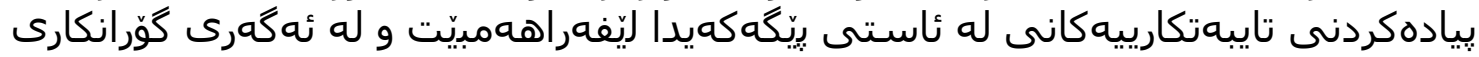

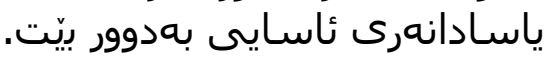

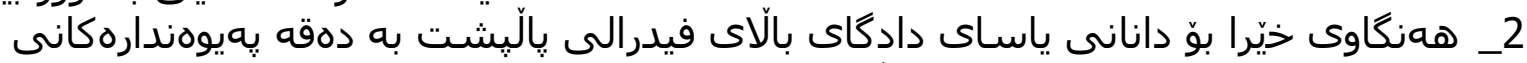

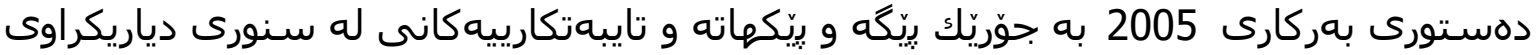

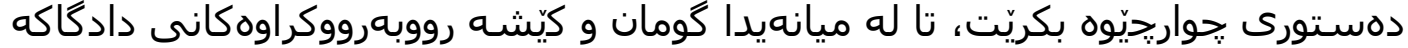

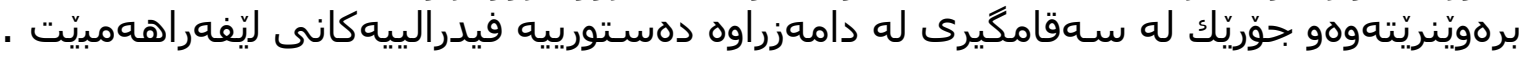

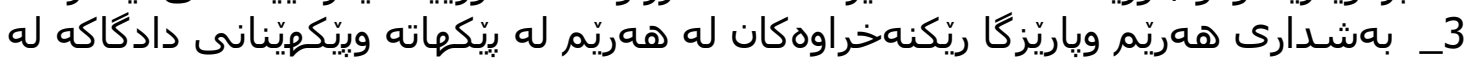

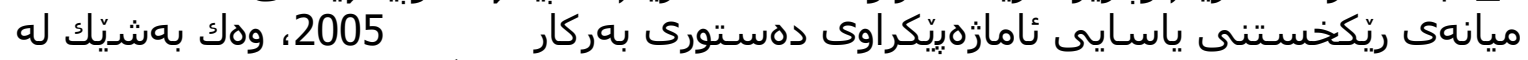

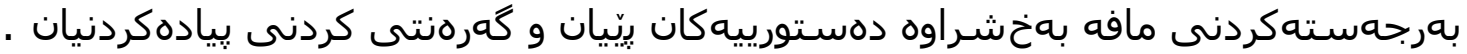

يهراويزيزهكان

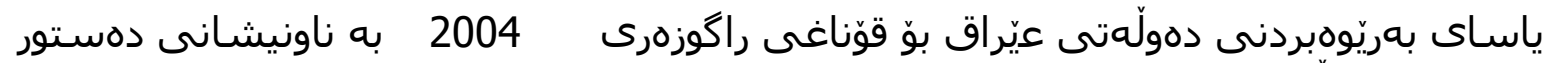

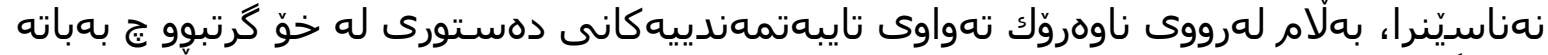

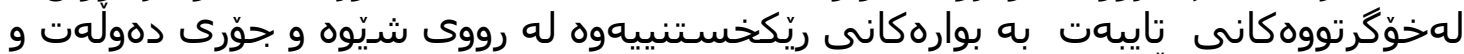

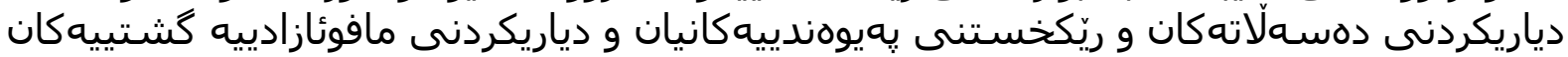

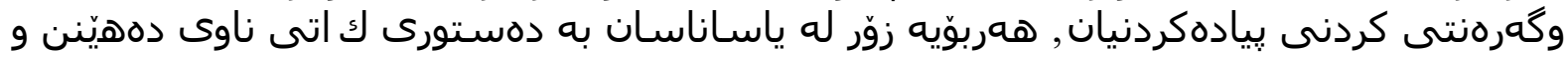

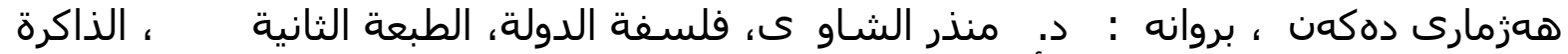

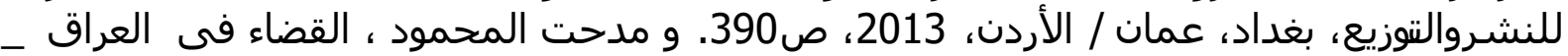

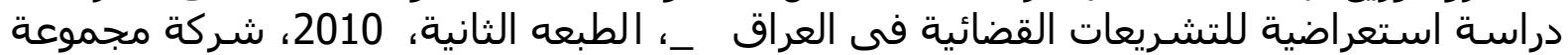

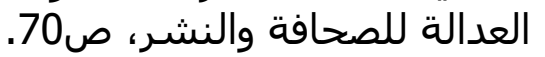

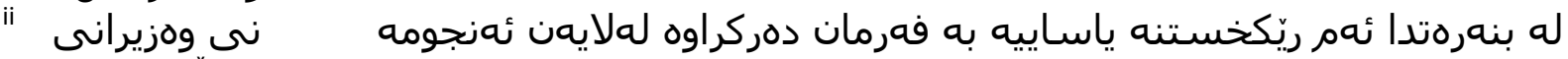

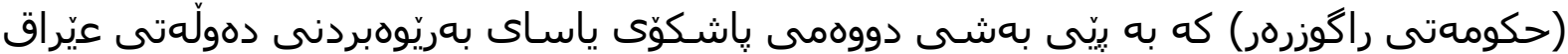

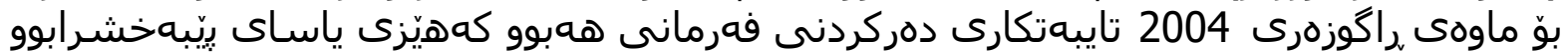

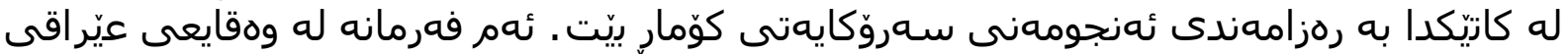

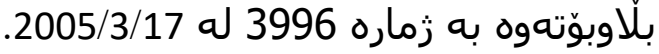

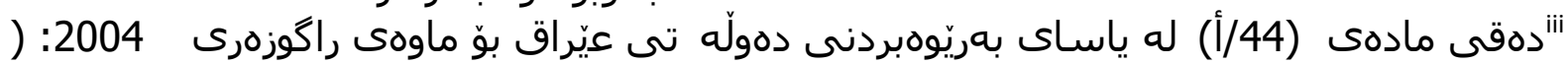

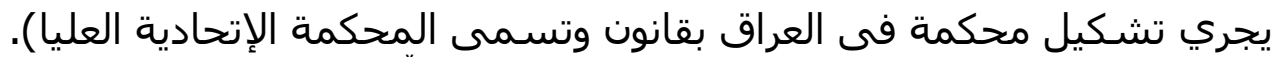

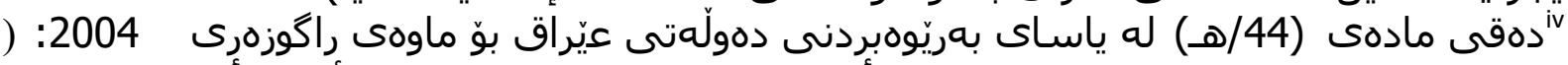

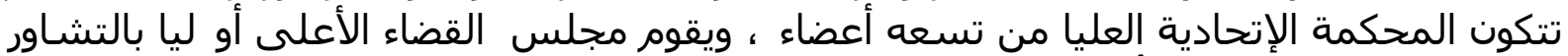

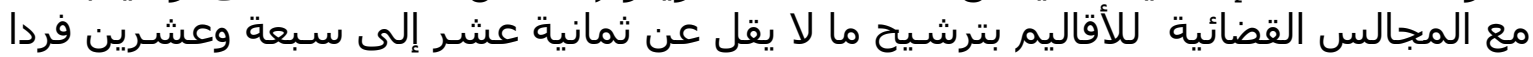

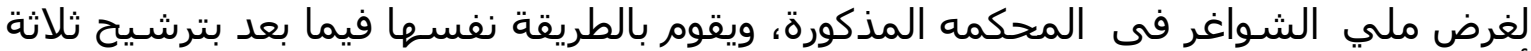

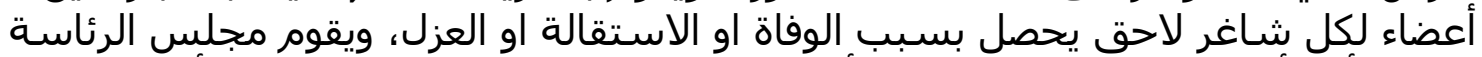

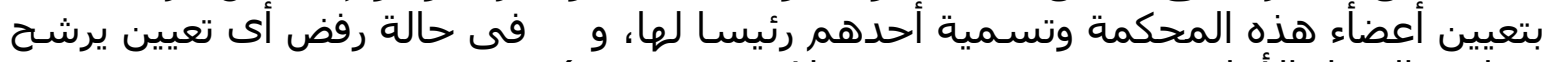

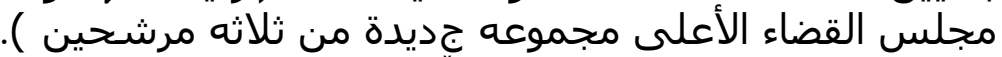

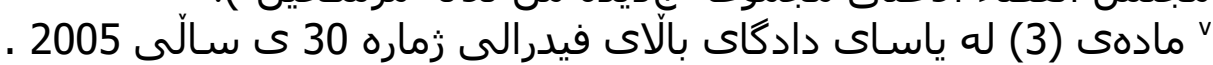

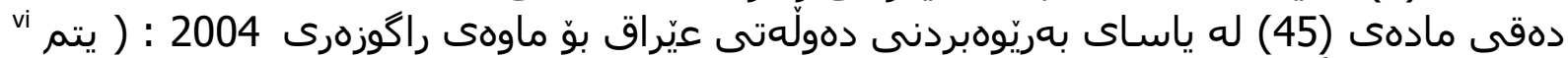

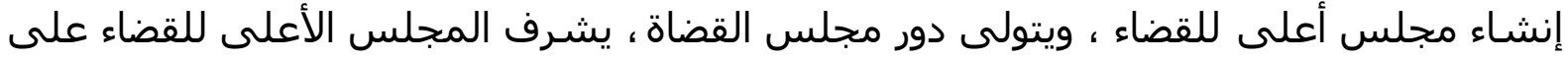




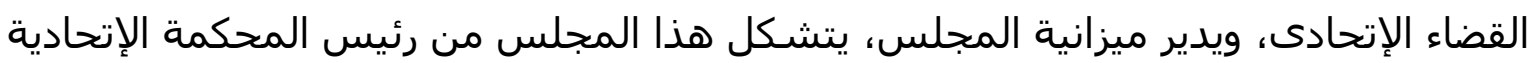

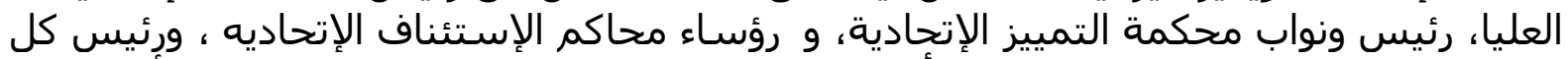

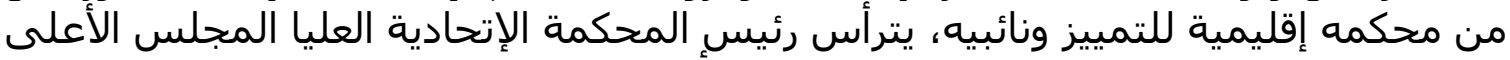

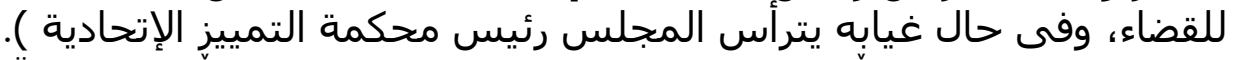

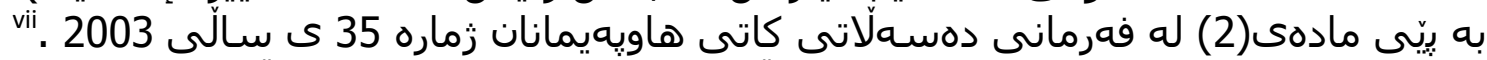

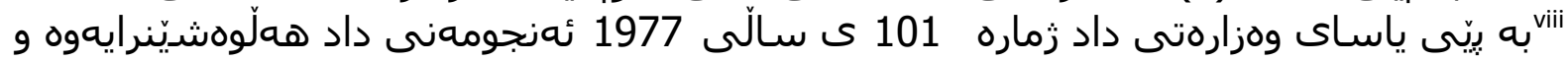

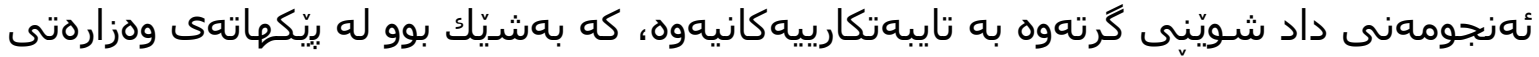

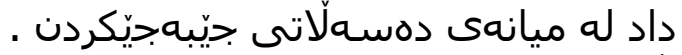
“ix

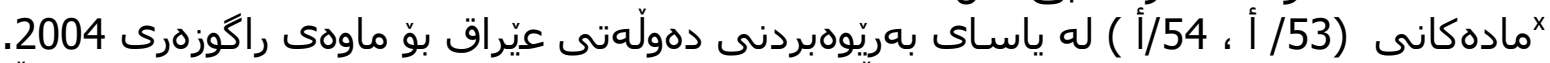

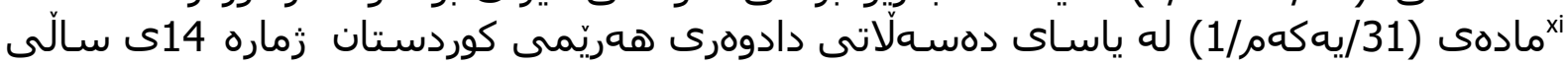
.1992

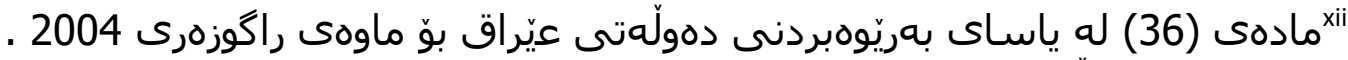

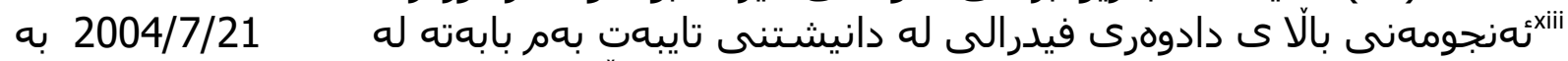

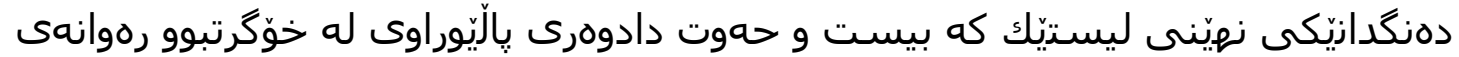

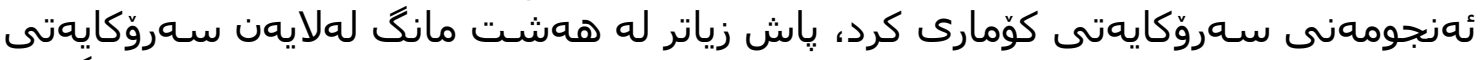

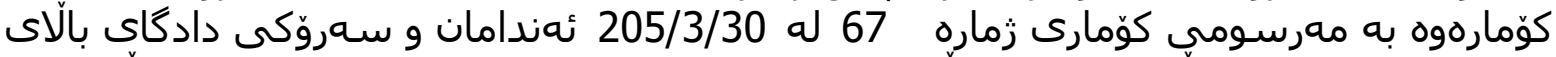

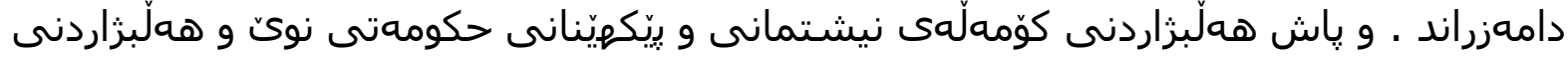

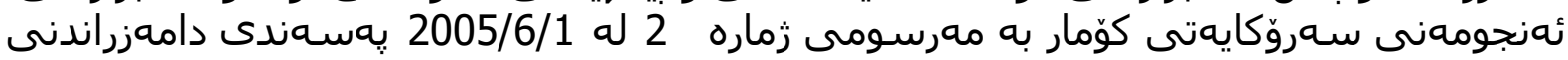

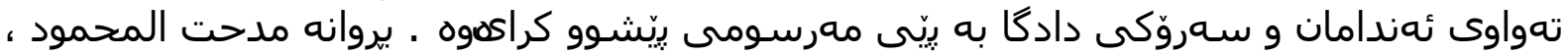

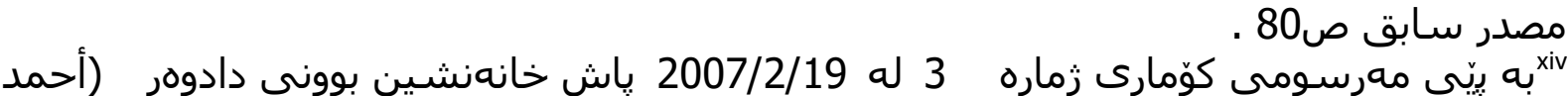

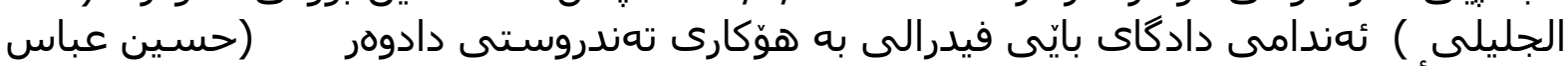

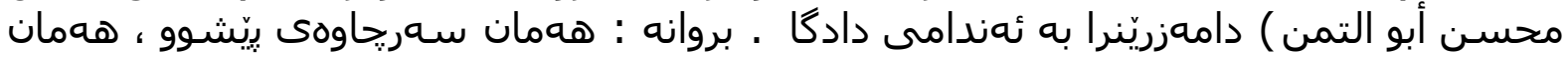

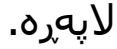

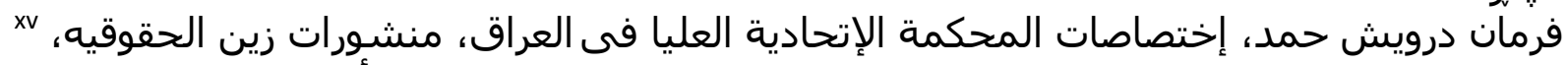

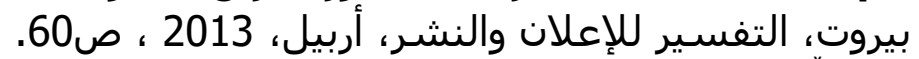

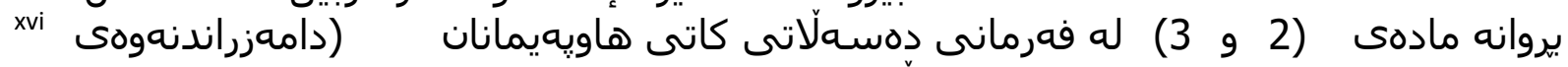

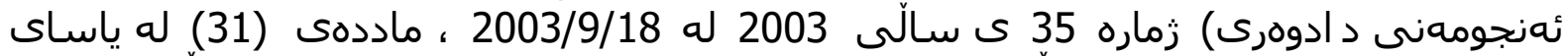

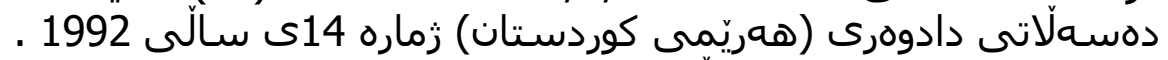

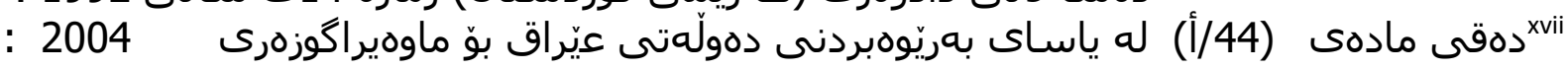

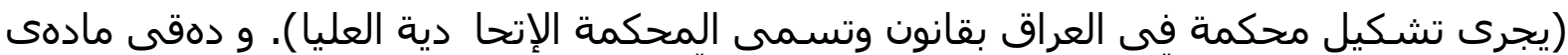

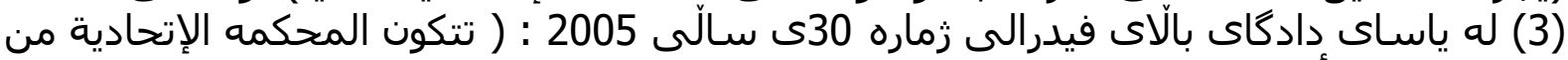

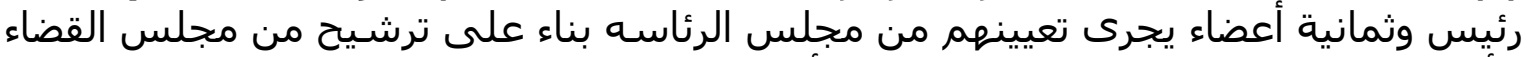

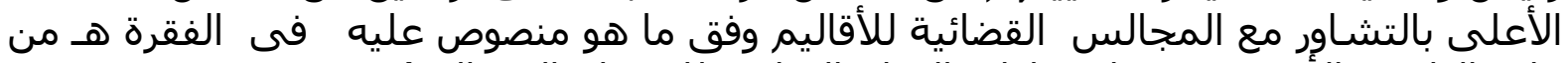

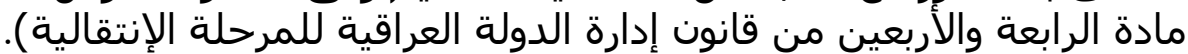

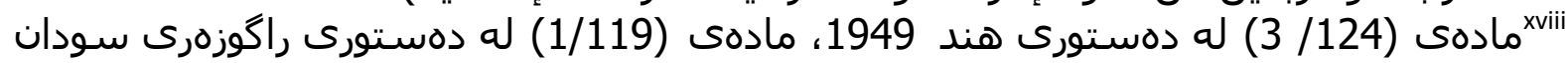

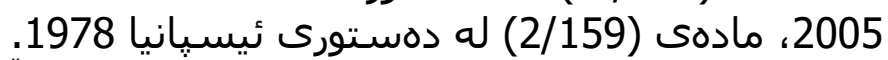

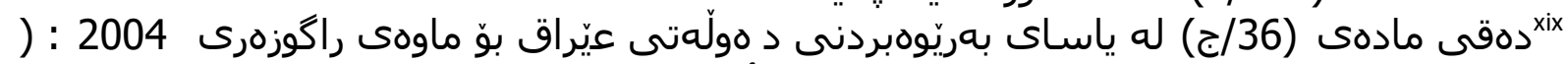

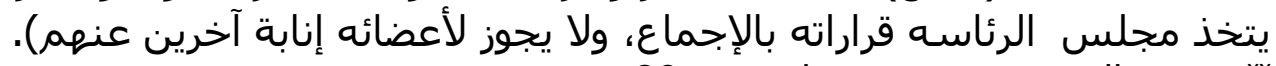

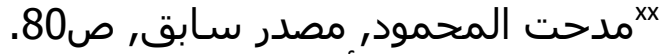

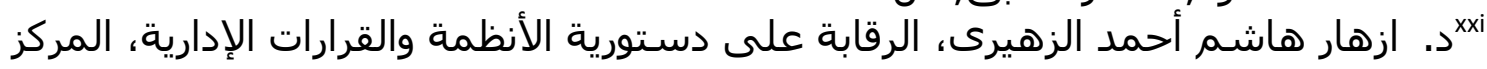
العربى للنشر والتوزيع، القاهرة، مصر،  التشكلم (دراسة مقارنة )، مجلة كلية القانون للعلوم القانونية والسياسية السية، جامعة كركوك،

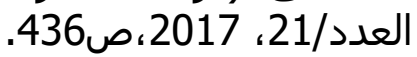


خaiii

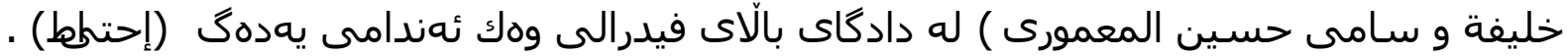

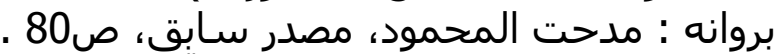

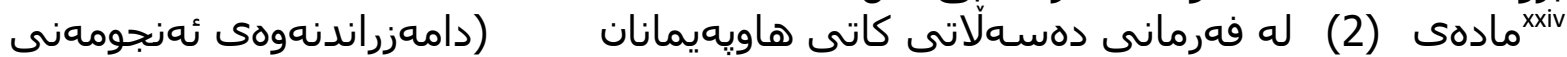
دادوهرى) زماره (250)

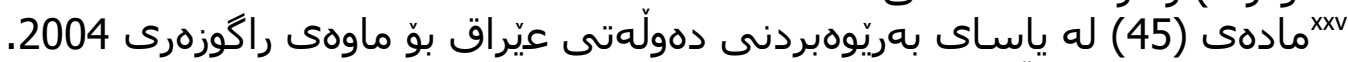
بxvi

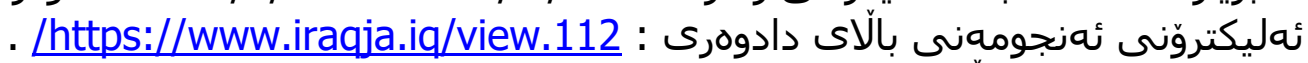

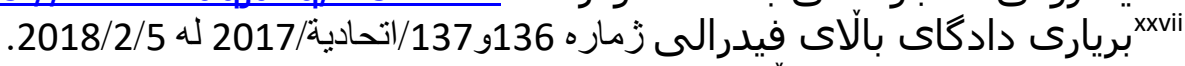

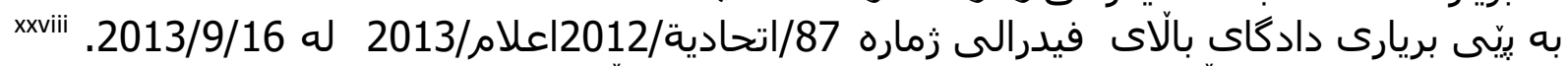

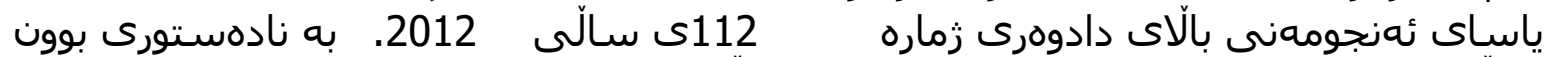

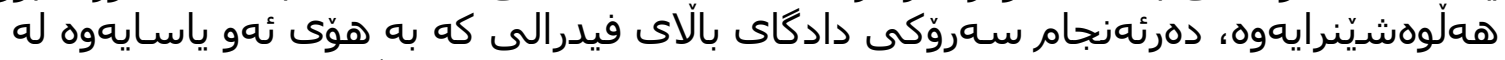

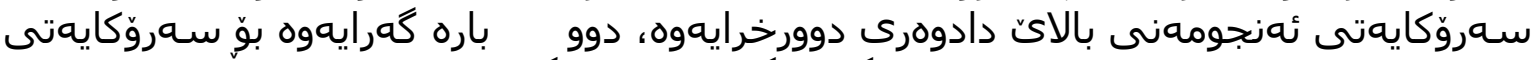

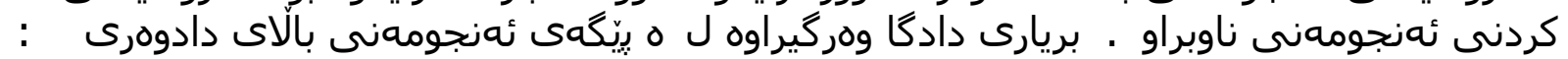

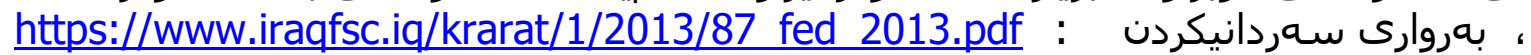
2018/1/15

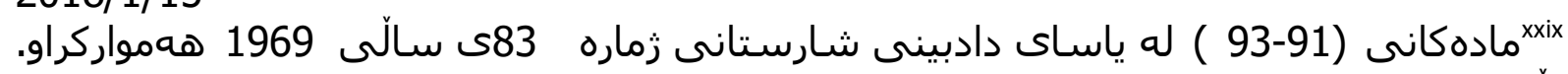

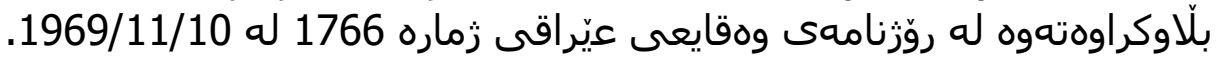

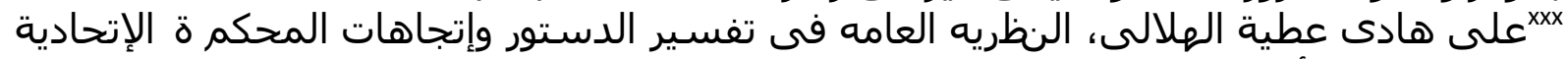

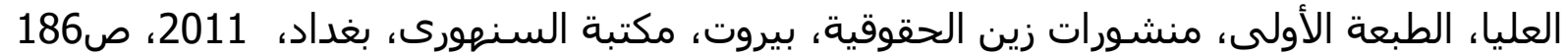
و 187 و العبا،

xxxi بxxii

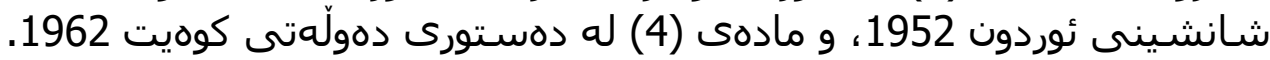
مادهادى (2xiii

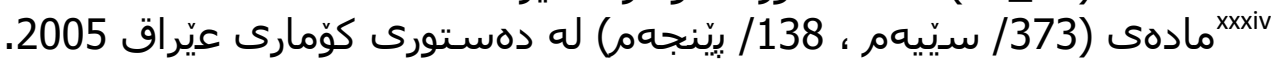

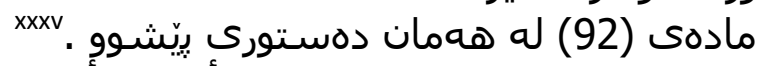

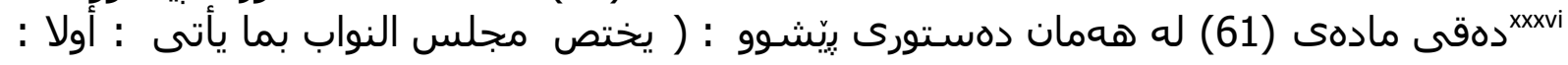

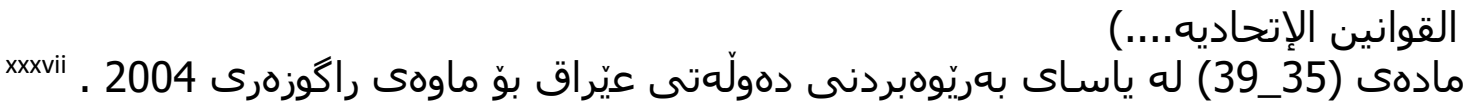
مادهى (138xviii

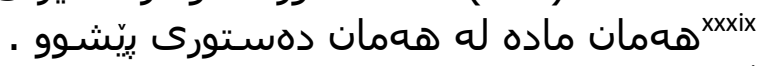

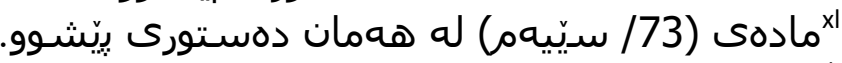

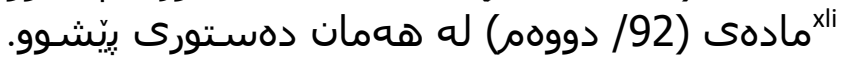

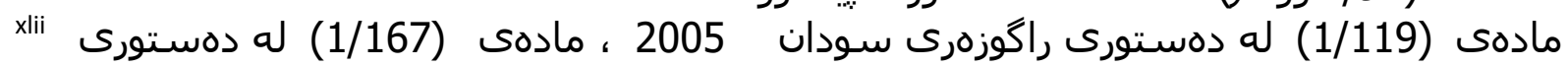

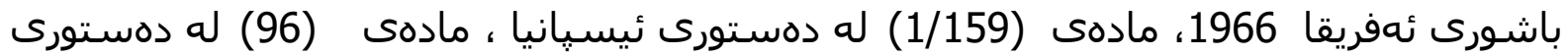

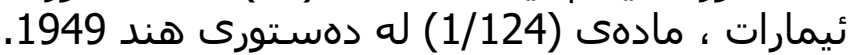

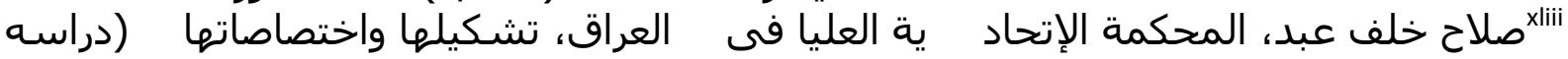

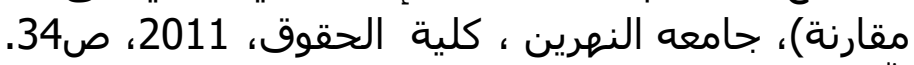

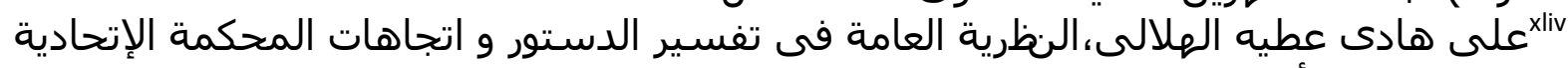

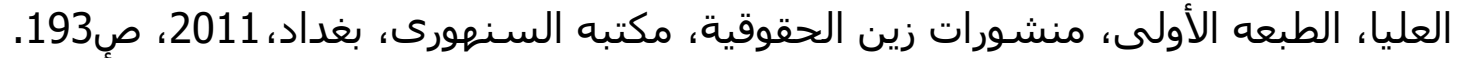

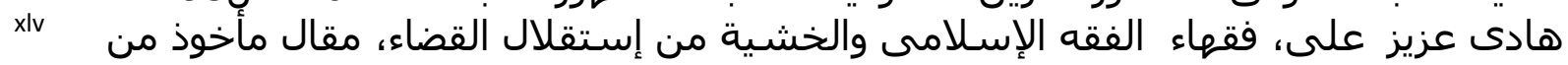

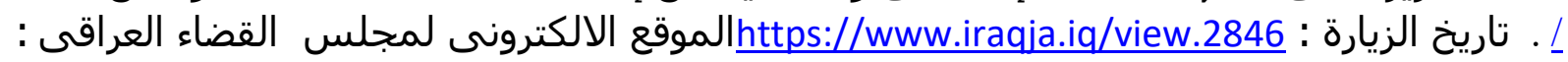
2018/1/18

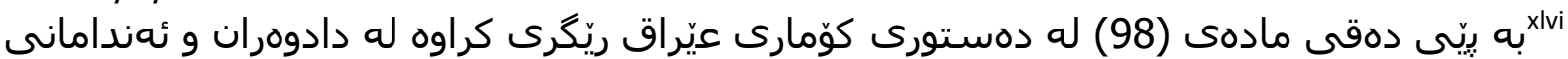

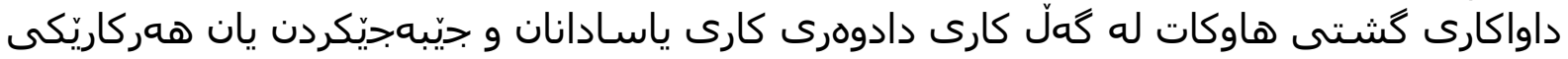


تر بياده بكهن ، سهرهراى ريّكهنهدانيان به ئهنداميّتى له يارت يان ريّكخراو يان هولّسان بهههر

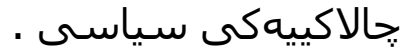

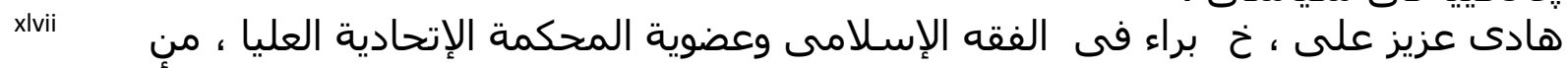

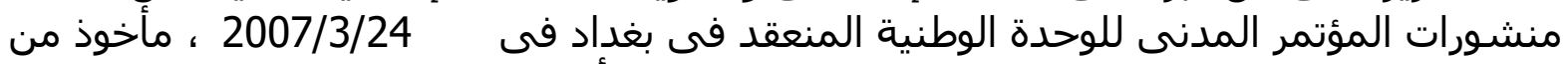

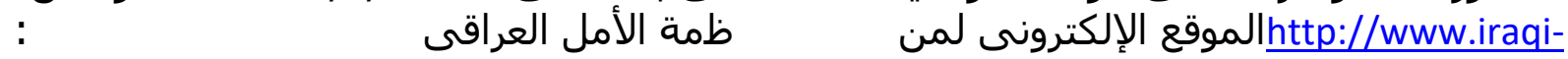
alamal.org/uploads/pdf/Old\%20web\%20site\%20PDF/interlacing/Jurisprudence\%20experts.p تأريخ الزيارة : 2018/1/18

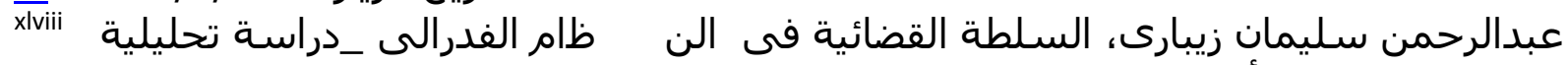

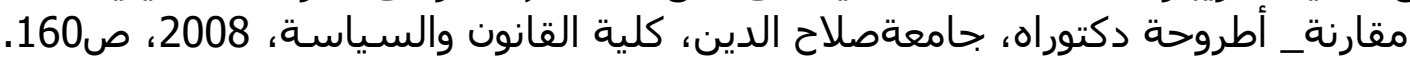

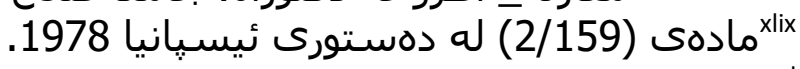

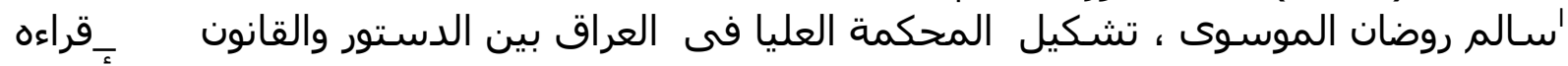

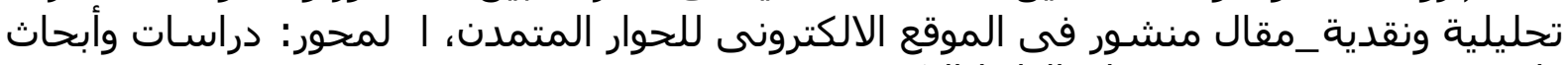
قانونية. http://www.ahewar.org/debat/show.art.asp?aid=158837

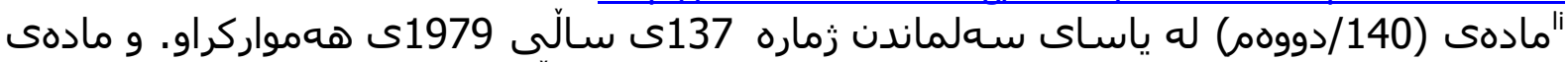

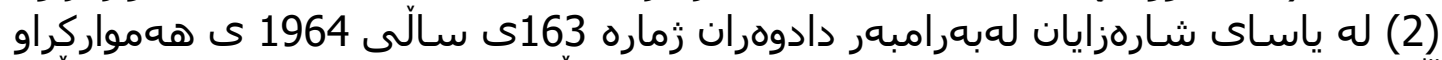

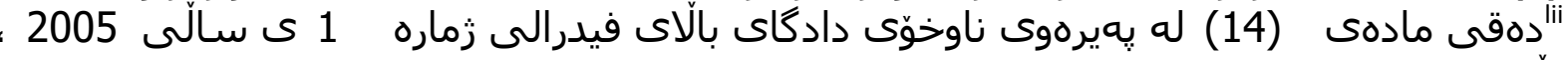

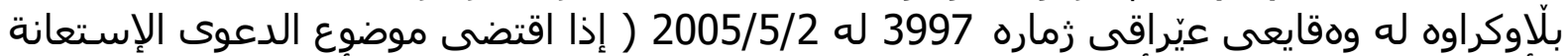

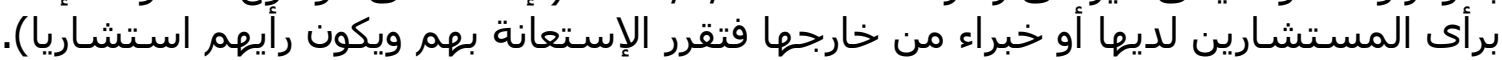

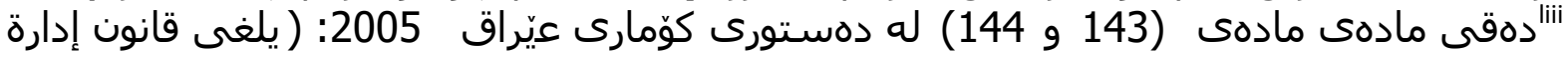

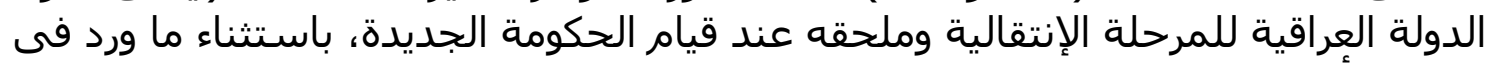

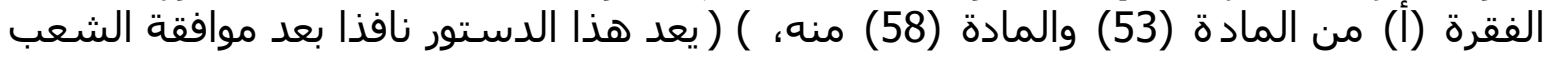

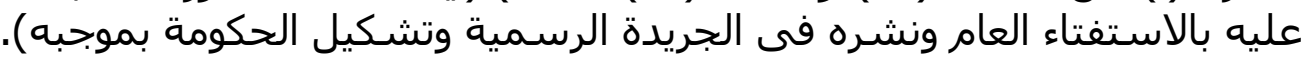

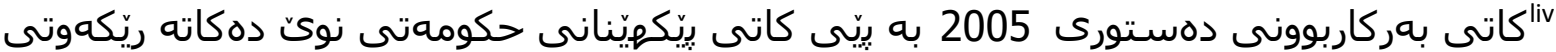

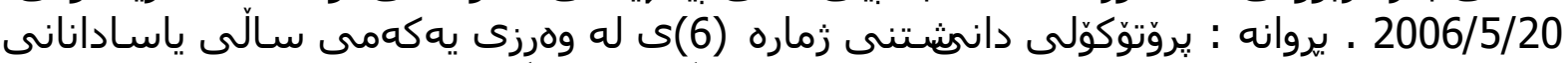

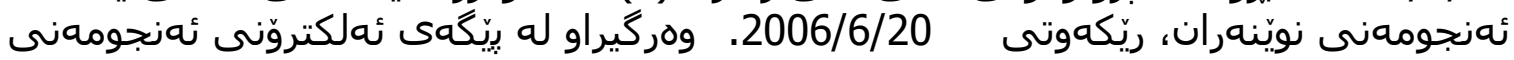
: نوينهران http://parliamentiraq.com/Iraqi Council of Representatives.php?name=articles ajsd yawqwadjasdba46s7a98das6dasda7das4da6sd8asdsawewqeqw465e4qweq4wq6e4q . w8eqwe4qw6eqwe4sadkj\&file=showdetails\&sid=463

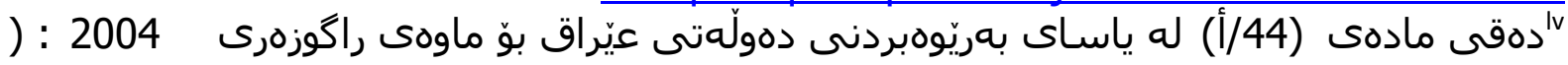

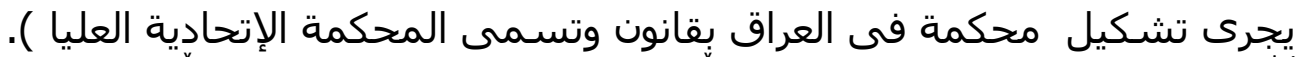

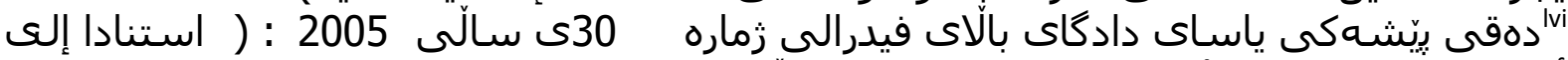

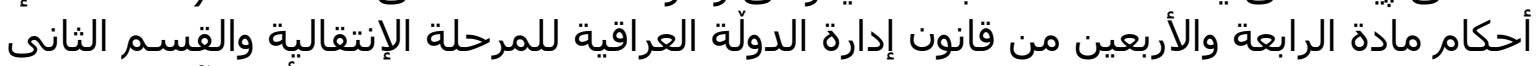

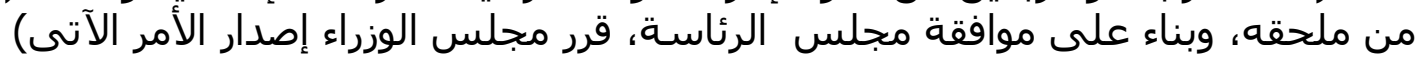

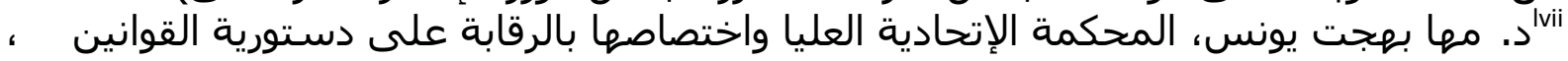

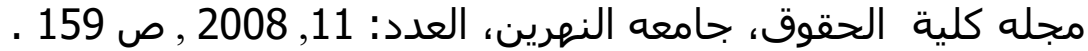
داندقى مادهى (130iii

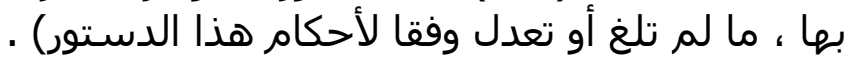

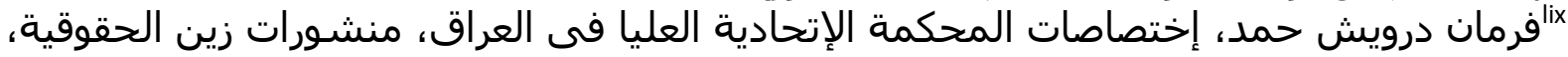

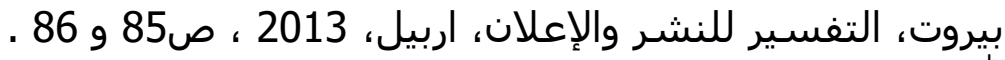

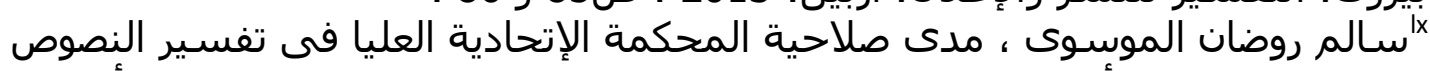

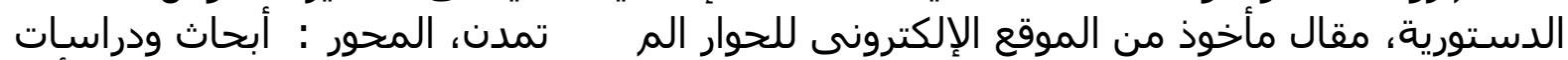
قانونية. عنوان الرابط :

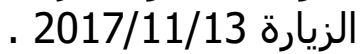




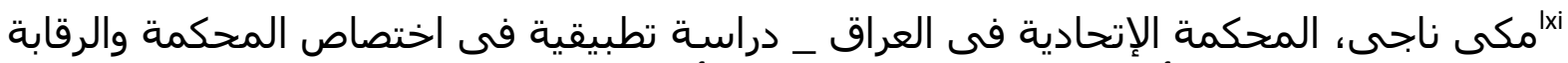

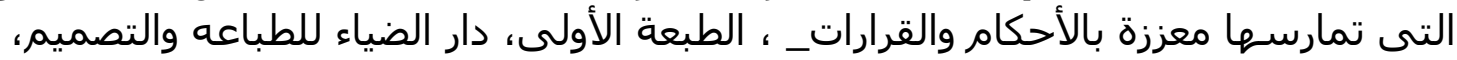

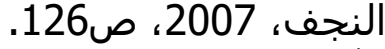

xii

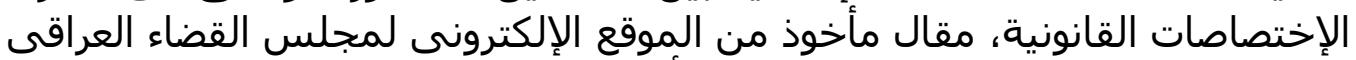

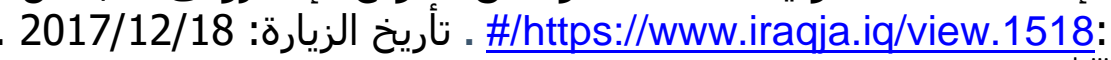

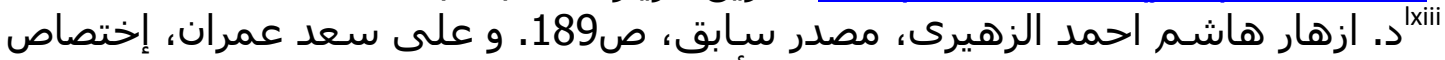

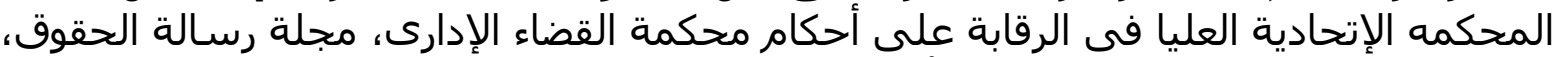

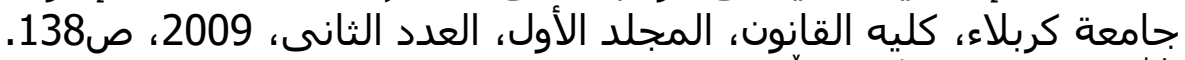
|xiv

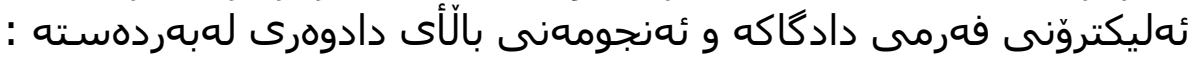
https://iraqja.iq/ethadai.php ، https://www.iraqfsc.iq/ethadai.php

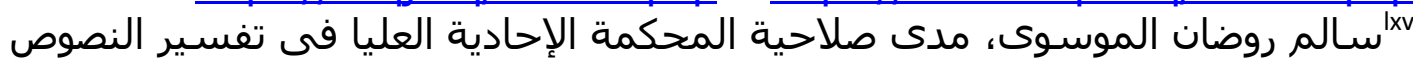

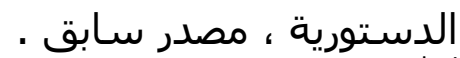

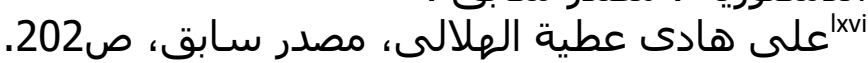

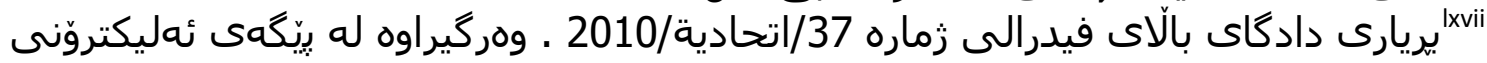

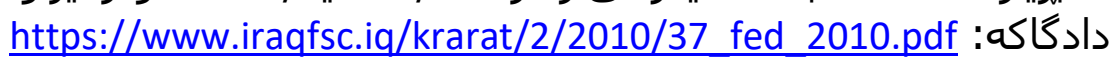

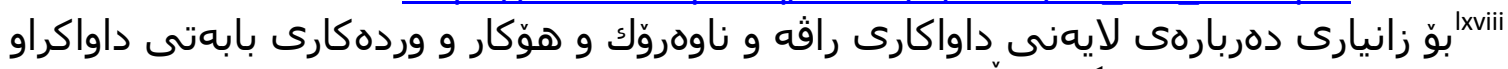

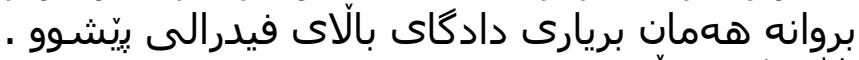

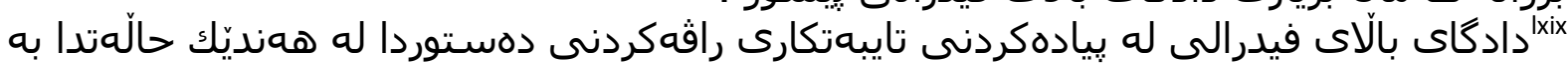

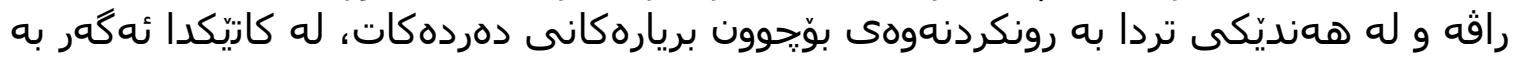

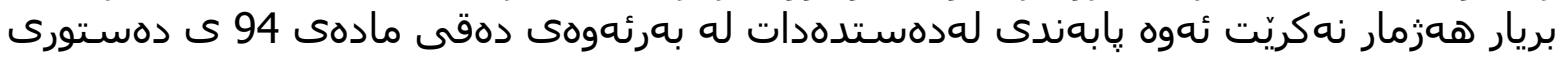

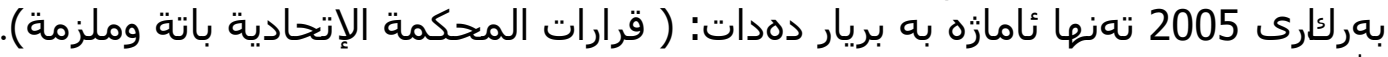

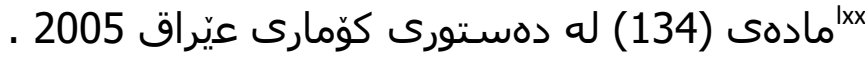
. |xii

مادادهى (35) له ياساى (13iii

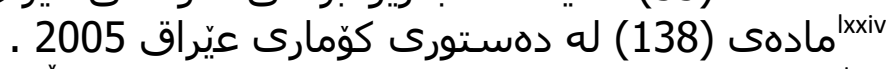

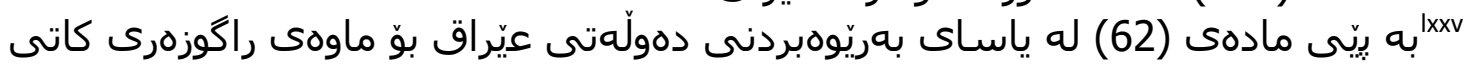

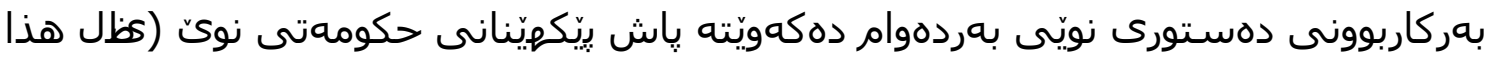

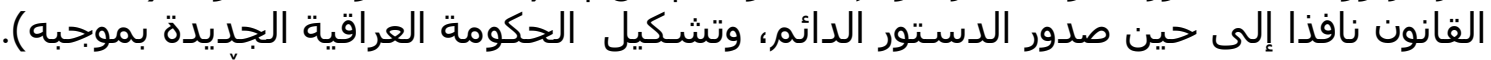

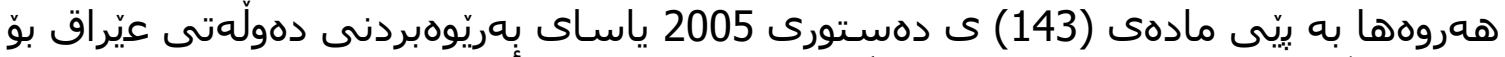

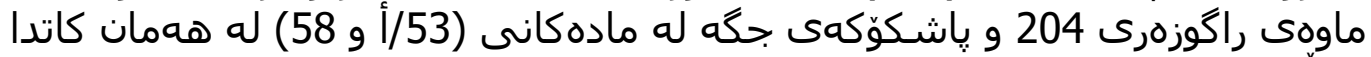

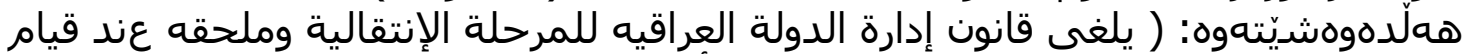

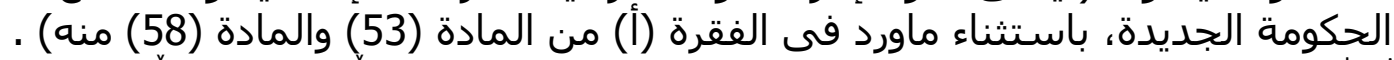

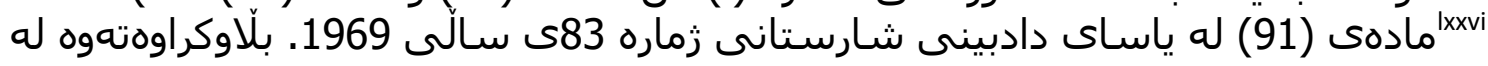

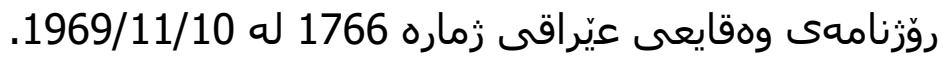
Xxii اxxviii

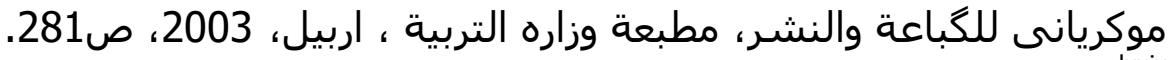

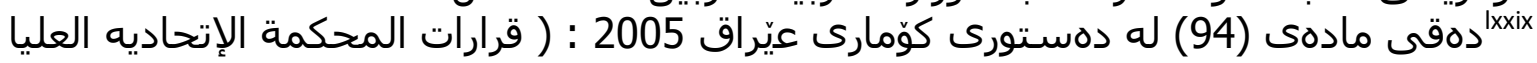
باتة وملزمة للسلطات كادمات كافة).

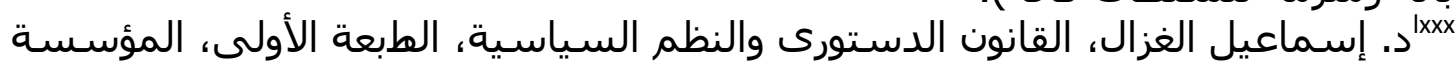

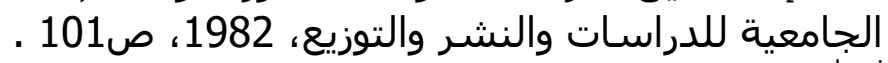
1xxi إد. عادل الطبطبائى، الرظظام الإتحادى فى الإمارات العربية، بدون مكان النشر، 1978، ص10. 
(3xxii

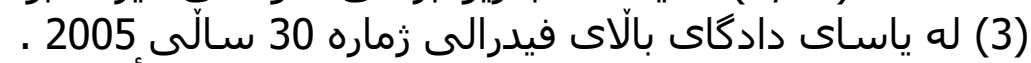

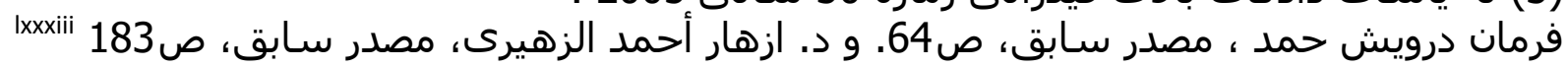

$$
\begin{aligned}
& \text { اxxxiv }
\end{aligned}
$$

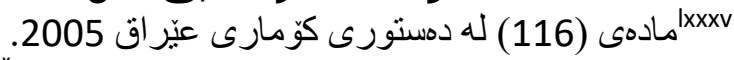

12xxvi

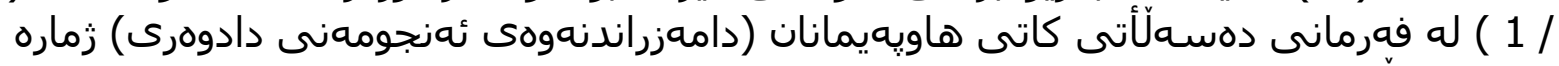

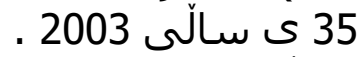
ماجxxvii

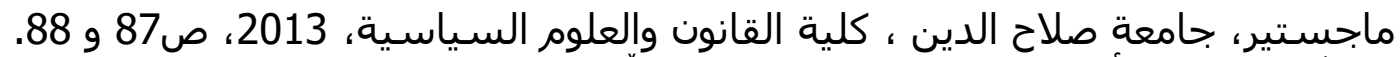

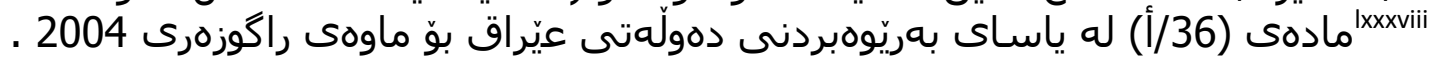

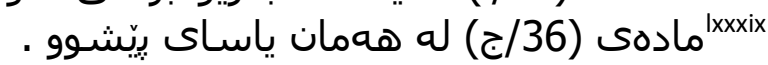

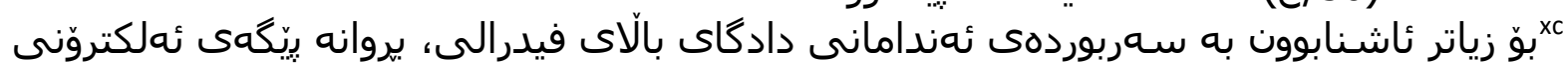

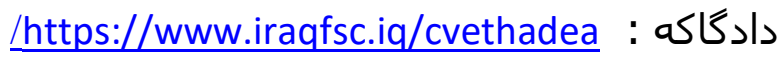

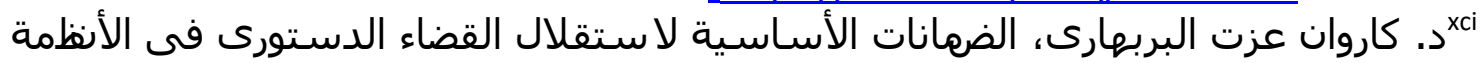

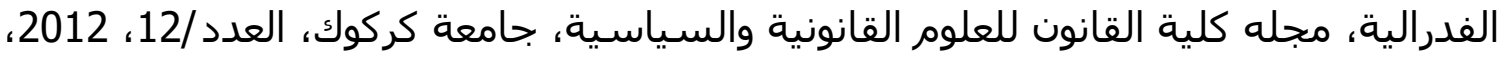
.112 xii

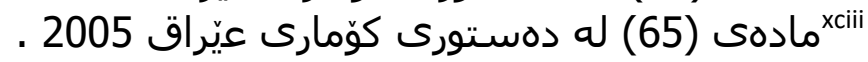
xiv

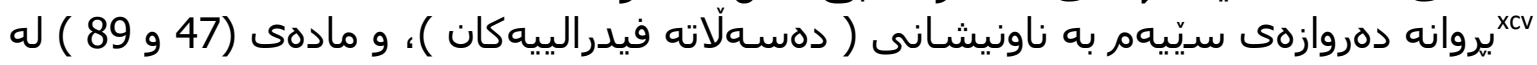
دهستورى كوّمارى عيّراق 2005.

\section{REFERENCES}

\section{Books:}

Adil Al_Tabtabaie, Federal system in the UAE, 1978.

Ali Hadi Al_Hilaly, The general theory in interpretation of the constitution and the attitudes of the Supreme Court, First Edition, Zain legal publications, Beirut, Al_Sanhury library, Baghdad, 2011.

Azhar Hashim Al-Zuhairy (2016).The censorship on the constitutionality of administrative regulations and decisions, $\mathrm{Al}_{-}$-Araby center for publishing and distribution, Cairo, Egypt,.

Farman Darwesh Hamad, The Specialties of federal Supreme Court in Iraq, Zain legal publications, Al_Tafser for advertising and publishing, Erbil, 2013.

Ismail Al-Ghazal, Constitutional law and political systems, First edition, Al_Jameaah Foundation for studies, publishing and distribution, 1982.

Madhat Al_Mahmood,Judiciary in Iraq_A review study for judicial legislations in Iraq_, Second edition, Al_Adaleh group for press and publishing, 2010. 
Maki Naji, Federal court in Iraq - An applied study in jurisdiction of the Court and its censorship which practiced by it - Enhanced by provisions and decisions_, First edition, Al_Ziyah house for printing and design, Al_Najaf, 2007.

Muhammed Omer Mawlood, Federalism and its applicability in Iraq, Second edition, Mukryany foundation for printing and publishing, Erbil, 2003.

Munzir Al-Shawi, The state philosophy, second edition, Al-Zakira for publishing and distribution, Baghdad, Amman/Jordan, 2013.

\section{University Thesis:}

Abdur-Rahman S. Zebari, The Judicial Power In the Iraqi Federal System, PH.D Thesis, Salahaddin University, College of Law and Political Since, 2008.

Salah Khalaf Abd, Establishing and Jurisdiction of the Federal Supreme Court in Iraq, Master Thesis, Al_nahrain University, College of Law ,2011.

Soran Ali Hasan, The Legal Regulation of The Constituent Units of The Federalism in Iraq, Master Thesis, Salahaddin University, College of Law and Political Since, 2013.

\section{Scientific researches}

Ali Saad, Jurisdiction of the Federal High Court in control provisions of the Administrative Court, Risalat Al_-huquq Journal, Kerbala University, NO:2, 2009.

Karwan. A. Brehary, Basic constitutional guarantees for the independence of the judiciary In federal systems, Kirkuk University,Journal of college of Law for Legal and Political Sciences, No:12, 2015.

Maha Bahjat Yuns, Federal Supreme court and its specialty by censoring constitutionality of laws, journal of college of law, Al-Nahrain University, No: 11, 2008.

Shorsh H.Omer, Controls the independence of the Federal Supreme Court in Iraq in terms of composition A comparative study, Journal of college of Law for Legal and Political Sciences, Kirkuk University, No:21, 2017.

\section{Electronic References:}

Council of Representatives protocols:

(http://ar.parliament.iq/category/\%D8\%AC\%D9\%84\%D8\%B3\%D8\%A7\%D8\%AA-

\%D8\%A7\%D9\%84\%D9\%85\%D8\%AC\%D9\%84\%D8\%B3/\%D9\%85\%D8\%AD\%D8

$\% \mathrm{~A} 7 \% \mathrm{D} 8 \% \mathrm{~B} 6 \% \mathrm{D} 8 \% \mathrm{~B} 1-$

\%D8\%A7\%D9\%84\%D8\%AC\%D9\%84\%D8\%B3\%D8\%A7\%D8\%AA/)

Federal Supreme Court decisions, cited from its website and Supreme judicial council.https://www.iraqfsc.iq/ethadai.php . https://iraqja.iq/ethadai.php.

Hadi Aziz Ali, Experts in Islamic jurisprudence and membership of the Federal Supreme Court, Fromcivil conference for national unity publications, Held in Baghdad on 24/3/2007, cited from (http://www.iraqi- 
alamal.org/uploads/pdf/Old\%20web\%20site\%20PDF/interlacing/Jurisprudence $\% 20 \mathrm{ex}$ perts.pdf)

Hadi Aziz Ali, Jurists of Islamic jurisprudence and fear of the independence of the judiciary, Cited from Iraqi Judiciary council's website.(https://www.iraqja.iq/view.2846/ )

Salim Rawzan Al_Musawi, The formation of the supreme court in Iraq between the Constitution and the law, Analytical and critical reading, Article published in a Modern Discussion website, legal research and studies part: (http://www.ahewar.org/debat/show.art.asp?aid=158837)

Salim Rawzan Al_Musawi , The Validity of Federal Supreme Court in interpreting constitutional texts, Article cited from a Modern Discussion website, legal research and studies part. (http://www.ahewar.org/debat/show.art.asp?aid=221229)

Ziyaa Al-Saidi, Federal Court between constitutionality formation and the right to practice legal specialties, Article cited from Iraq judiciary council's website :( https://www.iraqja.iq/view.1518/\# )

\section{Constitutions:}

The Iraqi Transitional Administration Law 2004.

Constitution of the Republic of Iraq 2005.

Constitution of Syrian Arab Republic 2012.

Constitution of Sudan 2005.

Constitution of Spain 1978.

Constitution of the State of Kuwait 1962.

Constitution of Hashemite Kingdom of Jordan 1952.

Constitution of India 1949.

\section{Iraqi Laws:}

Law of experts in front of judiciary No: 163 of 1964(Amended).

Civil procedures law No: 83 of 1969(Amended).

Proof law No: 137 of 1979 (Amended)

Judiciary law (Kurdistan region) No: 14 of 1992.

Order of coalition authorityfor Reestablishing the Judicial Council No: 35 of 2003.

Law of Federal Supreme Court in Iraq No: 30 of 2005.

Internal regulations of federal supreme court No:1 of 2005. 